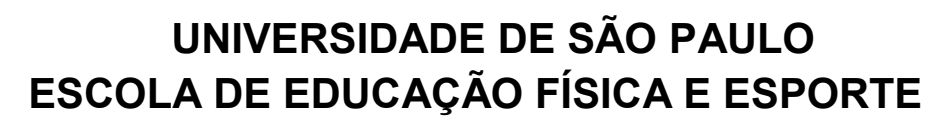

\title{
RELAÇÃO ENTRE PARÂMETROS BIOMECÂNICOS E A ACELERAÇÃO NO BASQUETEBOL
}

Rodrigo Maciel Andrade

SÃo PAULO

2009 
RELAÇÃO ENTRE PARÂMETROS BIOMECÂNICOS E A ACELERAÇÃO NO BASQUETEBOL

Rodrigo Maciel Andrade

Dissertação apresentada à Escola de Educação Física e Esporte da Universidade de São Paulo, como requisito parcial para obtenção do grau de Mestre em Educação Física. 
Andrade, Rodrigo Maciel

Relação entre parâmetros biomecânicos e a aceleração no basquetebol / Rodrigo Maciel Andrade. - São Paulo : [s.n.], 2009. $\mathrm{xv}, 78 \mathrm{p}$.

Dissertação (Mestrado) - Escola de Educação Física e Esporte da Universidade de São Paulo.

Orientador: Prof. Dr. Alexandre Moreira.

1. Biomecânica 2. Teste T 3. Teste de salto vertical 4. Atletas 5. Basquetebol I. Título. 
“...Conserve a vontade de viver, não se chega a parte alguma sem ela. Abra todas as janelas que encontrar e as portas também.

Persiga seus sonhos, mas não o deixe viver sozinho. Alimente sua alma com amor, cure suas feridas com carinho. Descubra-se todos os dias, deixe-se levar pelas vontades, mas não enlouqueça por elas. Procure sempre o fim da história, seja ela qual for. De um sorriso a quem se esqueceu como se faz. Acelere seus pensamentos, mas não permita que eles te consumam. Olhe para o lado, alguém precisa de ti. Abasteça seu coração de fé, não a perca nunca. Mergulhe de cabeça nos seus desejos e satisfaça-os... ... Procure os seus caminhos, mas não magoe ninguém nessa procura..." 


\section{AGRADECIMENTOS}

Certa vez ouvi alguém dizer...

“...eu lembro a mim mesmo toda manhã: nada que eu disser neste dia me ensinará coisa alguma. Portanto se pretendo aprender, devo fazê-lo através do ouvir..."

Sendo assim, minha eterna gratidão para aqueles que me orientaram, que muito me ensinaram com suas sábias palavras nos momentos de maior angústia, Prof. Dr. Alexandre Moreira e Prof. Dr. Júlio Cerca Serrão. Sem estes, tenho absoluta certeza que esta etapa não teria sido bem sucedida. Obrigado pelos incentivos, aconselhamentos, e pela confiança depositada em mim nesta nossa "curta" jornada.

Obrigado ao Prof. Ms. João Nunes e a comissão da seleção brasileira de basquetebol feminina adulta por depositarem confiança neste trabalho e permitiram a participação das atletas.

As atletas da seleção brasileira de basquetebol feminina adulta que participaram do estudo, sem elas este jamais seria possível.

Devo agradecer ainda, aqueles que tiveram imensa participação em todo o processo, desde o início:

- Prof. Dr. Aylton Figueria Jr., por despertar-me para a busca do conhecimento ainda nos tempo de graduação, obrigado pelos ensinamentos.

- A aquela que depositou em mim confiança e abriu as portas na Universidade de São Paulo, Prof ${ }^{a}$. Dr ${ }^{a}$. Maria Augusta Pedutti Dal'Mollin Kiss. 
Agradeço a CAPES pela bolsa de estudos e fomento desta pesquisa.

Não poderia deixar de agradecer ao Márcio e Ilza da secretaria de PósGraduação, pela compreensão e prestação quanto às informações que por muitas vezes foram solicitadas, e a bibliotecária Lúcia pelo auxílio no fechamento deste trabalho.

Tenho ainda que agradecer as pessoas que sempre com grande afinco, buscaram me desestimular, e que por vezes, desdenharam quanto ao cumprimento desta etapa. Tenham vocês em mente...

"...o que não provoca minha morte faz com que eu fique mais forte..."

Friedrich Niezsche

Tenho em mim sempre...

“...o inimigo mais perigoso que você poderá encontrar será sempre você mesmo...."

Friedrich Niezsche

Para você, os meus mais sinceros agradecimentos.

Obrigado as minhas duas famílias...

- família de sangue...

Obrigado aos meus pais e irmãos, que cada um da sua forma, incentivou, trabalhou e contribuiu para o cumprimento deste trabalho.

- e família de escolha (amigos), afinal, o grupo de amigos é a família que escolhemos. Obrigado a vocês amigos dos mais diferentes lugares, sendo:

- amigos do Laboratório de Biomecânica: Fábio José Rodrigues, pela disposição, competência e ajuda na coleta de dados, assim como pela paciência nos ensinamentos e no tratamento dos dados; Carolina de Salles Franco, pelo auxílio nas longas sessões de coleta de dados; Ana Paula da Silva Azevedo e Jú "Bruninha" pelo companheirismo e estímulo nas horas a fio que passamos no laboratório.

- ao amigo Ricardo Saraceni Gomides, pela amizade, e por se mostrar sempre disposto a ajudar nos momentos mais difíceis, em que nem eu mesmo acreditava que tudo daria certo. 
- ao amigo do Laboratório de Fisiologia do Comportamento: José Thales Sena Rebouças, pelo imenso apoio e ensinamento matemático e de linguagem de programação, que muito me foram úteis na confecção deste trabalho.

- amigos do Laboratório de Desempenho Esportivo: Ao técnico Edson Toshiyuki Degaki, e aos alunos Nilo Okuno e Eduard Rumenig, pelo auxílio na coleta de dados, e nas discussões sempre muito proveitosas.

Quero ainda agradecer muito aquele que tem sido minha fonte de alegria....

...que com um "simples" sorriso, com seus olhinhos azuis tão espertos, e suas mãozinhas sempre tão ágeis, querendo descobrir o mundo, desperta o carinho, a ternura, a alegria e a emoção, fazendo-me esquecer os problemas e tristezas, dando-me força e disposição na busca pelo melhor...

...a você Erick.

Eu te amo demais "pitiquinho", impossível descrever com palavras o que sinto por você... 


\section{SUMÁRIO}

Página

LISTA DE TABELAS ................................................................... vii

LISTA DE FIGURAS ................................................................... viii

LISTA DE SIGLAS, ABREVIAÇÕES E SÍMBOLOS ..............................

LISTA DE APÊNDICES ..........................................................

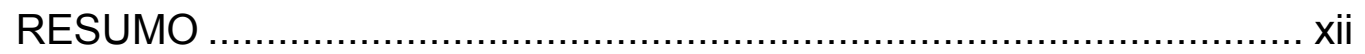

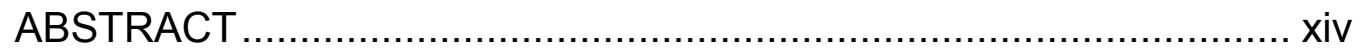

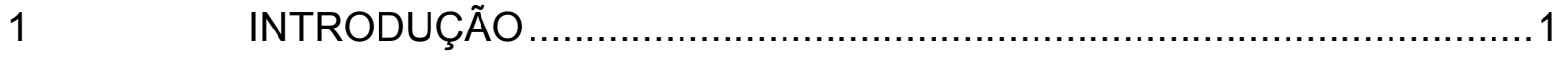

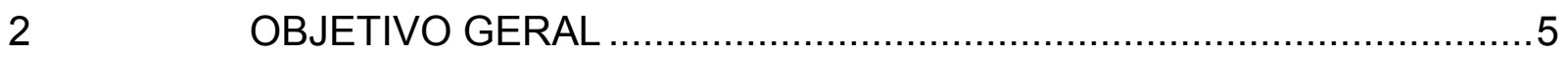

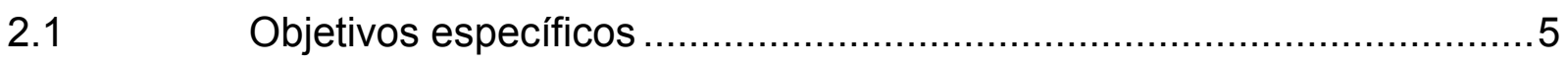

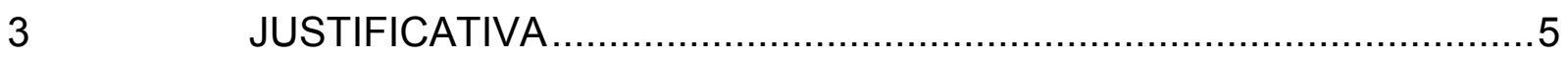

$4 \quad$ HIPÓTESE

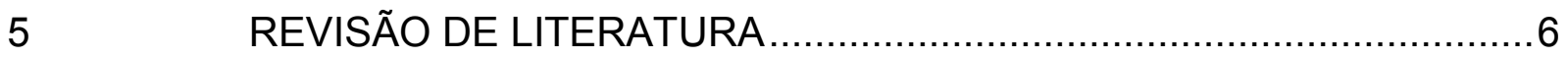

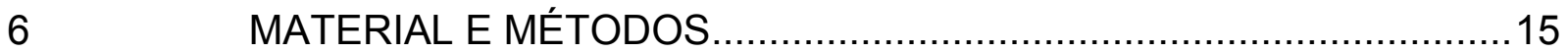

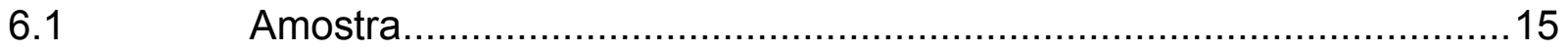

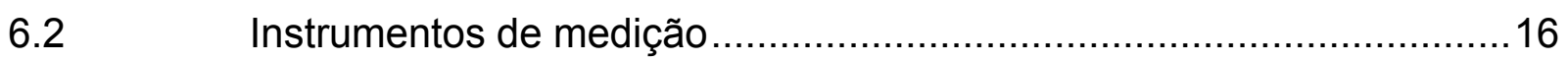

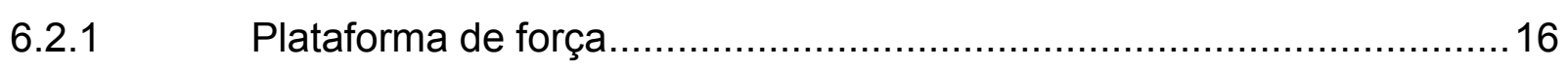

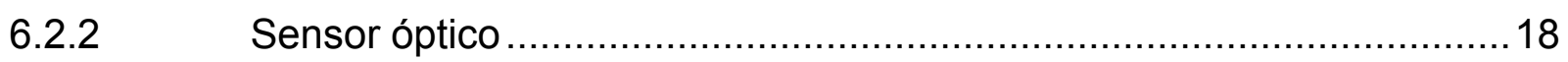

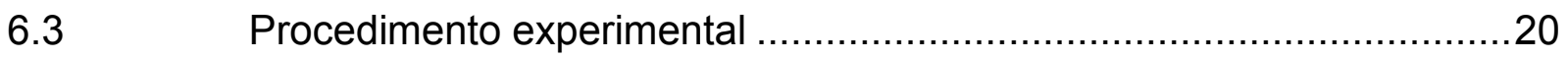

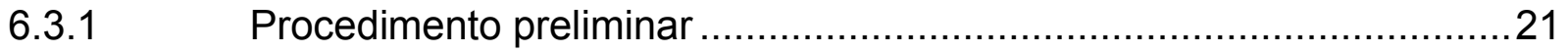

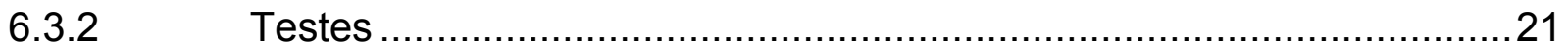

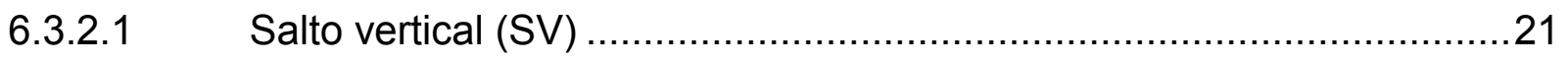

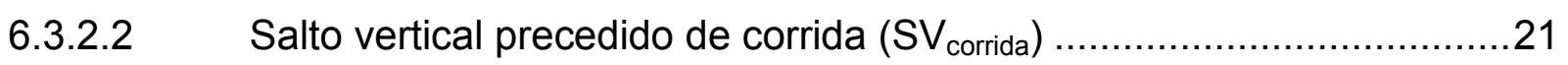

6.3.2.3 Teste de múltiplas acelerações (teste T) ….....................................23

6.3.2.4 Critério para realização dos testes e coleta dos dados.........................26

6.4 Parâmetros biomecânicos do salto ................................................27 


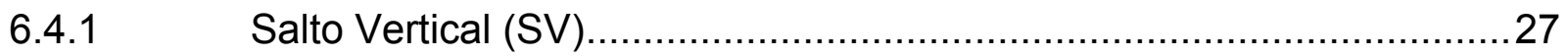

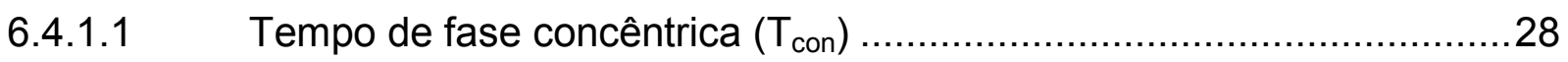

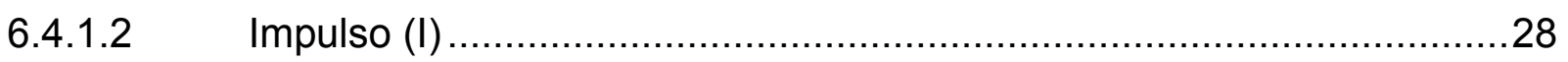

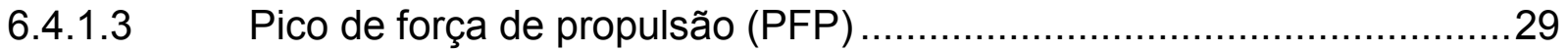

6.4.1.4 Tempo decorrido entre o início de fase concêntrica e o pico de força de

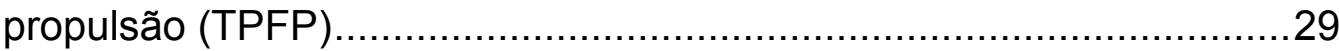

6.4.1.5 Taxa de desenvolvimento de força (TDF) .................................... 30

6.4.2 Salto vertical precedido de corrida $\left(\mathrm{SV}_{\text {corrida }}\right)$.................................. 30

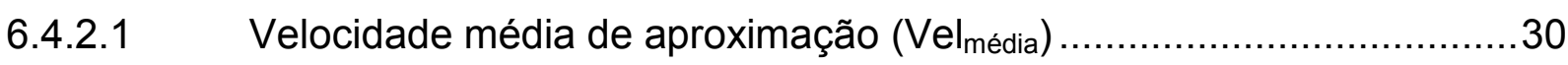

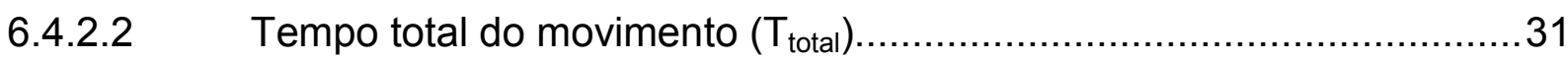

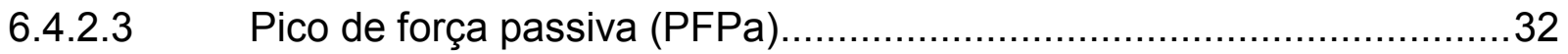

6.4.2.4 Tempo decorrido entre o início da fase de apoio e o pico de força

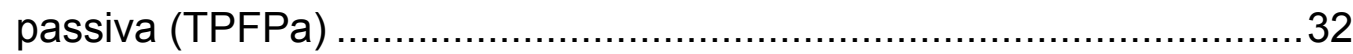

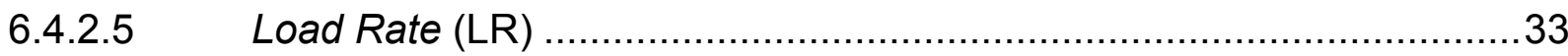

6.4.2.6 Pico de força de propulsão (PFP) ............................................. 33

6.4.2.7 Tempo decorrido entre o início da fase de apoio e o pico de força de

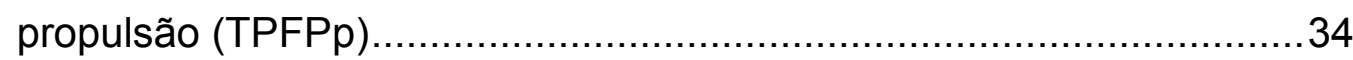

6.4.2.8 Taxa de desenvolvimento de força (TDF) ................................... 34

6.5 Parâmetros do teste de múltiplas acelerações (teste T) ......................35

ANÁLISE DOS DADOS ........................................................... 35

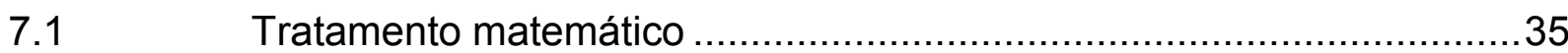

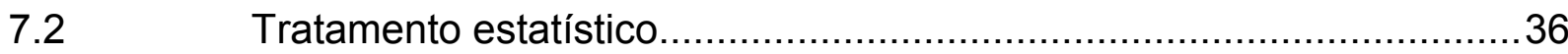

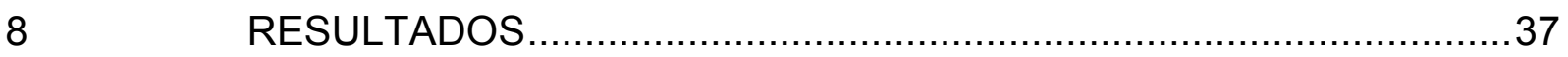

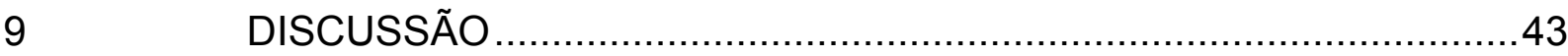

9.1 Contribuição dos parâmetros biomecânicos para o desempenho no salto vertical e no salto vertical precedido de corrida........................43

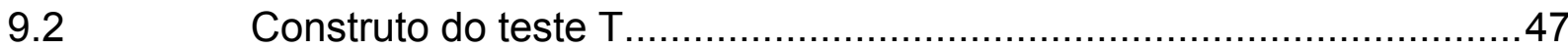

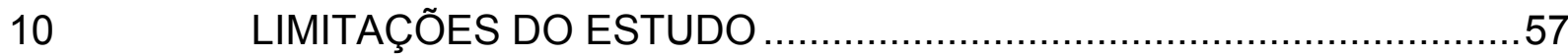

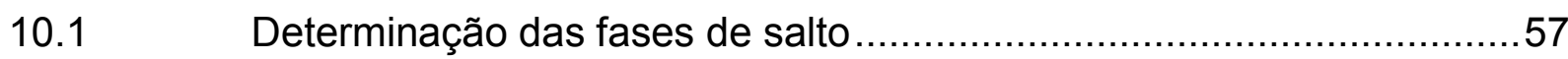

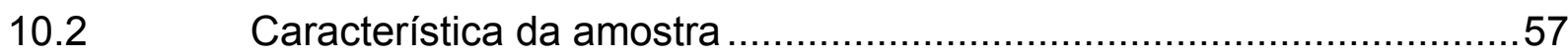

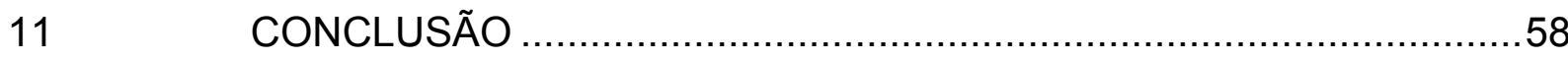

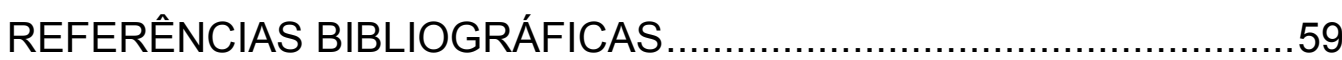




\section{LISTA DE TABELAS}

Página

TABELA 1 - Correlação entre força explosiva (FE) e aceleração (tempo para

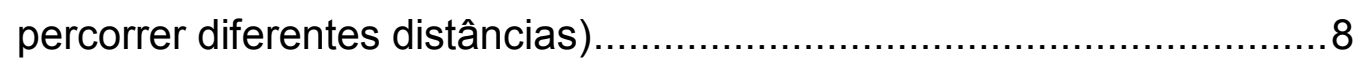

TABELA 2 - Média e desvio-padrão (DP) dos parâmetros biomecânicos obtidos a partir do salto vertical (SV).

TABELA 3 - Variação explicada para cada componente no teste de salto vertical (SV) 38

TABELA 4 - Matriz de componentes do teste de salto vertical (SV) 39

TABELA 5 - Média e desvio-padrão (DP) dos parâmetros biomecânicos obtidos a partir do salto vertical precedido de corrida $\left(\mathrm{SV}_{\text {corrida }}\right)$

TABELA 6 - Variação explicada para cada componente no teste de salto vertical precedido de corrida ( $\left.\mathrm{SV}_{\text {corrida }}\right)$. 40

TABELA 7 - Matriz de componentes do teste de salto vertical precedido de corrida $\left(\mathrm{SV}_{\text {corrida }}\right)$ 41

TABELA 8 - Média e desvio-padrão (DP) dos parâmetros considerados no teste T.41

TABELA 9 - Correlação entre o teste T e os parâmetros biomecânicos obtidos a partir do salto vertical (SV).

TABELA 10 - Correlação entre o teste T e os parâmetros biomecânicos obtidos a partir do salto vertical precedido de corrida ( $\left.S \mathrm{~V}_{\text {corrida }}\right)$ 43 


\section{LISTA DE FIGURAS}

Página

FIGURA 1 - Modelo determinístico de múltiplas acelerações ................................1

FIGURA 2 - Definição dos sinais e parâmetros necessários ao cálculo das variáveis relacionadas à força de reação do solo .....................................17

FIGURA 3 - Diagrama do sensor óptico................................................... 18

FIGURA 4 - Componentes do sensor óptico ...................................................

FIGURA 5 - Princípio de funcionamento do sensor óptico ..................................19

FIGURA 6 - Estrutura composta por sensor óptico-tripé ....................................20

FIGURA 7 - Posicionamento do sensor óptico no teste de salto vertical precedido de

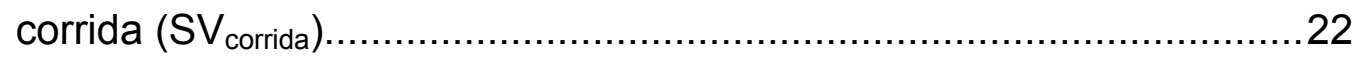

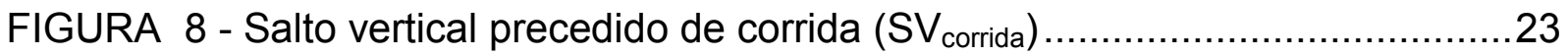

FIGURA 9 - Posicionamento dos sensores ópticos para a realização do teste de múltiplas acelerações (teste T) ...........................................24

FIGURA 10 - Orientação para a realização do teste de múltiplas acelerações (teste T)

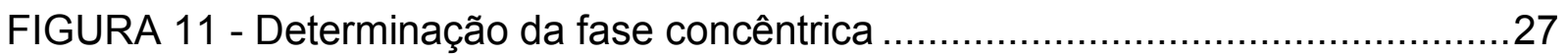

FIGURA 12 - Determinação do tempo de fase concêntrica ..................................28

FIGURA 13 - Determinação do pico de força de propulsão .................................29

FIGURA 14 - Determinação do tempo decorrido entre o início de fase concêntrica e o pico de força de propulsão ....................................................29

FIGURA 15 - Determinação da taxa de desenvolvimento de força..........................30

FIGURA 16 - Determinação da fase de apoio................................................ 31

FIGURA 17 - Determinação do tempo total do movimento .................................. 31

FIGURA 18 - Determinação do pico de força passiva......................................... 32

FIGURA 19 - Determinação do tempo decorrido entre início da fase de apoio e o pico de força passiva 
FIGURA 20 - Determinação do Load Rate .................................................. 33

FIGURA 21 - Determinação do pico de força de propulsão ...................................33

FIGURA 22 - Determinação do tempo decorrido entre o início da fase de apoio e o pico de força de propulsão ...................................................... 34

FIGURA 23 - Determinação da taxa de desenvolvimento de força ..........................34

FIGURA 24 - Parâmetros considerados do teste de múltiplas acelerações (teste T) 35

FIGURA 25 - Fases da corrida (adaptado de DELECLUSE et al., 1995).................48 


\section{LISTA DE SIGLAS, ABREVIAÇÕES E SÍMBOLOS}

$\begin{array}{ll}\text { I } & \text { Impulso } \\ \text { LR } & \text { Load Rate } \\ \text { PFP } & \text { Pico de força de propulsão } \\ \text { PFPa } & \text { Pico de força passiva } \\ \text { SV } & \text { Salto vertical } \\ \text { SV } & \text { Salto vertical precedido de corrida } \\ \text { T }_{\text {con }} & \text { Tempo de fase concêntrica } \\ \text { TDF } & \text { Taxa de desenvolvimento de força } \\ \text { TPFP } & \text { Tempo decorrido entre início da fase concêntrica e o pico de força de } \\ & \text { propulsão } \\ \text { TPFPa } & \text { Tempo decorrido entre início da fase de apoio e pico de força passiva } \\ \text { TPFPp } & \text { Tempo decorrido entre início da fase de apoio e pico de força de } \\ & \text { propulsão } \\ \text { Ttotal } & \text { Tempo total do movimento } \\ \text { Vel } & \text { Védia }\end{array}$




\section{LISTA DE APÊNDICES}

Página

APÊNDICE 1 - Termo de Consentimento Livre e Esclarecido .............................72 APÊNDICE 2 - Coeficiente de correlação intraclasse (CCl) dos parâmetros

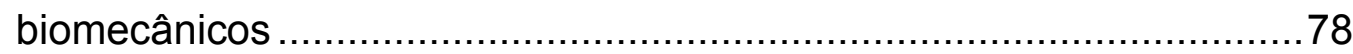




\title{
RESUMO
}

\section{RELAÇÃO ENTRE PARÂMETROS BIOMECÂNICOS E ACELERAÇÃO NO BASQUETEBOL}

\author{
Autor: RODRIGO MACIEL ANDRADE \\ Orientador: PROF. DR. ALEXANDRE MOREIRA
}

O objetivo do estudo foi investigar o construto da tarefa de múltiplas acelerações a partir de parâmetros biomecânicos de saltos verticais. 19 jogadoras da seleção brasileira adulta de basquetebol feminino realizaram o teste de múltiplas acelerações (teste T), salto vertical com contramovimento (SV) e salto vertical com contramovimento precedido de corrida ( $\mathrm{SV}_{\text {corrida }}$ ). Os parâmetros biomecânicos do $\mathrm{SV}$ foram, tempo de fase concêntrica ( $T_{\text {con }}$ ), pico de força de propulsão (PFP), tempo decorrido entre início da fase concêntrica e o pico de força de propulsão (TPFP), taxa de desenvolvimento de força (TDF) e impulso (I); para $S V_{\text {corrida, velocidade média de }}$ aproximação (Vel $\left.\mathrm{I}_{\text {média }}\right)$, tempo total do movimento $\left(T_{\text {total }}\right)$, pico de força passiva (PFPa), tempo decorrido entre início da fase de apoio e pico de força passiva (TPFPa), pico de força de propulsão (PFP), tempo decorrido entre início da fase de apoio e pico de força de propulsão (TPFPp), Load Rate (LR) e taxa de desenvolvimento de força (TDF). Para análise dos dados, inicialmente, recorreu-se a análise de componentes principais, revelando que $61,3 \%$ da variância total do SV foi explicada pelo componente predominantemente temporal ( $T_{\text {con }}$, TPFP e PFP) e 20,7\% pelo componente predominantemente cinético (I e TDF); para $\mathrm{SV}_{\text {corrida, }}, 58,7 \%$ da variância total foi explicada pelo componente predominantemente temporal $\left(T_{\text {total, }}\right.$, 
TPFPa, TPFPp, LR e TDF), 15,4\% pelo componente predominantemente cinético (PFPa e PFP) e 12,8\% pelo componente velocidade (Vel $\mathrm{l}_{\text {média }}$ ). Adicionalmente, foram reveladas correlações significantes de 0,55 ( $\left.T_{\text {con }}\right),-0,54$ (Vel $\left.l_{\text {média }}\right)$ e -0,49 (PFP) com o teste $\mathrm{T}$, evidenciando um construto determinado pela capacidade de se gerar elevada força na fase concêntrica, reduzir o tempo de fase concêntrica e se aproximar do ponto de mudança de direção com elevada velocidade.

Palavras chaves: teste $\mathrm{T}$, salto vertical, atletas 


\title{
ABSTRACT \\ RELATIONSHIP BETWEEN BIOMECHANICS PARAMETERS AND ACCELERATION TASKS ON BASKETBALL PLAYERS
}

\author{
Author: RODRIGO MACIEL ANDRADE \\ Adviser: PROF. DR. ALEXANDRE MOREIRA
}

The main aim of the study was to investigate the multiple-acceleration task construct from vertical jumps biomechanics parameters. Nineteen female basketball players from Brazilian national team performed the multiple-acceleration test ( $T$ test), countermovement jump (VJ) and countermovement jump preceded by run (VJr). The VJ biomechanics parameters observed were: concentric phase duration (CPD), propulsion peak force (PPF), time to reach propulsion peak force (TPPF), rate of force development (RFD) and impulse (I); for VJr the parameters were mean velocity (MV), movement total duration (MTD), passive peak force (PaPF), time to reach passive peak force (TPaPF), propulsion peak force (PPF), time to reach propulsion peak force (TPpPF), load rate (LR) and rate of force development (RFD). Data were first analyzed by principal component analysis. The results showed that $61.3 \%$ of $\mathrm{VJ}$ variance could be explained by time factor (CPD, TPPF and PPF), and $20.7 \%$ by kinetic factor (I and RFD). To VJr, 58.7\% of total variance could be explained by time factor (MTD, TPaPF, TPpPF, LR, RFD) and $15.4 \%$ by kinetic factor (PPF and PaPF) and $12.8 \%$ by velocity factor (MV). Furthermore, significant correlations were found between $T$ test with CPD, MV and PPF $(0.55,-0.54$ and -0.49 , respectively), revealing a $\mathrm{T}$ test construct related to the ability of generating high level of force in concentric 
phase, diminishing time of concentric phase, and to reach the change direction point with greatest possible speed.

Keywords: T test, vertical jump, athletes 


\section{INTRODUÇÃO}

O basquetebol pode ser caracterizado como uma atividade intermitente realizada através de freqüentes ações de alta intensidade e deslocamentos em distância reduzida, evidenciando a importância da aceleração para um bom desempenho (ACQUESTA, PENEIREIRO, BIANCO, AMADIO \& SERRÃO, 2007; BEN ABDELKRIM, EL FAZAA \& EL ATI, 2007; DRINKWATER, PYNE \& MCKENNA, 2008).

A busca pelo entendimento das variáveis determinantes da aceleração, dentre elas a força, tem sido alvo de considerações, investigações e suposições de diversos pesquisadores e especialistas da modalidade.

Visto que para grande parte dos esportes parece ser mais importante a grandeza de força gerada por unidade tempo do que altas expressões da força máxima, dada as características explosivas e de velocidade dos gestos, como o salto (AAGAARD, SIMONSEN, ANDERSEN, MAGNUSSON \& DYHRE-POULSEN, 2002; CARVALHO \& CARVALHO, 2006; CORMIE, MCBRIDE \& MCCAULLEY, 2009; VANEZIS \& LEES, 2005; YOUNG, WILSON \& BYRNE, 1999), estudos tem direcionado sua atenção à força explosiva, entendida como uma manifestação da capacidade força motora e definida como a capacidade de exercer a máxima força no mínimo tempo (ZATSIORSKY, 1999).

Usualmente tem-se considerado o desempenho nos testes de salto como um indicador da força explosiva (ARRUDA \& HESPANHOL, 2008) e, o tempo para percorrer diferentes distâncias, como indicador de aceleração. Neste sentido, os resultados encontrados na literatura reportam de forma consensual a relação entre a força explosiva e aceleração, independentemente da modalidade estudada e distância adotada nos testes (CRONIN \& HANSEN, 2005; HAKKINEN, 1989; HENNESSY \& KILTY, 2001; SANTOS, 2006; SMIRNIOTOU, KATSIKAS, PARADISIS, ARGEITAKI, ZACHAROGIANNIS \& TZIORTZIS, 2008).

Todavia, vale ressaltar que os estudos têm considerado deslocamentos realizados em linha reta e em distâncias geralmente superiores a 10 metros, o que pode apresentar limitada contribuição quanto a elucidação da questão (relação entre aceleração versus força explosiva) em esportes como o basquetebol, no qual a estrutura funcional, caracterizada pelas condições de espaço, tempo, dimensões da 
quadra, número de jogadores, adversários, etc, limita o deslocamento em linha reta em distâncias superiores a 10 metros (BEN ABDELKRIM, EL FAZAA \& EL ATI, 2007; DELEXTRAT \& COHEN, 2008; MCINNES, CARLSON, JONES \& MCKENNA, 1995).

Adicionalmente, no basquetebol tem-se uma elevada demanda para se produzir elevada aceleração, tanto no sentido de um aumento rápido da velocidade ("saídas" nas mais diferentes condições), quanto no que diz respeito à brusca diminuição (desaceleração), dada a necessidade de constantes mudanças de direção.

Estas características, adicionada a natureza das ações no basquetebol ressaltam a importância de um bom desempenho relativo à aceleraçãodesaceleração, ou múltiplas acelerações (CRONIN, MCNAIR \& MARSHALL, 2001; MCINNES et al., 1995; MOREIRA, OLIVEIRA, RONQUE, OKANO \& SOUZA, 2008c; MOREIRA, SOUZA \& OLIVEIRA, 2003; SLEIVERT \& TAINGAHUE, 2004), sugerindo uma outra abordagem, tanto de investigação, quanto o que diz respeito ao treinamento.

Neste sentido, vale destacar que a aceleração produzida com o intuito exclusivo de aumento da velocidade possui baixa correlação com as tarefas em que é requerido produzir múltiplas acelerações, o que poderia ser explicado, em parte, pelo aumento da complexidade da tarefa (SHEPPARD \& YOUNG, 2006), e pela possível contribuição de diferentes parâmetros da força na tarefa de múltiplas acelerações (CRONIN, MCNAIR \& MARSHALL, 2001; PAUOLE, MADOLE, GARHAMMER, LACOURSE \& ROZENEK, 2000; SHEPPARD \& YOUNG, 2006).

Com o objetivo de se aumentar a validade ecológica, norteada pelas considerações anteriores no tocante a avaliação da aceleração no basquetebol, estudos com diferentes delineamentos têm adotado como indicador de desempenho na tarefa de múltiplas acelerações, o resultado no "teste T" (MOREIRA, 2008; MOREIRA, OKANO, RONQUE, OLIVEIRA, ARRUDA, MORTATTI \& PAES, 2008a; MOREIRA, OKANO, RONQUE, SOUZA \& OLIVEIRA, 2008b; MOREIRA, OKANO, SOUZA, OLIVEIRA \& GOMES, 2005; MOREIRA, SOUZA \& OLIVEIRA, 2003)

Os autores têm justificado a utilização do teste $T$, em função de se assumir que os resultados decorrentes deste poderiam contemplar a natureza de múltiplas acelerações realizadas no jogo de basquetebol (aumento e diminuição de velocidade 
e mudanças de direção) (DELEXTRAT \& COHEN, 2008; MCINNES et al., 1995; ZIV \& LIDOR, 2009a) que por sua vez, apresentam características próximas as encontradas no próprio teste (PAUOLE et al., 2000; SEMENICK, 1990) e, ainda, com a possibilidade de se discriminar o nível competitivo dos atletas (DELEXTRAT \& COHEN, 2008; PAUOLE et al., 2000).

Porém, apesar destas vantagens e da validade revelada pelos pesquisadores concernente a utilização do teste $T$, pouco se conhece a respeito de seu construto, que por vezes, tem sido abordado na forma de especulação e suposição (PAUOLE et al., 2000).

Nos estudos que se propuseram a avançar no entendimento a respeito de múltiplas acelerações, a partir do teste $\mathrm{T}$, emergiram indícios da relação do desempenho no teste com os níveis de força explosiva; SASSI, DARDOURI, YAHMED, GMADA, MAHFOUDHI \& GHARBI (2009) encontraram correlação significante entre múltiplas acelerações e força explosiva em uma amostra composta por mulheres atletas de futebol, voleibol, basquetebol e handebol; MOREIRA, SOUZA \& OLIVEIRA (2003) investigaram a relação entre o desempenho de jogadores de basquetebol de alto rendimento no teste $\mathrm{T}$ com medidas de diferentes saltos verticais e horizontais, e relataram correlação alta e significante do desempenho no teste $\mathrm{T}$ com $\mathrm{o}$ resultado no teste de salto horizontal triplo consecutivo.

Apesar destes achados reportados na literatura, é razoável admitir certa escassez na formação de um corpo de conhecimento mais consistente inerente a esta temática, bem como, no que diz respeito à compreensão do fenômeno (CRONIN, MCNAIR \& MARSHALL, 2001; ZIV \& LIDOR, 2009a), ainda mais considerando jogadores de alto rendimento de basquetebol (ZIV \& LIDOR, 2009a).

Outro ponto que merece atenção quanto à compreensão da relação entre o teste $T$ com os níveis de força, diz respeito à contribuição dos parâmetros de força no desempenho de salto.

Enquanto alguns estudos apontam para uma maior necessidade da geração de força por unidade de tempo (componente temporal) (DE RUITER, VAN LEEUWEN, HEIJBLOM, BOBBERT \& DE HAAN, 2006; HAKKINEN, 1993; JARIC, RISTANOVIC \& CORCOS, 1989; KYROLAINEN, AVELA, MCBRIDE, KOSKINEN, 
ANDERSEN, SIPILA, TAKALA \& KOMI, 2005; THORLUND, AAGAARD \& MADSEN, 2009; VIITASALO \& AURA, 1984), outros refutam tal argumento (KAWAMORI, ROSSI, JUSTICE, HAFF, PISTILLI, O'BRYANT, STONE \& HAFF, 2006; NUZZO, MCBRIDE, CORMIE \& MCCAULLEY, 2008; UGARKOVIC, MATAVULJ, KUKOLJ \& JARIC, 2002; VANEZIS \& LEES, 2005) tendo como base de questionamento o fato dos estudos que apontaram para uma maior contribuição das respostas predominantemente temporais, tiveram seus achados fundamentados nos parâmetros de força obtidos em ações isométricas e isocinéticas, não sendo estas, consideradas as estratégias mais adequadas na elucidação de tarefas dinâmicas (BOSCO, 2007; BRUGHELLI, CRONIN, LEVIN \& CHAOUACHI, 2008; NUZZO et al., 2008; SANTOS, 2006; UGRINOWITSCH, BARBANTI, GONÇALVES \& PERES, 2000; VIITASALO \& AURA, 1984).

Ainda, tem sido apontado que, além das relações entre testes isométricos e de salto serem modalidade-dependente, ao se adotar angulação única para a determinação dos parâmetros de força, pode ser atribuído certa incongruência entre a manifestação da força produzida nesta angulação específica e aquela encontrada durante a execução de tarefas funcionais específicas como o salto vertical (ROUSANOGLOU, GEORGIADIS \& BOUDOLOS, 2008).

Corroborando com tais argumentos, outros estudos (KOLLIAS, HATZITAKI, PAPAIAKOVOU \& GIATSIS, 2001; LAFFAYE, BARDY \& DUREY, 2007) demonstraram que por vezes, se torna imperante os parâmetros predominantemente cinéticos, como o pico de força.

Embora não se possa negar a inter-relação entre os componentes predominantemente cinéticos e predominantemente temporais, a magnitude de contribuição destes parâmetros para o salto vertical parece ser amostra-dependente (KOLLIAS et al., 2001; LAFFAYE, BARDY \& DUREY, 2007), portanto ainda sendo discutível a generalização quanto a contribuição dos componentes predominantemente cinéticos e predominantemente temporais determinantes do desempenho no salto vertical. Logo, dificultando à compreensão da relação entre os parâmetros de força e o teste $\mathrm{T}$.

Sendo assim, faz-se necessário avançar no conhecimento quanto ao construto das tarefas de múltiplas acelerações em atletas de basquetebol de alto rendimento e 
suas relações com parâmetros biomecânicos decorrentes de diferentes testes de salto.

\section{OBJETIVO GERAL}

O objetivo do presente estudo foi investigar o construto da tarefa de múltiplas acelerações a partir de parâmetros biomecânicos de dois tipos de teste de salto vertical.

\subsection{Objetivos específicos}

A. Investigar os parâmetros biomecânicos de maior contribuição para o desempenho no salto vertical.

B. Investigar os parâmetros biomecânicos de maior contribuição para o desempenho no salto vertical precedido de corrida.

C. A partir dos parâmetros biomecânicos que mais contribuíram para o desempenho nos testes de salto vertical, investigar a associação destes com o desempenho na tarefa de múltiplas acelerações (teste T).

\section{JUSTIFICATIVA}

A tarefa de múltiplas acelerações pode ser considerada de extrema importância para o desempenho no basquetebol, fazendo com que a necessidade do conhecimento dos fatores determinantes desta seja considerada. Neste sentido, a força tem sido apontada como um fator determinante no desempenho deste tipo de tarefa. Todavia, considerando a suposição de uma importante associação entre os testes de salto vertical e de múltiplas acelerações (teste $\mathrm{T}$ ), o papel dos parâmetros biomecânicos, conhecidos a partir dos testes de salto vertical, no desempenho no teste $\mathrm{T}$, ainda precisa ser elucidado.

\section{HIPÓTESE}

Tem-se a hipótese de uma importante contribuição dos parâmetros biomecânicos revelados a partir dos testes de salto vertical, no teste $T$, e ainda, que 
esta contribuição não seja teste vertical-dependente, desta forma os parâmetros biomecânicos decorrentes dos dois tipos de salto se associariam de forma semelhante ao desempenho no teste $\mathrm{T}$.

\section{REVISÃO DE LITERATURA}

Definida como taxa de variação da velocidade (CHAVES \& SAMPAIO, 2007), a aceleração pode ser considerada de extrema importância nos esportes como o basquetebol, em que se faz necessário obter elevada taxa de variação de velocidade em reduzidos intervalos de tempo (DELEXTRAT \& COHEN, 2008; MOREIRA, MORTATTI, GOMES, PAES \& JELEILATE, 2009; MOREIRA et al., 2008c; MOREIRA, SOUZA \& OLIVEIRA, 2003; PAUOLE et al., 2000).

Evidenciando a importância da aceleração para o desempenho no basquetebol, $36,1 \%$ de todas as ações executadas durante uma partida são deslocamentos em alta velocidade e distância reduzida (NARAZAKI, BERG, STERGIOU \& CHEN, 2009). Estudos demonstram que são realizados entre 55 (BEN ABDELKRIM, EL FAZAA \& EL ATI, 2007) e 105 destas ações (MCINNES et al., 1995), sendo que $49 \%$ destas ações têm duração menor do que 1,5 segundos, $73 \%$ menor do que dois segundos, $88 \%$ menor do que três segundos e 95\% tem duração inferior a quatro segundos (MCINNES et al., 1995). Sendo assim, a busca pelo conhecimento dos parâmetros relacionados ao desempenho na aceleração tem sido foco de grande interesse.

Investigações sugerem importante contribuição da força máxima para aceleração em distâncias reduzidas, como SLEIVERT \& TAINGAHUE (2004) que encontraram em atletas de rugby e basquetebol associação significante da aceleração produzida na distância de cinco metros com o desempenho no teste de uma repetição máxima (1RM) no agachamento, e como MCBRIDE, BLOW, KIRBY, HAINES, DAYNE \& TRIPLETT (2009) que ao estudar atletas de futebol americano encontraram associação significante entre a aceleração nas distâncias de 10 jardas (aproximadamente 9,14 metros) e a força isométrica máxima normalizada pela massa corporal obtida no agachamento.

No entanto, uma vez que a maioria dos esportes apresenta ações motoras com características explosivas e de velocidade, o desempenho parece não depender 
de altas expressões da força máxima, mas sim o quanto desta força é produzida por unidade de tempo (AAGAARD et al., 2002; CARVALHO \& CARVALHO, 2006; CORMIE, MCBRIDE \& MCCAULLEY, 2009; VANEZIS \& LEES, 2005; YOUNG, WILSON \& BYRNE, 1999). Logo, a força explosiva, definida como a capacidade de exercer a máxima força no mínimo tempo (ZATSIORSKY, 1999), tem sido apontada como o parâmetro de força que mais poderia estar associada à aceleração.

Nas investigações acerca desta possível associação, usualmente tem-se considerado por um lado, o desempenho nos testes de salto como um indicador da força explosiva (ARRUDA \& HESPANHOL, 2008), e por outro lado, o tempo para percorrer determinada distância como indicador de aceleração.

Por exemplo, correlação significante entre força explosiva e a aceleração nas distâncias de cinco e 10 metros em atletas de rugby (CRONIN \& HANSEN, 2005) e em velocistas (SMIRNIOTOU et al., 2008) foram reportadas.

Resultados semelhantes foram encontrados em um grupo de atletas de nível regional de basquetebol, rugby e futebol, quando considerada a relação entre força explosiva (distância do salto horizontal) e a aceleração na distância de cinco metros $(r=-0,55), 10$ metros $(r=-0,61)$ e 25 metros $(r=-0,51)$ (HOLM, STALBOM, KEOGH \& CRONIN, 2008), e entre força explosiva (salto vertical) e a aceleração na distância de 30 metros $(r=-0,59)$ em jogadores de basquetebol juvenis (SANTOS, 2006). Todavia, correlações não significantes também têm sido reportadas em velocistas, ao ser investigada a relação do desempenho no salto vertical e a aceleração na distância de cinco metros (CHAOUACHI, BRUGHELLI, CHAMARI, LEVIN, BEN ABDELKRIM, LAURENCELLE \& CASTAGNA, 2009).

De uma forma geral, os estudos que tiveram sua amostra composta por atletas reportam correlações negativas, moderadas e significantes, entre força explosiva e aceleração, independentemente da modalidade e distância analisada (TABELA 1). 
TABELA 1 - Correlação entre força explosiva (FE) e aceleração (tempo para percorrer diferentes distâncias)

\begin{tabular}{cccc}
\hline Aceleração em: & Correlação entre FE e aceleração & Atletas/amostra & Referência \\
\hline 5 metros & $-0,60^{*}$ & Rugby & CRONIN \& HANSEN (2005) \\
10 metros & $-0,62^{*}$ & Rugby & CRONIN \& HANSEN (2005) \\
10 metros & $-0,61^{* *}$ & Velocistas & SMIRNIOTOU et al. (2008) \\
10 metros & $-0,64^{* *}$ & Velocistas & CHAOUACHI et al. (2009) \\
20 metros & $-0,47^{* *}$ & Voleibol/Basquetebol & HAKKINEN (1989) \\
30 metros & $-0,72^{* *}$ & WISLOFF, CASTAGNA, & HELGERUD, JONES \& HOFF \\
30 metros & $-0,60^{*}$ & Futebol & $(2004)$ \\
30 metros & $-0,56^{*}$ & Velocistas & HENNESSY \& KILTY (2001) \\
30 metros & $-0,68^{* *}$ & Rugby & CRONIN \& HANSEN (2005) \\
30 metros & $-0,83^{* * *}$ & Velocistas & SMIRNIOTOU et al. (2008)
\end{tabular}


Todavia, em muitos esportes, as condições de espaço, tempo, dimensões da quadra, número de jogadores, adversários, entre outras características, não permitem o deslocamentos em linha reta e em grande distância (DELEXTRAT \& COHEN, 2008). Nesta situação, produzir elevada taxa de variação de velocidade (aceleração), tanto para aumento, quanto para diminuição da velocidade parece ser de grande importância.

Neste sentido, considerar apenas a aceleração para aumento da velocidade parece não ser a melhor estratégia para avaliar atletas de basquetebol, onde se faz necessário a busca pela máxima velocidade possível seguida pela diminuição brusca da velocidade (frenagem), logo múltiplas acelerações (DELEXTRAT \& COHEN, 2008; MCINNES et al., 1995; MOREIRA et al., 2008c; MOREIRA, SOUZA \& OLIVEIRA, 2003; SLEIVERT \& TAINGAHUE, 2004). Ainda, estudos têm demonstrado que em partidas de basquetebol, aproximadamente $88 \%$ dos deslocamentos em alta velocidade duram menos de que três segundos (MCINNES et al., 1995), tempo gasto para percorre aproximadamente 10 metros, tornando de pouca validade ecológica testes que perdurem por mais tempo/distância.

Além do mais, as tarefas visando aceleração e múltiplas acelerações parecem ser indicadores de diferentes atributos físicos (LITTLE \& WILLIAMS, 2005; MEYLAN, MCMASTER, CRONIN, MOHAMMAD, ROGERS \& DEKLERK, 2009; SASSI et al., 2009; YOUNG, MCDOWELL \& SCARLETT, 2001) e quanto maior o número de mudanças de direção, maior a distinção entre elas (SHEPPARD \& YOUNG, 2006).

Corroborando com a idéia de distinção dos atributos físicos presentes nestas tarefas, tem sido encontrado que a capacidade de produzir aceleração buscando exclusivamente o alcance da máxima velocidade parece possuir de fraca a moderada associação ( $r$ entre 0,07 a - 0,61) com o desempenho nos testes em que se faz necessário múltiplas acelerações (CHAOUACHI et al., 2009; LITTLE \& WILLIAMS, 2005; MEYLAN et al., 2009; SASSI et al., 2009; SHEPPARD \& YOUNG, 2006; WISLOFF et al., 2004).

Este fenômeno poderia ser explicado, pelo menos em parte, pelo aumento da complexidade da tarefa, e pelo fato da aceleração ser apenas um dos componentes relacionados a tarefa de múltiplas acelerações [FIGURA 1] (SHEPPARD \& YOUNG, 2006). 


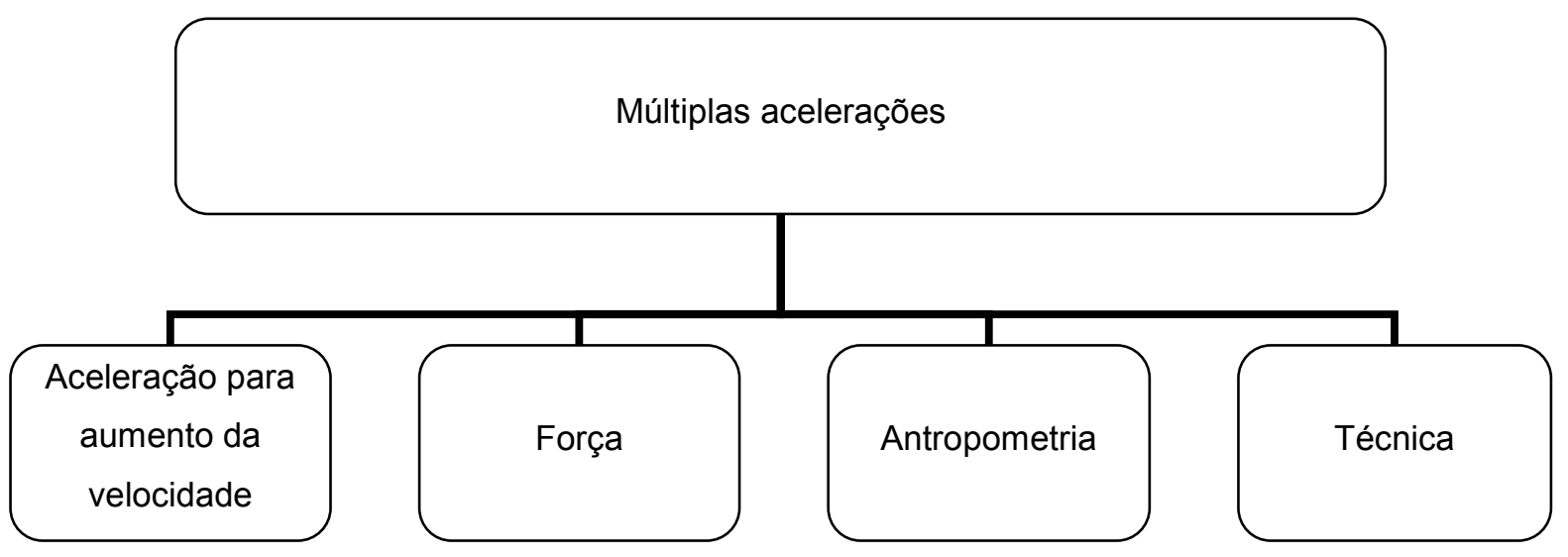

FIGURA 1 - Modelo determinístico de múltiplas acelerações

Outro fator que pode contribuir para o entendimento da associação de fraca a moderada magnitude entre a tarefa que requer produzir aceleração buscando exclusivamente o alcance da máxima velocidade com o desempenho nos testes em que se faz necessário produzir múltiplas acelerações (CHAOUACHI et al., 2009; MEYLAN et al., 2009; SASSI et al., 2009; SHEPPARD \& YOUNG, 2006; WISLOFF et al., 2004) é o fato da demanda mecânica e de qualidade neuromuscular, logo das contribuições dos parâmetros de força para a aceleração, ser distância-dependente (MOIR, SANDERS, BUTTON \& GLAISTER, 2007; YOUNG, MCLEAN \& ARDAGNA, 1995).

Como exemplo disto, YOUNG, MCLEAN \& ARDAGNA (1995) obtendo parâmetros de força a partir do salto vertical sem contramovimento com adição de sobrecarga de 19 quilogramas, demonstraram que na distância de 2,5 metros o pico de força apresentou maior correlação com a aceleração $(r=-0,86)$, sendo seguido pela força gerada após 100 milésimos de segundo $(r=-0,73)$, máxima taxa de desenvolvimento de força $(r=-0,62)$ e força gerada após 30 milésimos de segundo $(r=-0,46)$, ao ponto que para a distância de 10 metros para aceleração, a força gerada após 100 milésimos de segundo apresentou maior associação $(r=-0,80)$, seguida da máxima taxa de desenvolvimento de força $(r=-0,73)$, pico de força $(r=-$ $0,69)$ e força após 30 milésimos de segundo $(r=-0,49)$, enquanto que MOIR et al. (2007) ao analisar o efeito das adaptações do treinamento de força, encontraram 
aumento no tempo para percorrer a distância de 10 metros, porém com diminuição do tempo para percorrer a distância entre 10 e 20 metros.

Sendo assim, poder-se-ia supor que diferentes parâmetros da força estejam envolvidos na tarefa de aceleração buscando somente a máxima velocidade, e na tarefa de múltiplas acelerações, indo ao encontro do sugerido por LITTLE \& WILLIAMS (2005) quanto as possíveis diferenças no diz respeito aos fatores biomecânicos e fisiológicos que contribuem para o sucesso em cada um dos tipos de testes citados.

No entanto, por indicar em sua essência a capacidade do individuo de produzir múltiplas acelerações (PAUOLE et al., 2000; SEMENICK, 1990), o teste T tem sido uma das estratégias comumente adotadas na literatura como indicador desta capacidade em atletas de basquetebol (DELEXTRAT \& COHEN, 2008; DELEXTRAT \& COHEN, 2009; MOREIRA, 2008; MOREIRA et al., 2008a; MOREIRA et al., 2008b; MOREIRA et al., 2005; MOREIRA, SOUZA \& OLIVEIRA, 2003) por solicitar um padrão de execução com características próximas as encontradas durante o jogo (DELEXTRAT \& COHEN, 2008; MCINNES et al., 1995; ZIV \& LIDOR, 2009a) e pelo seu poder discriminatório quanto ao nível de desempenho esportivo (DELEXTRAT \& COHEN, 2008; PAUOLE et al., 2000), fato não proporcionado pelo teste de aceleração na distância de 20 metros (DELEXTRAT \& COHEN, 2008; DELEXTRAT \& COHEN, 2009).

Apesar da validade e da reprodutibilidade reportada para este teste (SASSI et al., 2009), pouco se sabe a respeito de seu construto (PAUOLE et al., 2000).

$\mathrm{Na}$ busca pelo melhor entendimento a respeito do teste $\mathrm{T}$, estudos têm investigado a relação deste com a força explosiva (salto vertical), e como resultado, apontam para correlações significantes quando considerado um grupo de mulheres, atletas universitárias de futebol, voleibol, basquetebol e handebol $(r=-0,47)$ (SASSI et al., 2009), de basquetebol, voleibol e softbol $(r=-0,71)$ (PETERSON, ALVAR \& RHEA, 2006), e em um grupo formado por atletas, indivíduos engajados na prática esportiva e indivíduos pouco ativos de homens $(r=-0,49)$ e de mulheres $(r=-0,55)$ (PAUOLE et al., 2000).

Resultados semelhantes foram reportados por MOREIRA, SOUZA \& OLIVEIRA (2003) que ao invés de considerar como indicador de força explosiva a 
altura de salto vertical, consideraram a distância obtida no salto horizontal e o salto horizontal triplo consecutivo. Neste estudo, os autores encontraram correlações significantes entre a distância no salto horizontal $(r=-0,85)$ e no salto horizontal triplo consecutivo $(r=-0,95)$ com múltiplas acelerações (teste $T$ ) em atletas de basquetebol, corroborando com PETERSON, ALVAR \& RHEA (2006) que encontraram associação significante entre o teste $\mathrm{T}$ e a distância no salto horizontal de -0,79 em um grupo de mulheres, atletas universitárias, de basquetebol, voleibol e softbol, e de -0,62 em um grupo de homens, atletas universitários, de basquetebol e basebol.

Embora tenha se buscado a conhecimento quanto à contribuição da força nesta tarefa (de múltiplas acelerações), o número de estudos ainda é bastante escasso, ainda mais considerando atletas de alto desempenho de basquetebol (ZIV \& LIDOR, 2009a).

Todavia, se por um lado este cenário pode ser um limitador quanto à generalização dos achados, por outro, nos permite supor que as manifestações da força encontradas no salto vertical, mais comumente utilizado, poderiam ser representativas daquelas requeridas na tarefa de múltiplas acelerações.

Corroborando com este raciocínio, tem sido suportada a idéia de que nas ações em que se faz necessário alcançar rapidamente elevada velocidade e parar (frear) da forma mais breve possível, o ciclo do alongamento-encurtamento parece exercer importante função para o desempenho (BRUGHELLI et al., 2008; YOUNG, JAMES \& MONTGOMERY, 2002), desta forma seria aceitável o estudo do papel da força nas múltiplas acelerações a partir do salto vertical.

Todavia, um ponto que merece atenção quanto à compreensão da relação entre a força explosiva e o teste $\mathrm{T}$, diz respeito à contribuição dos parâmetros de força no desempenho de salto vertical.

Enquanto alguns estudos apontam como sendo fundamental para 0 desempenho de salto a geração da força de forma mais breve possível (componente predominantemente temporal) (DE RUITER et al., 2006; HAKKINEN, 1993; JARIC, RISTANOVIC \& CORCOS, 1989; KYROLAINEN et al., 2005; THORLUND, AAGAARD \& MADSEN, 2009; VIITASALO \& AURA, 1984), outros refutam tal argumento (HAKKINEN, 1989; KAWAMORI et al., 2006; NUZZO et al., 2008; 
UGARKOVIC et al., 2002; VANEZIS \& LEES, 2005) e apontam, por vezes, o predomínio do componente predominantemente cinético (pico de força) (KOLLIAS et al., 2001; LAFFAYE, BARDY \& DUREY, 2007).

Como base de questionamento tem sido abordada a questão dos estudos que reportam que para o desempenho de salto se faz necessário a geração de força da forma mais breve possível (DE RUITER et al., 2006; HAKKINEN, 1993; JARIC, RISTANOVIC \& CORCOS, 1989; KYROLAINEN et al., 2005; THORLUND, AAGAARD \& MADSEN, 2009; VIITASALO \& AURA, 1984), e que até sugerem relação de casualidade entre elas (KYROLAINEN et al., 2005; VIITASALO \& AURA, 1984), tiveram seus achados fundamentados nos parâmetros de força obtidos em ações isométricas e isocinéticas, não sendo estas, consideradas as estratégias mais adequadas na elucidação de tarefas dinâmicas (BOSCO, 2007; BRUGHELLI et al., 2008; NUZZO et al., 2008; SANTOS, 2006; UGRINOWITSCH et al., 2000; VIITASALO \& AURA, 1984).

No que diz respeito as ações isométricas, BOSCO (2007) ao estudar atletas durante aproximadamente um ano, observou diminuição de força isométrica para extensão de joelhos, tanto absoluta quanto normalizada pela massa corporal, com concomitante aumento da altura de salto vertical com contramovimento, evidenciando possíveis limitações do uso de isometria no entendimento do salto.

Outro ponto a ser salientado é que na condição isométrica uma sobrecarga superior a $100 \%$ de uma repetição concêntrica dinâmica máxima é imposta ao movimento com a finalidade de impedir alterações na amplitude de movimento (ZATSIORSKY, 1999; ZATSIORSKY, 2006), por outro lado, a sobrecarga imposta pelo peso corporal durante a realização de movimentos sem o uso de sobrecarga externa representa entre $31,4 \%$ e $39,1 \%$ de uma repetição dinâmica máxima (CORMIE, MCBRIDE \& MCCAULLEY, 2009).

Visto que a grandeza de força gerada é proporcional a resistência oferecida (BOSCO, 2007; BRET, RAHMANI, DUFOUR, MESSONNIER \& LACOUR, 2002; CARVALHO \& CARVALHO, 2006; ZATSIORSKY, 2006) é de se esperar que em um dado gesto motor, os parâmetros de força obtidos com distinta sobrecarga sejam diferentes (VIITASALO \& KOMI, 1978; ZATSIORSKY, 1999; ZATSIORSKY, 2006; 
ZINK, PERRY, ROBERTSON, ROACH \& SIGNORILE, 2006) e nem sempre correlacionados em atletas (ZATSIORSKY, 1999; ZATSIORSKY, 2006).

Os achados de KAWAMORI et al. (2006) corroboram com este cenário. Os autores (KAWAMORI et al., 2006), ao investigar o pico de força gerada no movimento do exercício agachamento, reportaram correlação significante entre a condição isometrica a condição dinâmica a $90 \%$ de uma repetição máxima (1RM), todavia, com correlações não significantes quando considerando a condições dinâmicas a $30 \%, 60 \%$ e $120 \%$ de 1 RM.

Ainda, tem sido apontado que além das relações entre testes isométricos e de desempenho no salto serem modalidade-dependente, ao se adotar angulação única para a determinação dos parâmetros de força, pode ser atribuído certa incongruência entre a manifestação da força produzida nesta angulação específica e aquela encontrada durante a execução de tarefas funcionais específicas como o salto vertical (ROUSANOGLOU, GEORGIADIS \& BOUDOLOS, 2008).

Sendo assim, uma limitação poderia existir no uso de condições isométricas em investigações que incluem condições dinâmicas e/ou gestos esportivos (BOSCO, 2007; NUZZO et al., 2008; VIITASALO \& AURA, 1984).

Não obstante, questões temporais podem sugerir ainda mais cautela na interpretação dos estudos fundamentados em parâmetros de força obtidos em ações isométricas. Tem sido reportado que o tempo para alcance da força máxima, logo isométrica, varia de 0,4 a 1 segundo, mesmo quando solicitado ao avaliado que desenvolva o máximo de força de forma mais breve possível (BOSCO, 2007; CARVALHO \& CARVALHO, 2006; KOMI, 1984; ZATSIORSKY, 2006).

No entanto, a duração da fase concêntrica do salto vertical varia entre 0,07 e 0,11 segundos (VIITASALO \& AURA, 1984; ZATSIORSKY, 2006), logo, e considerando a curva força-tempo (ZATSIORSKY, 1999; ZATSIORSKY, 2006), poder-se-ia considerar a hipótese da força gerada isometricamente (entre 0,4 e 1 segundo) não obrigatoriamente representar a magnitude de força gerada em um breve intervalo de tempo e com diferente sobrecarga imposta, como no salto vertical.

Ao considerar a condição isocinética, apesar de dinâmica, nesta condição o movimento é realizado com velocidade constante e incremento de sobrecarga externa, o que contrapõem às condições experimentadas no salto em que se faz 
necessária alternância de velocidade e sobrecarga constante (massa corporal), logo, apontando para uma limitada capacidade de predição destas ações a partir da condição isocinética (UGRINOWITSCH et al., 2000).

O que pode ainda ser ressaltado e contribuir com a explanação a respeito das limitações dos métodos citados diz respeito a distinção quanto aos mecanismos de contração encontrados entre as condições isométrica, isocinética, e no salto, haja vista que o ciclo do alongamento-encurtamento é ausente nas condições isométrica e isocinética, mas presente no salto (BOSCO, 2007; BRUGHELLI et al., 2008; CRONIN \& HANSEN, 2005; DELEXTRAT \& COHEN, 2009; YOUNG, JAMES \& MONTGOMERY, 2002).

Sendo assim, pode-se perceber que apesar de algumas controvérsias, parece existir associação entre força explosiva e aceleração, no entanto, diferentes parâmetros são apontados a respeito da contribuição para o desempenho no salto, logo, quais os parâmetros que teriam papel determinante no construto da tarefa de múltiplas acelerações.

\section{MATERIAL E MÉTODOS}

\subsection{Amostra}

A amostra foi selecionada por conveniência e contou com 19 voluntárias atletas de basquetebol do sexo feminino pertencentes à seleção brasileira adulta da modalidade (média e desvio padrão: idade $=26,25 \pm 4,78$ anos; estatura $=1,81 \pm$ 0,07 metros; massa corporal $=75,64 \pm 12,59 \mathrm{~kg}$; adiposidade $=20,44 \pm 6,03 \%$ ).

A amostra analisada foi classificada como de "alto" desempenho por se tratar da seleção nacional adulta, que ocupava a quarta posição no ranking mundial de basquetebol feminino no momento desta investigação (FIBA, 2009).

Ainda, no grupo investigado, havia atletas medalhistas e participantes de Jogos Olímpicos, campeonatos mundiais, pan-americanos e sul-americanos.

As jogadoras se encontravam em período de preparação para a Copa América da Modalidade, competição conquistada de forma invicta pela equipe.

Foi adotado com critério de exclusão, o acometimento de qualquer lesão ortopédica e/ou problema de saúde que pudesse interferir na execução dos testes. 
Para tanto, inicialmente cada atleta foi submetida a uma entrevista e levantamento do histórico clínico e ortopédico detalhado por parte do departamento médico da seleção brasileira de basquetebol, a fim de determinar a condição ósteomioarticular do aparelho locomotor destas. Nenhuma atleta apresentou qualquer impedimento apontado pelo referido departamento médico.

\subsection{Instrumentos de medição}

\subsubsection{Plataforma de força}

Os parâmetros investigados a respeito da força de reação do solo foram mensurados por intermédio de uma plataforma de força KISTLER 9287A (FIGURA 2) (KISTLER INSTRUMENTE AG, 1993) fixa no solo do Laboratório de Biomecânica da Escola de Educação Física e Esporte da Universidade de São Paulo. 


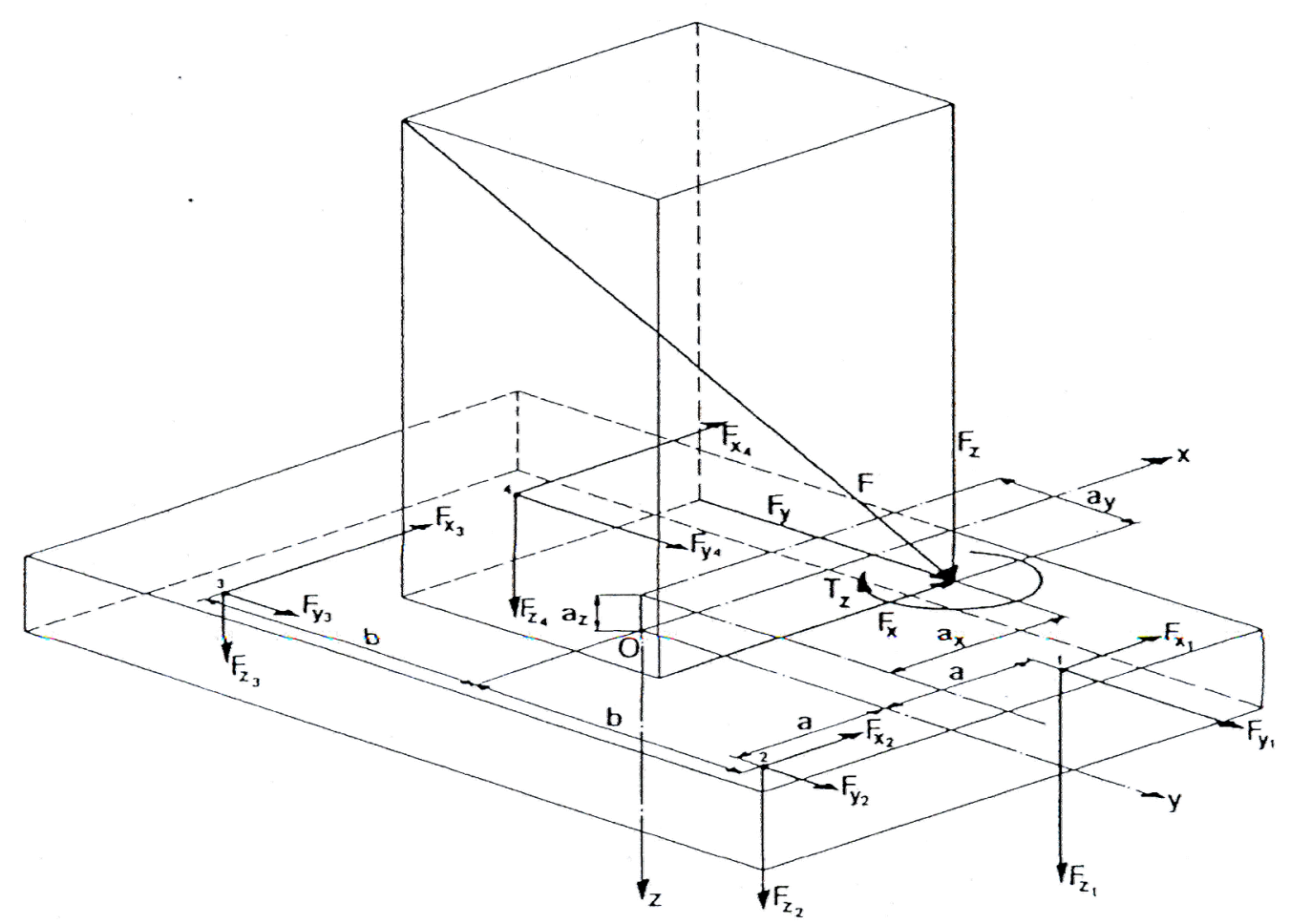

$F=$ força de reação resultante; $F x_{n}=$ força de reação no eixo $x$ medida pelo transdutor $n ; F y n=$ força de reação no eixo y medida pelo transdutor $n ; F z_{n}=$ força de reação no eixo $z$ medida pelo transdutor $\mathrm{n} ; \mathrm{Fy}, \mathrm{Fx}, \mathrm{Fz}$ = componentes vertical, ântero-posterior, e médio-lateral da força de reação do solo; $\mathrm{a}=$ distância do ponto de aplicação da força ao eixo $Y ; b$ = distância do ponto de aplicação da força ao eixo $X$

FIGURA 2 - Definição dos sinais e parâmetros necessários ao cálculo das variáveis relacionadas à força de reação do solo

Esta plataforma possui transdutores de força do tipo piezoelétrico localizados nos cantos da superfície de medição $(0,6 \times 0,9 \mathrm{~m})$. Os sinais obtidos pelos transdutores são enviados por intermédio de cabos e interruptores a um amplificador de sinais (KISTLER AG, 9865 B) programados automaticamente para obtenção dos valores das três componentes da força ( $F x, F z, F y)$, bem como dos momentos na superfície da plataforma ( $M y, M x, M z)$, das coordenadas $(A x, A z)$ do centro de pressão (COP) e do coeficiente de atrito (Cof), conforme apontado na FIGURA 2. O controle sobre a aquisição, análise e armazenamento dos dados foi realizado pelo programa de funções BIOWARE (282A1-20). 
Para o presente estudo, foi considerado somente o componente vertical da força de reação do solo $\left(F_{z}\right)$, visto que $97,3 \%$ de todo trabalho realizado na fase de propulsão do salto vertical é corresponde ao componente vertical (HATZE, 1998), logo, fazendo com que os componentes médio-lateral ( $F y)$ e ântero-posterior ( $F x)$ possam ser desconsiderados sem introdução de erro significativo nos cálculos e análise do salto vertical (ARAGÓN-VARGAS \& GROSS, 1997).

\subsubsection{Sensor óptico}

A quantificação dos parâmetros relacionados ao tempo no teste $T$ foi mensurado por intermédio de sensores do tipo óptico, do modelo $05 \mathrm{H} 200$, que são sensores de reflexão difusa de luz tipo vermelha (não visível), de 624 nanômetros (624 milionésimos de milímetro), com alcance de 1,4 metros e com freqüência de comutação de mil hertz, conforme FIGURA 3 (IFM ELETRONIC, 2009).
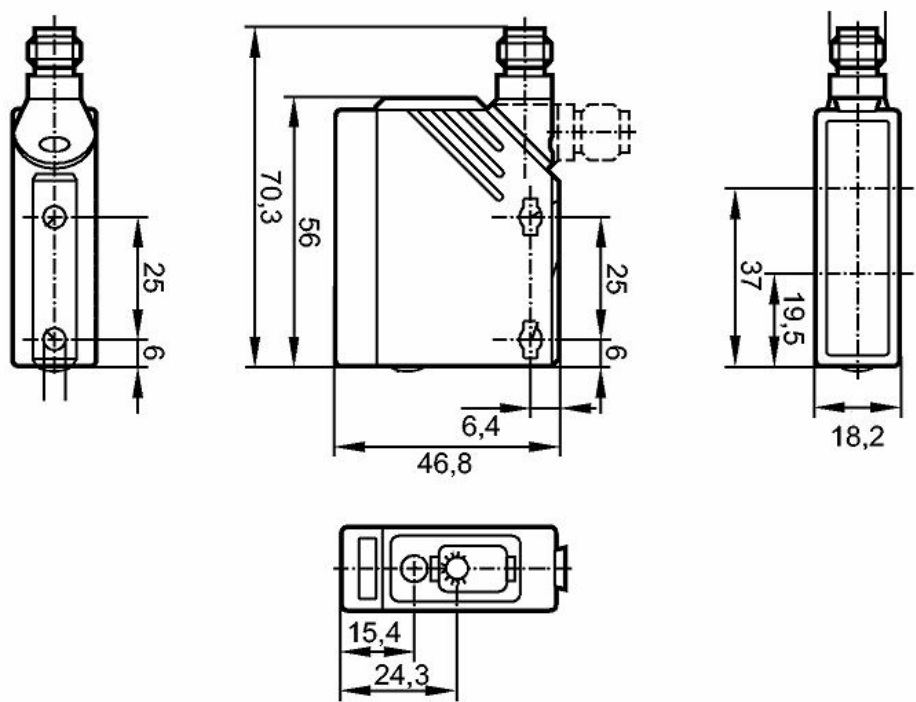

* valores em milímetros

FIGURA 3 - Diagrama do sensor óptico

Os sensores ópticos de reflexão difusa de luz tipo vermelha são caracterizados por possuir em uma única estrutura o componente gerador de 
radiação eletromagnética oscilatória não visível (componente emissor) e o componente foto-sensível (componente receptor) de identificação quanto presença ou ausência desta radiação eletromagnética oscilatória não visível (luz tipo vermelha) (FIGURA 4).

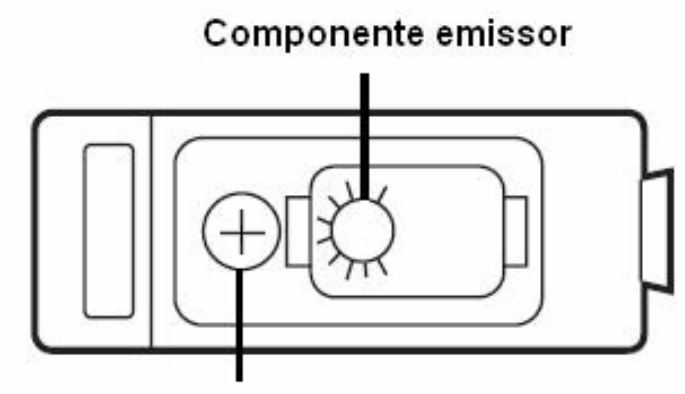

Componente receptor

FIGURA 4 - Componentes do sensor óptico

Pelo fato do componente emissor e o componente receptor estarem em uma mesma estrutura, seu funcionamento pode ser resumidamente explicado por ação retrorrefletiva do feixe de luz causada pela aproximação de um objeto (FIGURA 5).

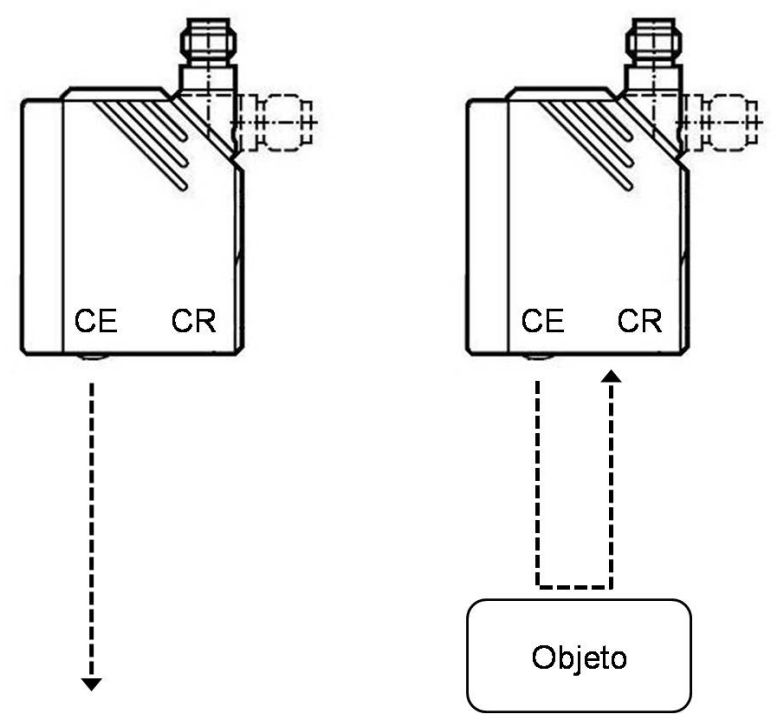

$\mathrm{CE}=$ Componente emissor; $\mathrm{CR}=$ Componente receptor

FIGURA 5 - Princípio de funcionamento do sensor óptico 
Os sensores foram utilizados no acionamento e desligamento de um contador de tempo, e foram gerenciados pelo software Multisprint ${ }^{\circledR}$ (Hidrofit ${ }^{\circledR}$, Brasil) (HIDROFIT, 2009).

Ainda, os sensores foram fixados sobre um tripé com altura ajustável entre 0,35 e 1,05 metros, da marca Greika, modelo WT3111 (GREIKA, 2009) (FIGURA 6), e interligados por cabos de conexão.

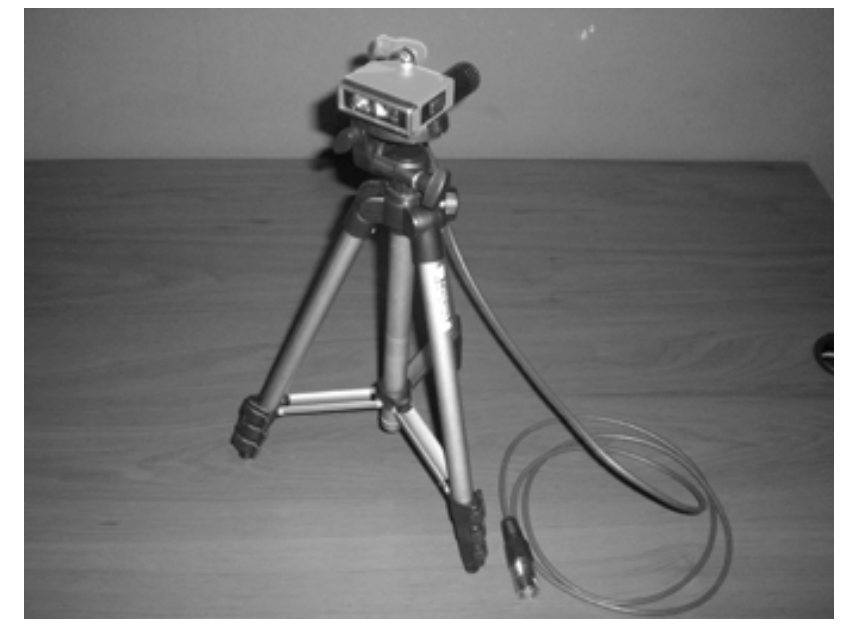

FIGURA 6 - Estrutura composta por sensor óptico-tripé

\subsection{Procedimento experimental}

Depois de feita a avaliação ortopédica, e não identificado qualquer limitação para a inclusão do estudo, cada voluntária (atleta), juntamente com a equipe técnica, foi informada a respeito dos procedimentos adotados na presente investigação. Foi dado início a coleta de dados e aplicação dos testes somente após leitura integral e assinatura do Termo de Consentimento Livre e Esclarecido (ANEXO 1). Todos os procedimentos experimentais adotados foram previamente aprovados pelo Comitê de Ética em Pesquisa da Escola de Educação Física e Esporte da Universidade de São Paulo sob o processo número 2009/35.

As voluntárias inicialmente foram submetidas ao processo de coleta de dados relacionado às medidas antropométricas, e posteriormente os testes de salto e múltiplas acelerações, ambos realizados em um mesmo período. 


\subsubsection{Procedimento preliminar}

Inicialmente a estatura e massa corporal das voluntárias foram coletadas com o uso de um estadiômetro e uma balança Filizola digital ID 1500 (Filizola ${ }^{\circledR}$ - Brasil). A adiposidade corporal foi estimada a partir as dobras cutâneas de tríceps, subescapular e abdominal e dos perímetros de coxa e perna (JACKSON, POLLOCK \& WARD, 1980). Para tanto, foi utilizado um plicômetro Harpenden (Harpenden ${ }^{\circledR}$ United Kingdom). Todos os procedimentos seguiram padronização proposta pela International Society for Advance of Kinanthropometry (NORTON, WHITTINGHAM, CARTER, KERR, GORE \& MARFELL-JONES, 2005).

\subsubsection{Testes}

Os testes foram realizados no Laboratório de Biomecânica da Escola de Educação Física e Esporte da Universidade de São Paulo e no ginásio poliesportivo com piso antiderrapante da mesma universidade, com três tentativas para cada teste.

\subsubsection{Salto vertical (SV)}

Foi utilizado o teste de salto vertical com contramovimento e livre movimentação dos braços (SV), originalmente proposto por JOHNSON \& NELSON (1974).

Para tanto, a voluntária foi posicionada sobre a plataforma de força, em posição em pé, mantendo os calcanhares em afastamento bitrocanteriano e os braços na posição que julgou mais confortável.

Nesta posição, após ter recebido por parte do avaliador um sinal sonoro, a voluntária realizou um salto com esforço máximo tentando alcançar a máxima amplitude vertical possível. Não sendo permitido ações de saltitar ou qualquer tipo de deslocamento antes da realização do salto, invalidando tal tentativa caso estes viessem acontecer.

\subsubsection{Salto vertical precedido de corrida (SV corrida $)$}

$\mathrm{Na}$ intenção de atribuir maior validade ecológica e aproximação das condições experimentadas pelos atletas de basquetebol, foi utilizado o teste de salto vertical 
com contramovimento e livre movimentação dos braços (SV) (JOHNSON \& NELSON, 1974) após breve deslocamento, como proposto por ZIV \& LIDOR (2009b).

Para tanto, foi inicialmente determinada de forma arbitrária, à distância de dois metros considerada a partir da plataforma de força, sendo esta sinalizada com fita adesiva fixada ao solo. Um sensor óptico foi posicionado em cada uma das extremidades destes dois metros, com a finalidade de ser determinado o tempo de cada voluntária ao percorrer tal distância (FIGURA 7).

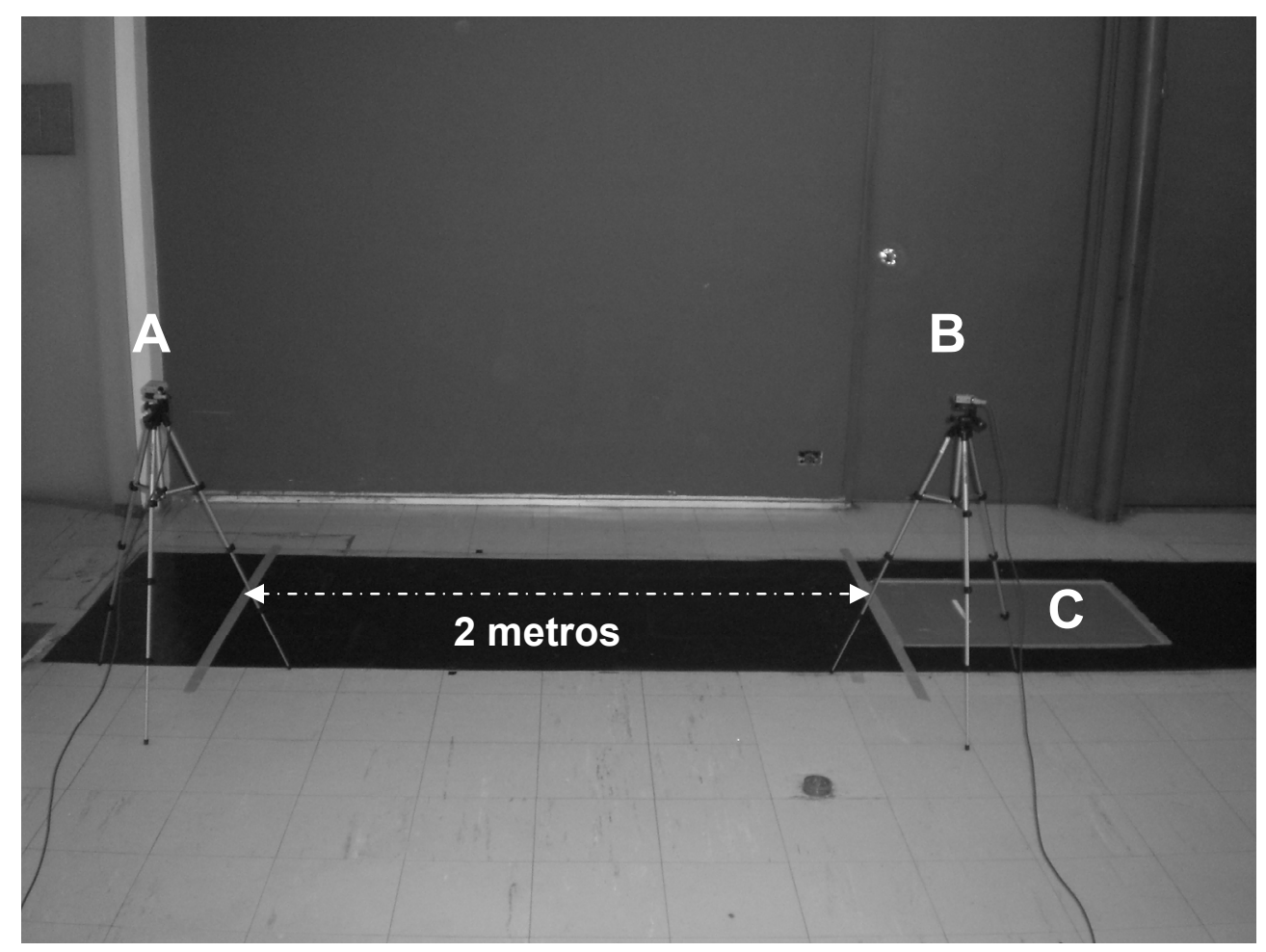

$A$ = sensor óptico $1, B$ = sensor óptico 2 e $C$ = plataforma de força

FIGURA 7 - Posicionamento do sensor óptico no teste de salto vertical precedido de corrida $\left(\mathrm{SV}_{\text {corrida }}\right)$

Cada voluntária foi posicionada imediatamente atrás da linha demarcada no solo, onde então recebeu a orientação quanto aos procedimentos do teste. Após receber o sinal sonoro emitido por parte do avaliador, esta atingiu a máxima velocidade possível para a distância e, imediatamente após ter cumprido a extensão de dois metros, e sobre a plataforma de força, realizou o salto vertical buscando a 
máxima amplitude vertical possível, sendo-lhe facultada a livre movimentação dos braços (FIGURA 8).

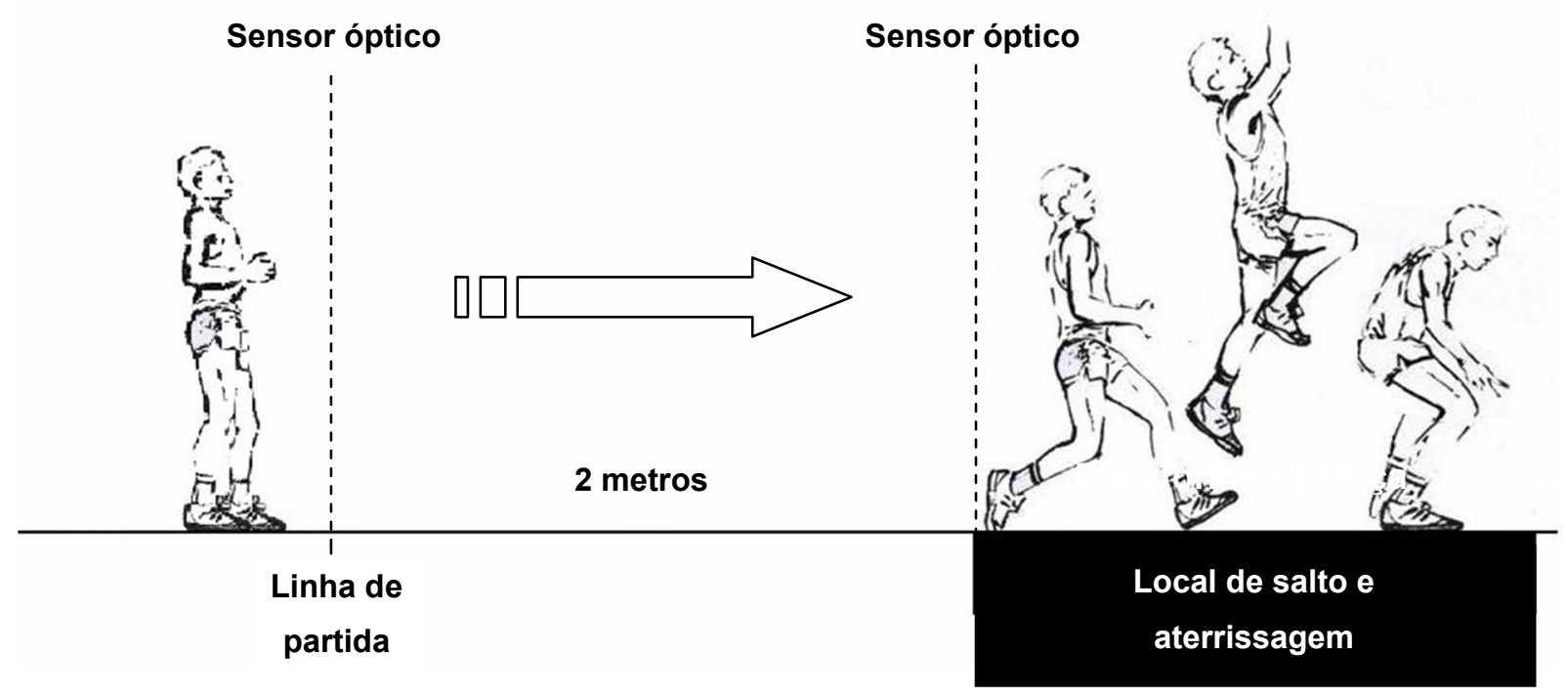

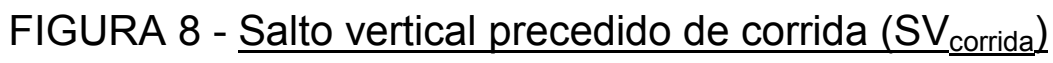

As voluntárias foram orientadas a realizar obrigatoriamente a fase de impulso de forma bipodal e a fase de aterrissagem sobre o a plataforma de força, inspeção feita de forma visual por dois avaliadores posicionados ao lado da plataforma de força.

Caso um dos avaliadores suspeitasse que a fase de impulso tivesse sido realizada de forma unipodal e/ou a aterrissagem não tivesse ocorrido sobre a plataforma de força, a tentativa seria descartada. A tentativa seria igualmente descartada no caso de suspeita do toque parcial dos pés (ante-pé ou retro-pé) com a plataforma nas fases de impulso e aterrissagem.

\subsubsection{Teste de múltiplas acelerações (teste T)}

O teste de múltiplas acelerações adotado no presente estudo foi o teste $T$ (SEMENICK, 1990) adaptado (MOREIRA, SOUZA \& OLIVEIRA, 2003).

$O$ teste foi realizado em uma quadra poliesportiva com piso antiderrapante demarcada com fitas no solo e cones nas distâncias estipuladas (FIGURA 9). O 
tempo em que cada voluntária executou o teste foi mensurado por sensores ópticos posicionados sobre a linha de saída/chegada (A). No entanto, foi posicionado sobre a marca central mais dois sensores ópticos ( $B$ e $E$ ), assim como um em cada extremidade do "T" (C e D), possibilitando a mensuração do tempo parcial do teste (FIGURA 9).

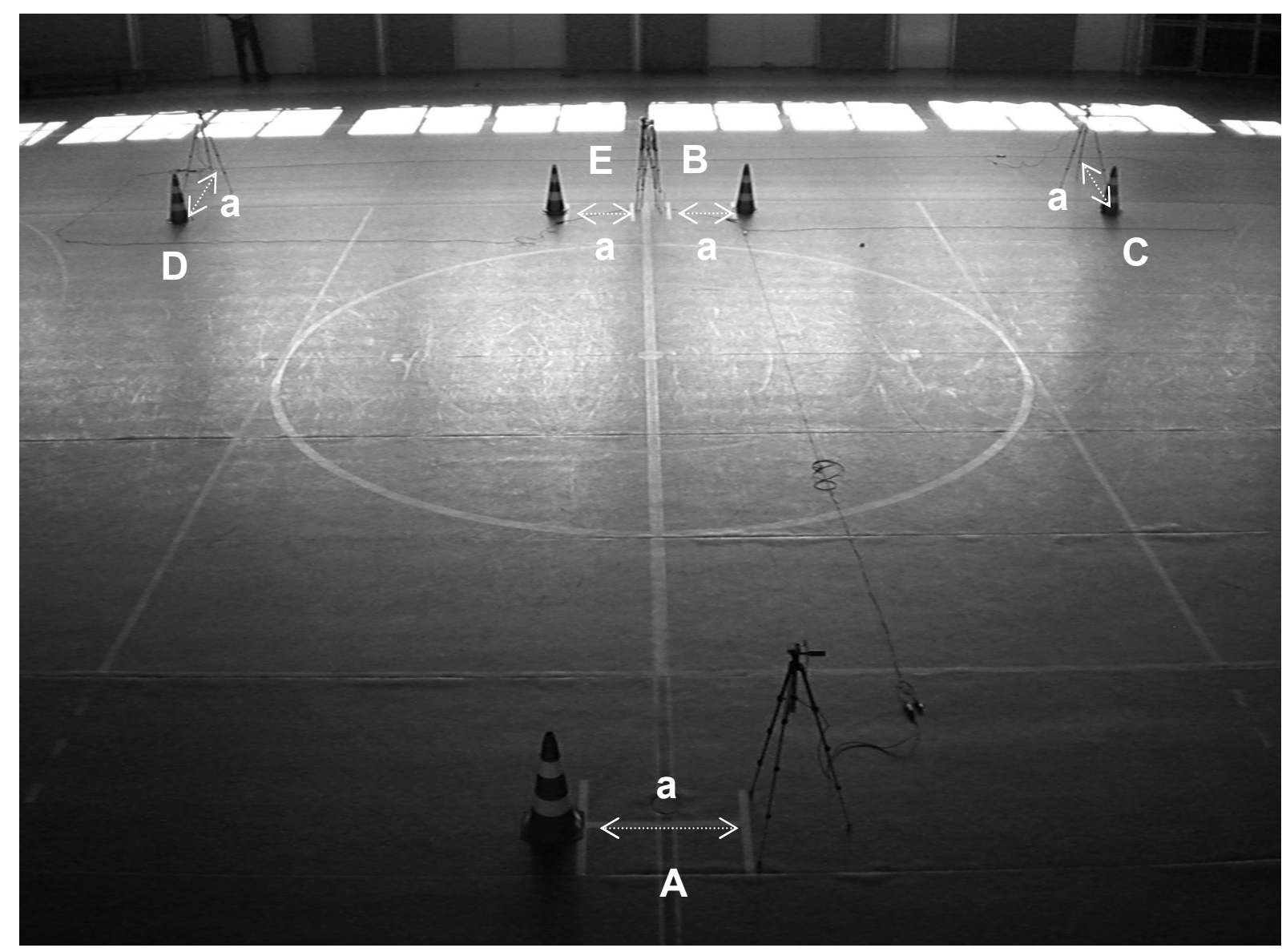

FIGURA 9 - Posicionamento dos sensores ópticos para a realização do teste de múltiplas acelerações (teste T)

Os sensores foram posicionados a uma altura de um metro em relação ao solo e a uma distância lateral de 0,70 metros em relação ao percurso a ser realizado pela voluntária (a - FIGURA 9). Estas manobras foram adotadas com a finalidade de posicionar o sensor óptico próximo a altura do quadril, para minimizar múltiplas leituras por deslocamentos dos braços e pernas, e a uma distância adequada para 
funcionamento do sensor, uma vez que este tem alcance máximo de 1,4 metros (IFM ELETRONIC, 2009).

Ao emitir a voz de comando "PREPARAR, JÁ !", o avaliador indicou à voluntária o início do teste. Todavia, foi iniciada a cronometragem no instante em que a voluntária cruzou o feixe de luz emitido pelo sensor óptico, logo, no instante em que esta passou em frente ao sensor posicionado na linha de saída/chegada. Não coube ao avaliador determinar o instante de início da cronometragem.

Ao ser iniciado o teste, cada voluntária correu em direção a marca central percorrendo dez metros (a); ao pisar sobre a linha demarcatória, correu cinco metros até a extremidade direita do "T" (b); ao pisar novamente sobre esta linha mudou de direção, e correu 10 metros até o outro extremo do "T" (c), tocou a fita com o pé, correu por mais cinco metros até o cone central $(d)$ e então retornou à linha de saída/chegada (e) percorrendo mais 10 metros (FIGURA 10).

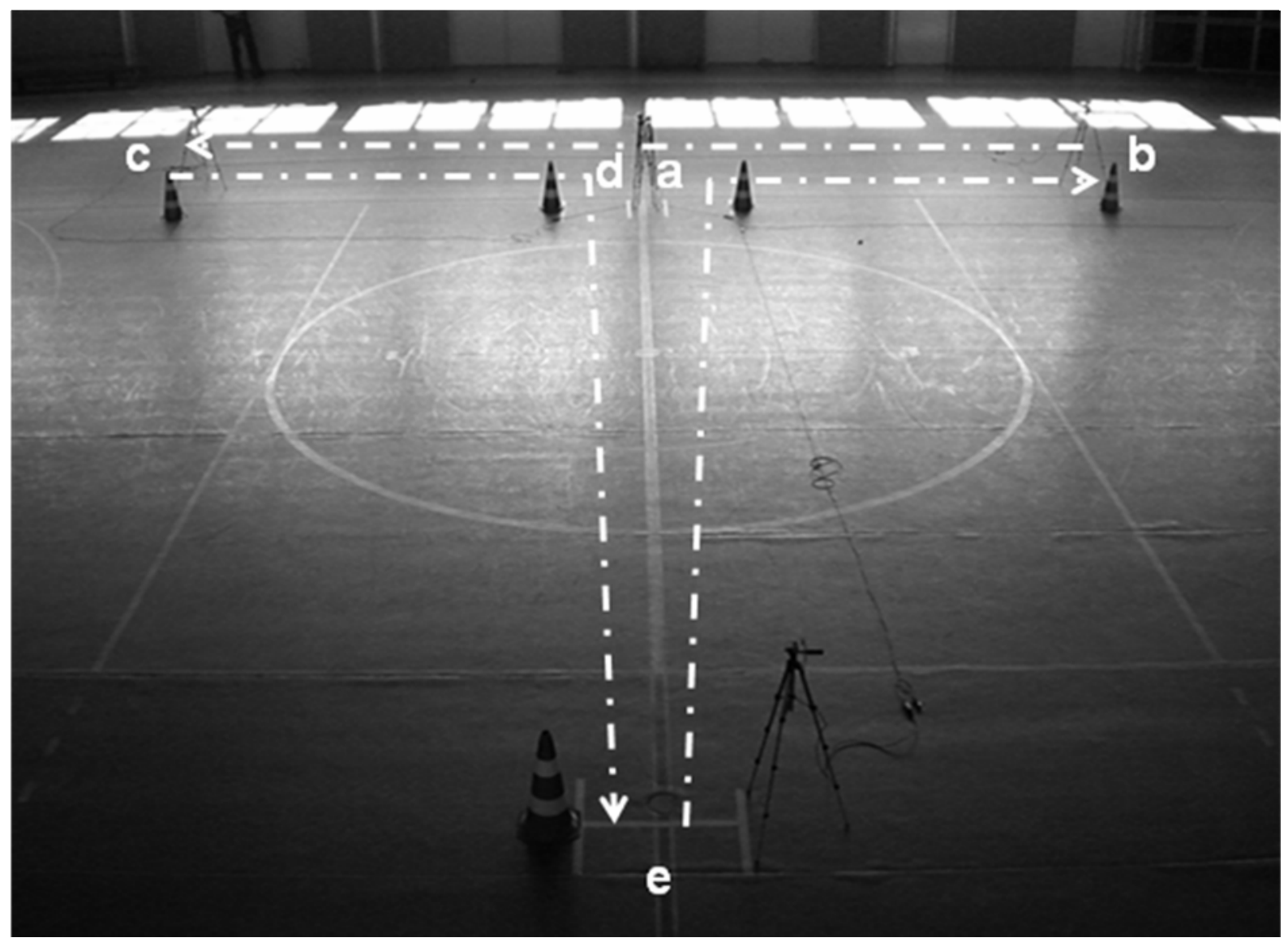

FIGURA 10 - Orientação para a realização do teste de múltiplas acelerações (teste T) 
Sendo assim, cada voluntária percorreu a distância total de 40 metros intercalados com quatro paradas bruscas e rápidas mudanças de direção.

A exemplo do ocorrido para início da cronometragem, o término desta se deu no instante em que a voluntária cruzou o feixe de luz emitido pela fotocélula posicionada na linha de saída/chegada.

Foi solicitado às voluntárias que realizassem todo o teste na máxima velocidade possível. Ainda, foram informadas para não cruzar as pernas nos instantes de mudança de direção e para tocar (pisar) com pelo menos um dos pés as fitas demarcatórias do solo.

\subsubsection{Critério para realização dos testes e coleta dos dados}

Anteriormente à realização dos testes as voluntárias foram submetidas a um protocolo de aquecimento com duração de 15 minutos, envolvendo exercícios de alongamento estático, corridas de baixa intensidade e corridas curtas, em linha reta e em maior velocidade. A aplicação dos testes e coleta de dados foi realizada de forma randômica a fim de evitar possíveis influências produzidas pela sua ordem de execução.

Tendo em vista que a realização de um do salto vertical tem duração aproximada de um segundo, e a realização do teste $T$ em torno de 10 segundos, logo, basicamente dependentes dos estoques de ATP e de creatina fosfato (FOX, BOWERS \& FOSS, 1989; WILMORE \& COSTILL, 2001), optou-se pelo intervalo de um minuto entre as tentativas de SV e $\mathrm{SV}_{\text {corrida }}$ e de três minutos para o teste $\mathrm{T}$, intervalos em que ocorre recuperação destas vias energéticas entre $70 \%$ e 95\% (FOX, BOWERS \& FOSS, 1989).

Tendo em vista que estes testes são habitualmente utilizados nas freqüentes rotinas de avaliação da seleção brasileira de basquetebol feminino, foi solicitado/permitido a cada uma das voluntárias a realização de até cinco tentativas para cada um dos testes, a fim de elucidar possíveis dúvidas quanto a realização, e conseqüentemente, a correta execução destes. No entanto, nenhuma das voluntárias necessitou mais do que duas tentativas para total adequação dos protocolos. 


\subsection{Parâmetros biomecânicos do salto}

\subsubsection{Salto Vertical (SV)}

Tendo em vista a dificuldade encontrada na determinação dos pontos de início e fim da fase excêntrica a partir da força de reação do solo, fez-se a análise dos parâmetros biomecânicos do salto vertical (SV) somente na fase concêntrica.

Para tanto, foi inicialmente calculada a curva aceleração-tempo, e a partir desta, por dupla integração numérica calculada pela regra trapezoidal, foi obtido a curva posição-tempo do centro de gravidade corporal.

Como instante de início da fase concêntrica $\left(t_{i}\right)$ foi considerado o instante de menor valor na curva posição-tempo, enquanto que o fim da fase concêntrica $\left(t_{f}\right)$ foi considerado como sendo o instante em que a curva força-tempo normalizada pelo peso corporal da voluntária, apresentou valor de uma vez o peso corporal negativo, logo perda de contato com o solo (FIGURA 11).

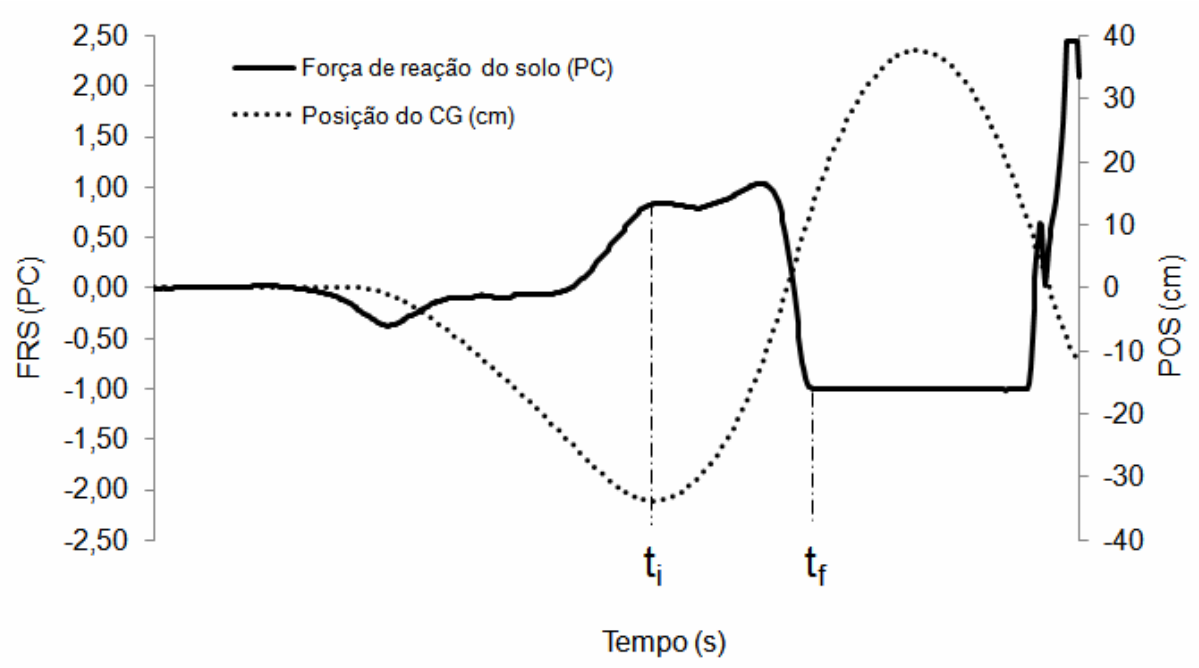

$t_{i}=$ instante de início da fase concêntrica; $t_{f}=$ instante de fim da fase concêntrica; FRS = força de reação do solo; POS = posição do centro de gravidade corporal; $\mathrm{PC}=$ vezes do peso corporal; $\mathrm{cm}=$ centímetros; $\mathrm{CG}=$ centro de gravidade corporal

FIGURA 11 - Determinação da fase concêntrica 
Feito isto, foram determinados os seguintes parâmetros biomecânicos:

\subsubsection{Tempo de fase concêntrica $\left(T_{\text {con }}\right)$}

O tempo de fase concêntrica ( $\left.T_{\text {con }}\right)$ foi considerado como sendo o intervalo de tempo decorrido entre o instante de início da fase concêntrica $\left(\mathrm{t}_{\mathrm{i}}\right)$ e o instante de fim da fase concêntrica $\left(t_{f}\right)$ (FIGURA 12).

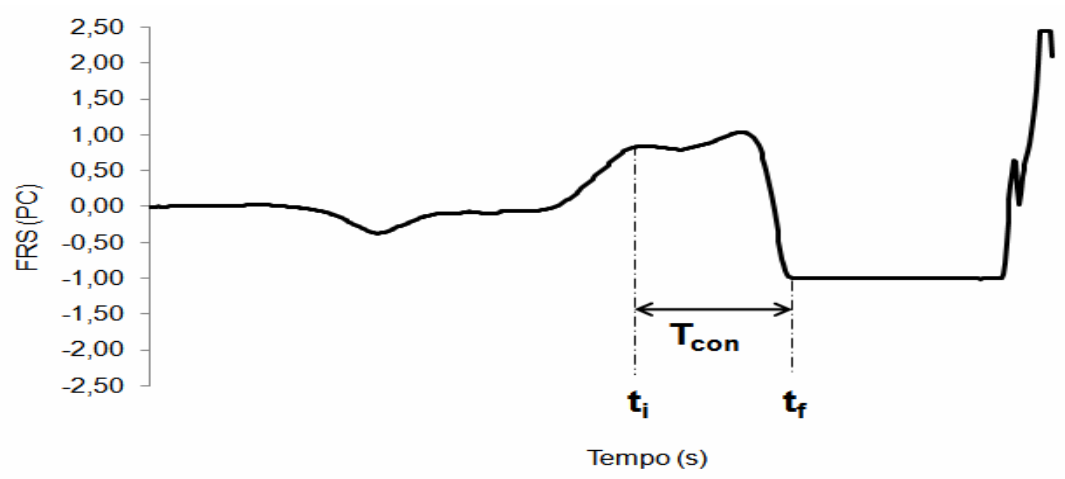

$t_{i}=$ instante de início da fase concêntrica; $t_{f}=$ instante de fim da fase concêntrica; $T_{\text {con }}=$ tempo de fase concêntrica; FRS = força de reação do solo; $P C$ = vezes do peso corporal

FIGURA 12 - Determinação do tempo de fase concêntrica

\subsubsection{Impulso (I)}

O impulso foi obtido pelo cálculo da integral da curva força-tempo entre os instantes de início da fase concêntrica $\left(\mathrm{t}_{\mathrm{i}}\right)$ e fim da fase concêntrica $\left(\mathrm{t}_{\mathrm{f}}\right)$, calculado tendo por base de cálculo a regra trapezoidal (equação 1).

$$
\text { Impulso }=\int_{\mathrm{ti}}^{\mathrm{tf}} \mathrm{FRS} \bullet \mathrm{dt} \quad \text { equação }(1)
$$

$\int_{\mathrm{ti}}^{\mathrm{tf}}=\mathrm{a}$ integral da força de reação do solo na curva força-tempo entre os instantes de início da fase concêntrica $\left(\mathrm{t}_{\mathrm{i}}\right)$ e fim da fase concêntrica $\left(\mathrm{t}_{\mathrm{f}}\right)$; $d \mathrm{~d}=$ tempo de fase concêntrica. 


\subsubsection{Pico de força de propulsão (PFP)}

Para pico de força de propulsão (PFP) foi considerado o maior valor de força de reação do solo encontrado entre os instantes de início $\left(t_{i}\right)$ e fim da fase concêntrica $\left(\mathrm{t}_{\mathrm{f}}\right)$ (FIGURA 13).

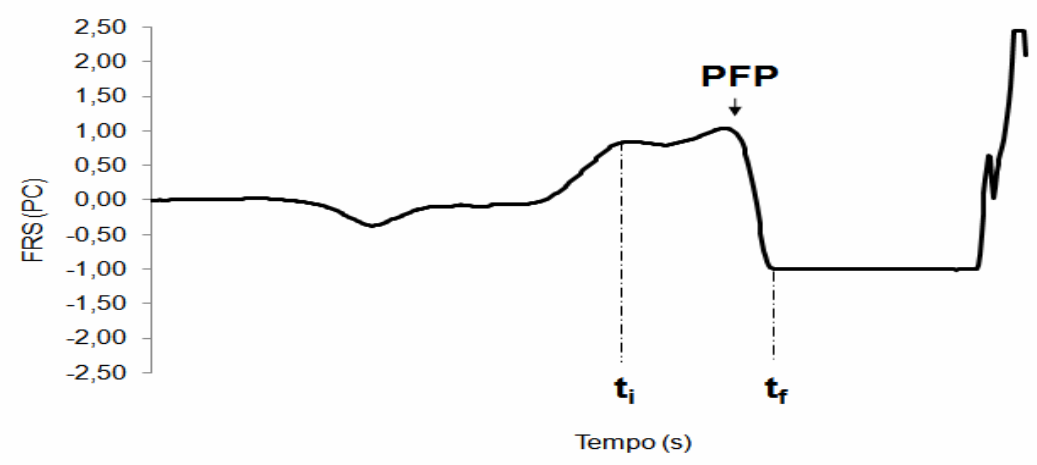

$t_{i}=$ instante de início da fase concêntrica; $t_{f}=$ instante de fim da fase concêntrica; PFP = pico de força de propulsão; FRS = força de reação do solo; $P C=$ vezes do peso corporal

FIGURA 13 - Determinação do pico de força de propulsão

\subsubsection{Tempo decorrido entre o início de fase concêntrica e o pico de força de propulsão (TPFP)}

Foi considerado o intervalo de tempo decorrido entre $\mathrm{O}$ início de fase concêntrica $\left(\mathrm{t}_{\mathrm{i}}\right)$ e o pico de força de propulsão (PFP) (FIGURA 14).

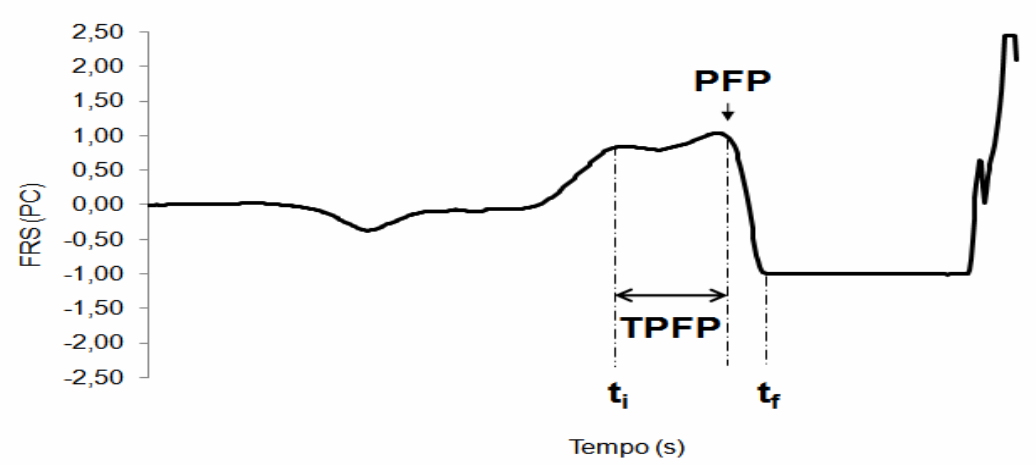

$t_{i}=$ instante de início da fase concêntrica; $t_{f}=$ instante de fim da fase concêntrica; TPFP = tempo decorrido entre o início de fase concêntrica e o pico de força de propulsão; PFP = pico de força de propulsão; FRS = força de reação do solo; $P C=$ vezes do peso corporal

FIGURA 14 - Determinação do tempo decorrido entre o início de fase concêntrica e o pico de força de propulsão 


\subsubsection{Taxa de desenvolvimento de força (TDF)}

Foi considerada como TDF a razão do pico de força de propulsão (PFP) e do tempo decorrido entre início de fase concêntrica e o pico de força de propulsão (TPFP) (AAGAARD et al., 2002; CARVALHO \& CARVALHO, 2006; ZATSIORSKY, 2006) (FIGURA 15).

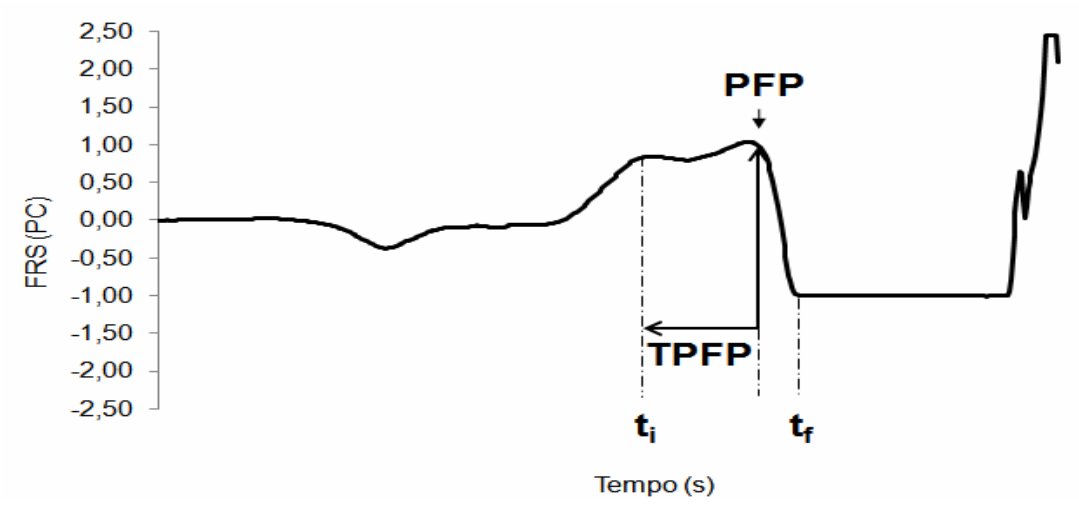

$t_{i}=$ instante de início da fase concêntrica; $t_{f}=$ instante de fim da fase concêntrica; TPFP = tempo decorrido entre início de fase concêntrica e o pico de força de propulsão; PFP = pico de força de propulsão; FRS = força de reação do solo; $P C=$ vezes do peso corporal

FIGURA 15 - Determinação da taxa de desenvolvimento de força

\subsubsection{Salto vertical precedido de corrida ( $\left(\mathrm{SV}_{\text {corrida }}\right)$}

\subsubsection{Velocidade média de aproximação (Vel $I_{\text {média }}$ )}

Inicialmente se fez a determinação da velocidade média de aproximação (Vel $\left.\right|_{\text {média }}$, sendo esta a razão da distância percorrida de dois metros e o tempo para percorrer tal distância.

Feito isto, para a determinação dos parâmetros biomecânicos do salto vertical precedido de corrida ( $S \mathrm{~V}_{\text {corrida }}$ ) se fez necessário a identificação dos instantes de início da fase de apoio $\left(\mathrm{t}_{\mathrm{i}}\right)$ e fim da fase de apoio $\left(\mathrm{t}_{\mathrm{f}}\right)$, considerados, respectivamente, os instantes em que a força de reação do solo normalizada pelo peso corporal foi maior do que zero $\left(\mathrm{t}_{\mathrm{i}}\right)$, e instante em que a força de reação do solo foi igual a zero $\left(\mathrm{t}_{\mathrm{f}}\right)$ (FIGURA 16). 


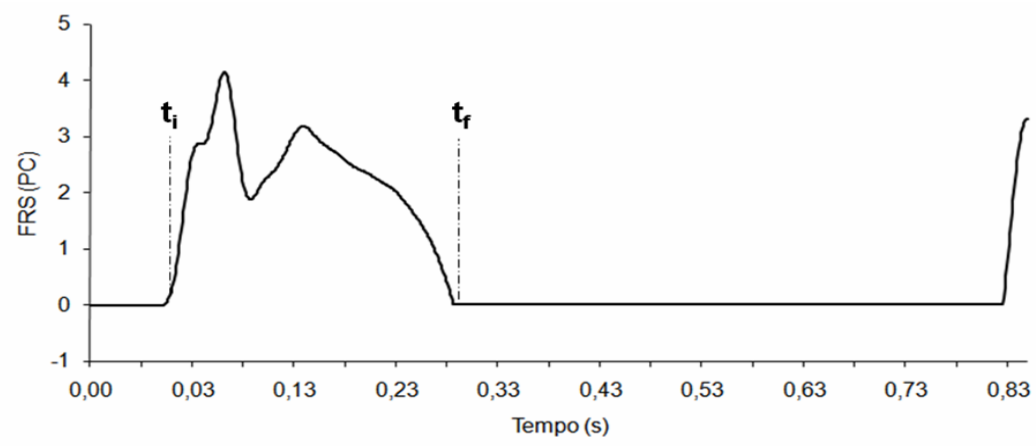

$t_{i}=$ instante de início de fase de apoio; $t_{f}=$ instante de fim da fase de apoio; FRS = força de reação do solo; $\mathrm{PC}=$ vezes do peso corporal

FIGURA 16 - Determinação da fase de apoio.

Identificado os instantes de inicio da fase de apoio $\left(\mathrm{t}_{\mathrm{i}}\right)$ e fim da fase de apoio $\left(\mathrm{t}_{\mathrm{f}}\right)$, foram determinados os seguintes parâmetros biomecânicos:

\subsubsection{Tempo total do movimento $\left(T_{\text {total }}\right)$}

O tempo total do movimento ( $\left.T_{\text {total }}\right)$ foi considerado como sendo o tempo decorrido entre o início da fase de apoio $\left(\mathrm{t}_{\mathrm{i}}\right)$ e o instante de fim da fase de apoio $\left(\mathrm{t}_{\mathrm{f}}\right)$ (FIGURA 17).

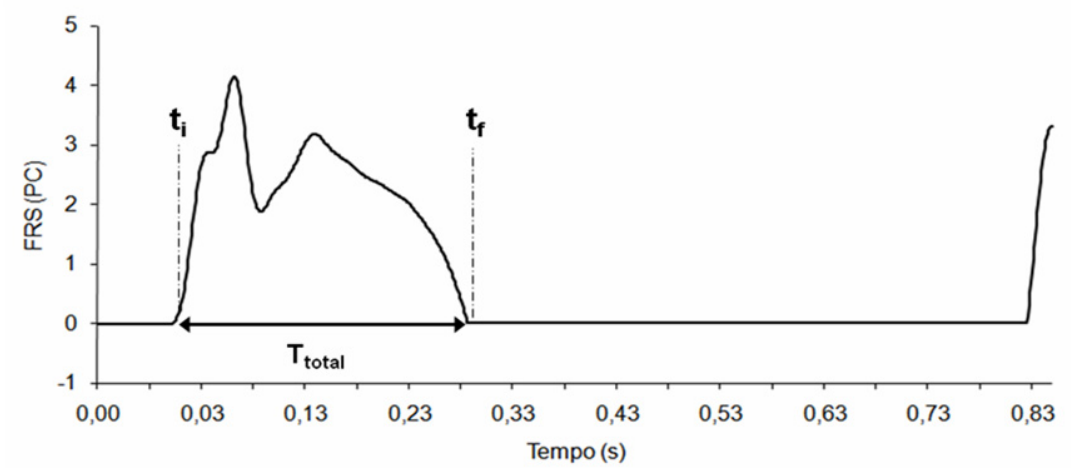

$t_{i}=$ instante de início de fase de apoio; $t_{f}=$ instante de fim da fase de apoio; $T_{\text {total }}=$ tempo total do movimento; FRS = força de reação do solo; $P C=$ vezes do peso corporal

FIGURA 17 - Determinação do tempo total do movimento 


\subsubsection{Pico de força passiva (PFPa)}

Como indicativo do pico de força passiva (PFPa) foi considerado o primeiro pico de força de reação do solo encontrado entre o início da fase de apoio $\left(\mathrm{t}_{\mathrm{i}}\right)$ e o fim da fase de apoio $\left(t_{f}\right)$ (FIGURA 18).

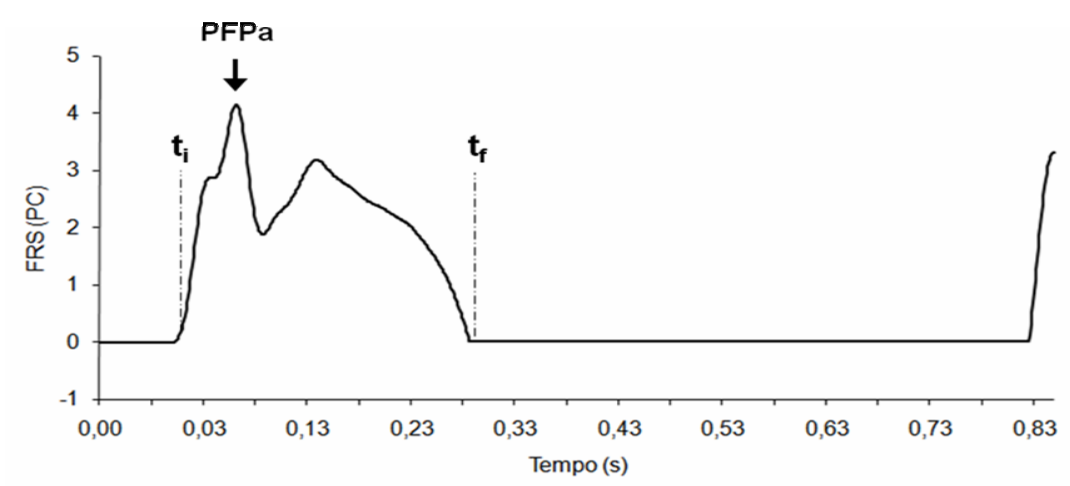

$t_{i}=$ instante de início de fase de apoio; $t_{f}=$ instante de fim da fase de apoio; PFPa = pico de força passiva; FRS = força de reação do solo; $P C$ = vezes do peso corporal

FIGURA 18 - Determinação do pico de força passiva

\subsubsection{Tempo decorrido entre o início da fase de apoio e o pico de força passiva (TPFPa)}

Foi considerado como TPFPa o intervalo de tempo decorrido entre início da fase de apoio $\left(t_{i}\right)$ e o pico de força passiva (PFPa) (FIGURA 19).

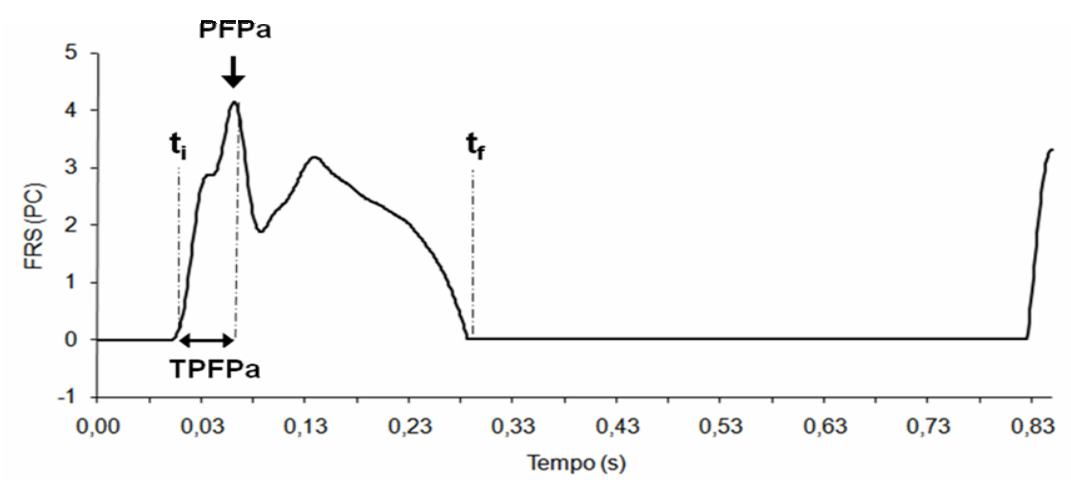

$\mathrm{t}_{\mathrm{i}}=$ instante de início de fase de apoio; $\mathrm{t}_{\mathrm{f}}=$ instante de fim da fase de apoio; PFPa = pico de força passiva; TPFPa = tempo decorrido entre início da fase de apoio e o pico de força passiva; FRS = força de reação do solo; $P C=$ vezes do peso corporal

FIGURA 19 - Determinação do tempo decorrido entre início da fase de apoio e o pico de força passiva 


\subsubsection{Load Rate (LR)}

O parâmetro Load Rate (LR) foi obtido como sendo a razão do pico de força passiva (PFPa) e do tempo decorrido entre início da fase de apoio e o pico de força passiva (TPFPa), semelhante ao método usado para o cálculo da TDF em SV (FIGURA 20).

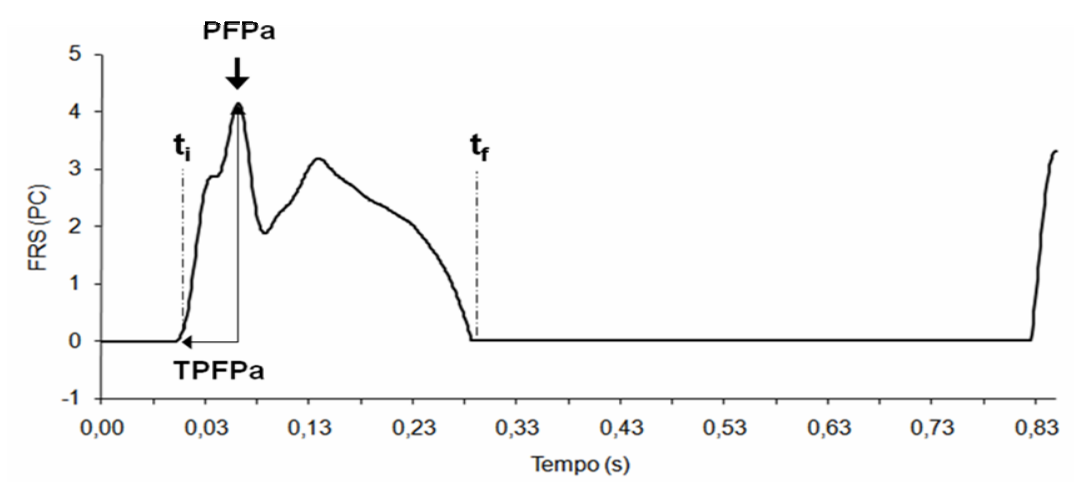

$t_{i}=$ instante de início de fase de apoio; $t_{f}=$ instante de fim da fase de apoio; PFPa = pico de força passiva; TPFPa = tempo decorrido entre início do apoio e pico de força passiva; FRS = força de reação do solo; $\mathrm{PC}=$ vezes do peso corporal

FIGURA 20 - Determinação do Load Rate

\subsubsection{Pico de força de propulsão (PFP)}

O pico de força de propulsão (PFP) foi considerado como sendo o maior valor de força de reação do solo encontrado entre o pico de força de passiva (PFPa) e o fim da fase de apoio $\left(\mathrm{t}_{\mathrm{f}}\right)$ (FIGURA 21).

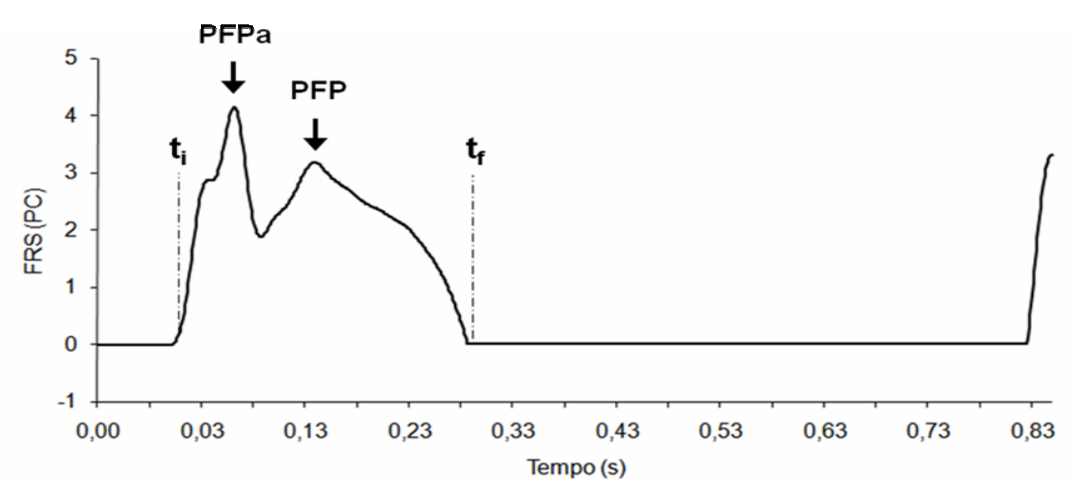

$t_{i}=$ instante de início de fase de apoio; $t_{f}=$ instante de fim da fase de apoio; PFPa = pico de força passiva; PFP = pico de força de propulsão; FRS = força de reação do solo; PC = vezes do peso corporal

FIGURA 21 - Determinação do pico de força de propulsão 


\subsubsection{Tempo decorrido entre o início da fase de apoio e o pico de força de propulsão (TPFPp)}

Foi considerado TPFPp o intervalo de tempo decorrido entre o início da fase de apoio $\left(\mathrm{t}_{\mathrm{i}}\right)$ e o pico de força de propulsão (PFP) (FIGURA 22).

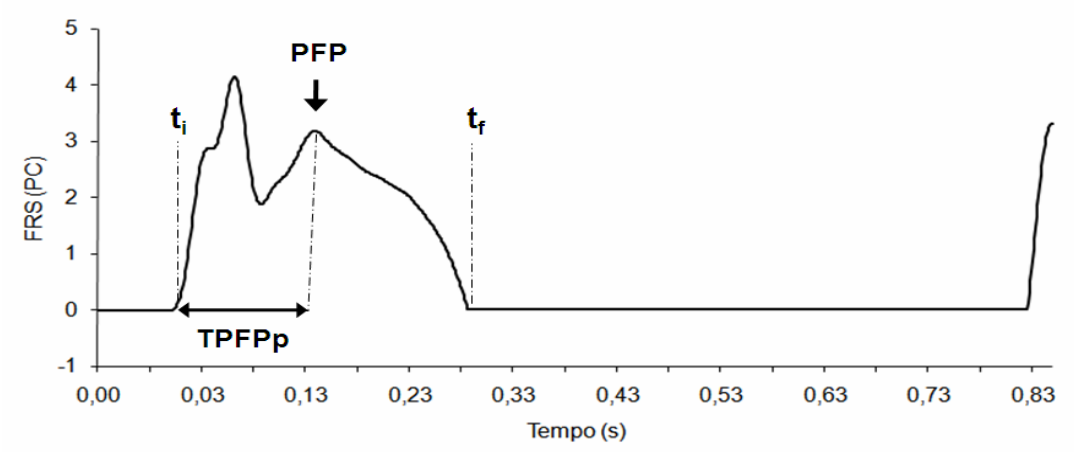

$t_{i}=$ instante de início de fase de apoio; $t_{f}=$ instante de fim da fase de apoio; PFP = pico de força de propulsão; TPFPp = tempo decorrido entre início de apoio e o pico de força de propulsão; FRS = força de reação do solo; $P C=$ vezes do peso corporal

FIGURA 22 - Determinação do tempo decorrido entre o início da fase de apoio e o pico de força de propulsão

\subsubsection{Taxa de desenvolvimento de força (TDF)}

A taxa de desenvolvimento de força (TDF) foi obtida pela razão do pico de força de propulsão (PFP) e do tempo decorrido entre o início da fase de apoio e o pico de força de propulsão (TPFPp), semelhante ao método usado para o cálculo da TDF em SV (FIGURA 23).

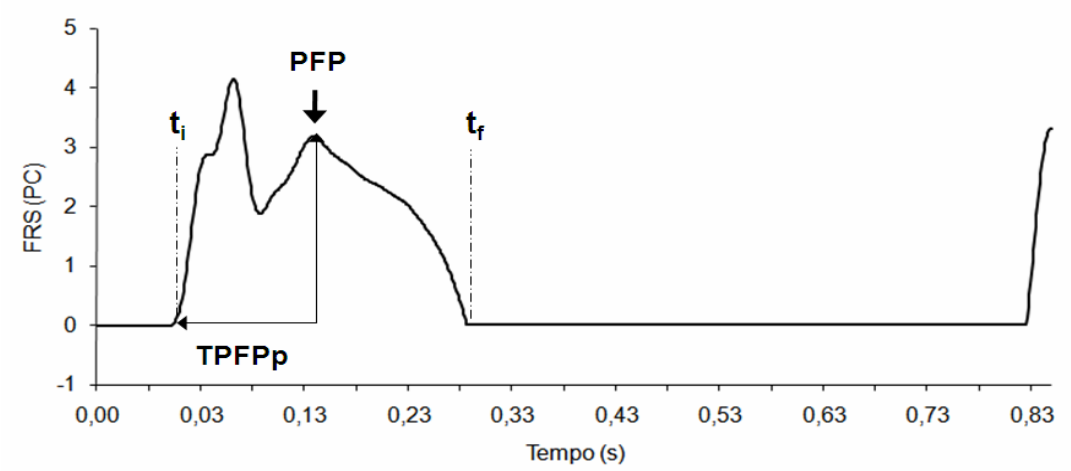

$t_{i}=$ instante de início de fase de apoio; $t_{f}=$ instante de fim da fase de apoio; PFP = Pico de força de propulsão; TPFPp = Tempo decorrido entre início do apoio e pico de força de propulsão; FRS = Força de reação do solo; $\mathrm{PC}=$ Vezes do peso corporal

FIGURA 23 - Determinação da taxa de desenvolvimento de força 


\subsection{Parâmetros do teste de múltiplas acelerações (teste $\mathrm{T}$ )}

Foi mensurado o tempo para percorrer as distâncias de 0 a 40 metros ( $\left.T_{\text {total }}\right)$, de 0 e 10 metros $\left(T_{1}\right)$, de 15 a 25 metros $\left(T_{2}\right)$ e de 30 a 40 metros $\left(T_{3}\right)$ (FIGURA 24).

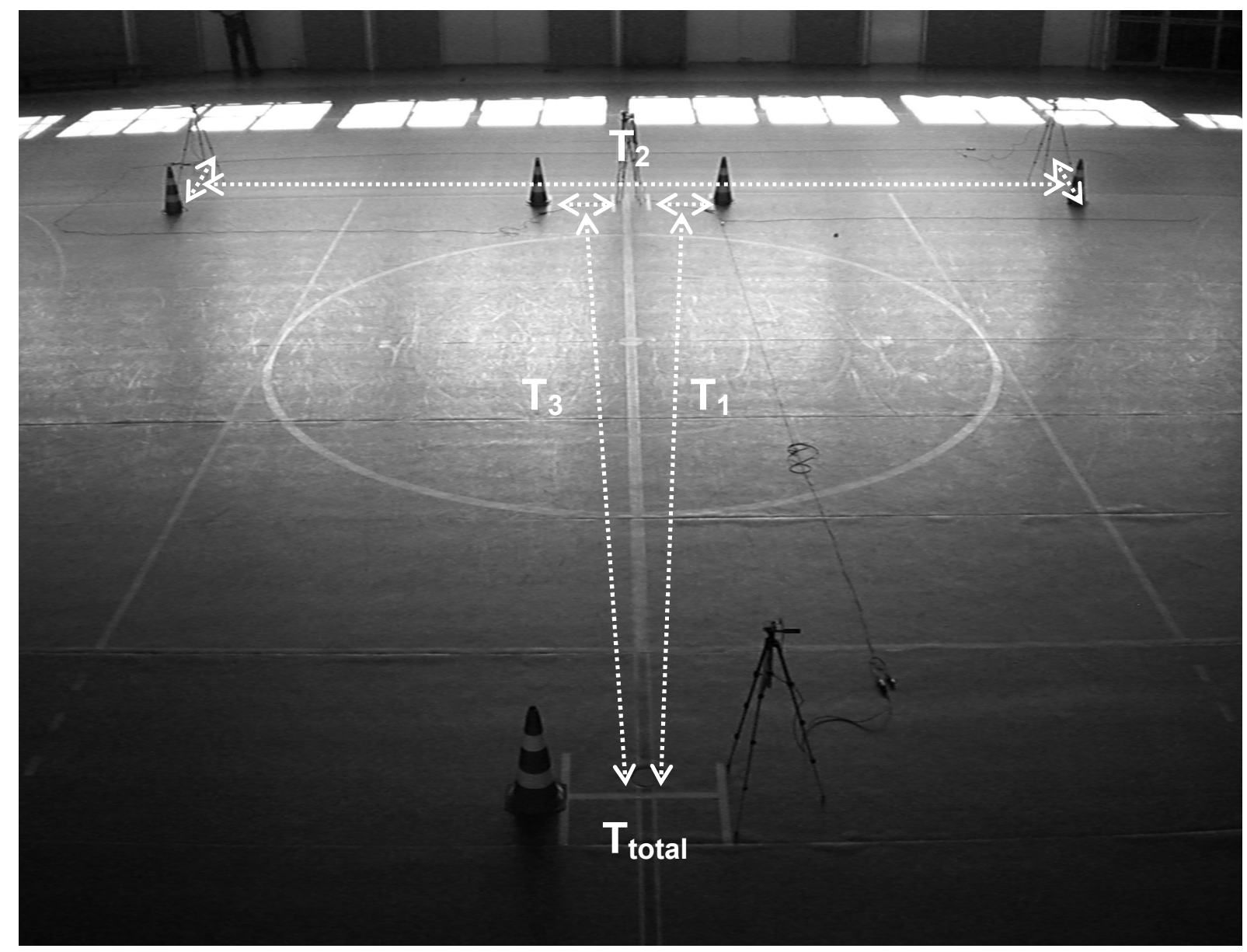

FIGURA 24 - Parâmetros considerados do teste de múltiplas acelerações (teste T)

\section{ANÁLISE DOS DADOS}

\subsection{Tratamento matemático}

Para todos os testes foi considerado para análise a média das três tentativas sem distinção quanto à posição de jogo, uma vez que não tem sido apontado diferenças significantes em atletas de basquetebol (DELEXTRAT \& COHEN, 2009).

A força de reação do solo obtida durante a realização do SV e SV $V_{\text {corrida }}$ de cada voluntária foi mensurada com freqüência de amostragem de mil hertz e normalizada 
pelo próprio peso corporal da voluntária, sendo este peso o produto da massa corporal e aceleração gravitacional (adotado como sendo 9,81 $\mathrm{m} \cdot \mathrm{s}^{-1}$ ).

A identificação dos instantes de início e fim de fase concêntrica em SV e início e fim da fase de apoio em SV corrida, assim como a quantificação de todos os parâmetros biomecânicos anteriormente citados foram obtidos por algoritmo escrito no software Matrix Laboratory ${ }^{\circledR}\left(\right.$ MATLAB $\left.^{\circledR}\right)$ [MathWorks Inc., Natick, USA] versão 7.2.0.232 (R2006a)

Os dados provenientes da plataforma de força foram inicialmente submetidos ao filtro Butterworth de $4^{\mathrm{a}}$ ordem do tipo passa baixa, com freqüência de corte de quarenta hertz, a fim de minimizar o efeito de ruídos originários de fatores externos e internos. A freqüência do filtro Butterworth foi definida por análise residual conforme proposto por WINTER (2004).

\subsection{Tratamento estatístico}

Para a análise dos dados recorreu-se ao teste de normalidade de Shapiro-Wilk e então seguiu-se a apresentação da estatística descritiva (média e desvio-padrão).

Para análise da consistência interna dos parâmetros foi utilizado o método de teste-reteste; foi considerado os parâmetros das três tentativas selecionadas de cada de teste, e calculado coeficiente de correlação intraclasse $(\mathrm{CCl})$ para cada um dos parâmetros.

Com o intuito de identificar os parâmetros que explicariam as relações dos parâmetros biomecânicos com a tarefa de múltiplas acelerações, recorreu-se a analise fatorial, utilizando-se a técnica multivariada de análise de componentes principais, a fim de se sumarizar os dados e observar a formação de fatores (componentes) e as respectivas contribuições dos parâmetros para cada componente formado. Os parâmetros que contribuíssem com maiores "pesos" para os componentes formados seriam retidos para a análise posterior de associação de parâmetros com o desempenho no teste $T$.

Inicialmente construiu-se uma matriz de correlação com todos os parâmetros biomecânicos. Para assegurar a escolha da análise fatorial como técnica adequada, foi utilizado o teste de esfericidade de Bartlett. Assumida a conveniência do modelo, selecionou-se o método de análise dos componentes principais (ACP) a fim de 
determinar o número mínimo de fatores que responderiam pela máxima variância nos dados. Para tanto, primeiramente, determinou-se o número máximo de fatores, sendo em seguida, retido somente os componentes que apresentaram autovalor igual ou maior que 1. A partir da matriz original houve a rotação pelo método varimax (rotação ortogonal).

Os parâmetros que mais contribuíram com a formação dos componentes principais, foram retidos para a análise de associação com o desempenho no teste $T$, realizada pelo cálculo dos coeficientes de correlação de Pearson.

Neste sentido, foi utilizada a matriz de correlação incluindo os parâmetros biomecânicos e o desempenho no teste T e o nível de significância foi estabelecido em $5 \%$.

Todas as análises foram realizadas no pacote estatístico Statistical Package for the Social Sciences - SPSS ${ }^{\circledR}$ versão 15.0 para Windows ${ }^{\circledR}$ (SPSS Inc, Chicago).

\section{RESULTADOS}

No que diz respeito aos coeficientes de correlação intraclasse $(\mathrm{CCl})$, foram encontrados coeficientes significantes para todos os parâmetros biomecânicos com valores entre 0,62 e 0,97 (APÊNDICE 2).

$\mathrm{Na}$ TABELA 2 é apresentado o valor médio e desvio-padrão (DP) dos parâmetros biomecânicos obtidos a partir do salto vertical (SV).

TABELA 2 - Média e desvio-padrão (DP) dos parâmetros biomecânicos obtidos a partir do salto vertical (SV)

\begin{tabular}{lcc}
\hline Parâmetros & Média & DP \\
\hline Tempo de fase concêntrica (s) & 0,30 & 0,09 \\
Tempo decorrido entre início da fase concêntrica e o pico de força de propulsão (s) & 0,13 & 0,08 \\
Taxa de desenvolvimento de força (N/ms) & 26,26 & 21,14 \\
\hline Impulso (N•s) & 165,94 & 36,20 \\
Pico de força de propulsão (PC) & 2,18 & 0,76 \\
\hline segundo (s); Newton (N); milésimo de segundo (ms); vezes do peso corporal (PC) &
\end{tabular}


A matriz de fatores gerada a partir do teste de salto vertical (SV) é apresentada na TABELA 3, enquanto que a contribuição dos parâmetros para cada um dos componentes pode ser visualizada na TABELA 4.

TABELA 3 - Variação explicada para cada componente no teste de salto vertical (SV)

\begin{tabular}{cccc}
\hline componente & autovalor & \% de variação & \% acumulado \\
\hline 1 & 3,06 & 61,27 & 61,27 \\
2 & 1,03 & 20,70 & 81,97 \\
3 & 0,65 & 12,98 & 94,95 \\
4 & 0,22 & 4,42 & 99,37 \\
5 & 0,03 & 0,63 & 100,00 \\
\hline
\end{tabular}

$\mathrm{Na}$ análise dos componentes principais do salto vertical, foi gerada uma matriz de cinco fatores que responderam pela variância total de SV (TABELA 3).

Considerando exclusivamente os componentes com autovalor igual ou maior do que 1 , com o intuito de estabelecer significância prática para a análise das associações com a tarefa de múltiplas acelerações, os componentes (fatores) 1 e 2 foram considerados.

O componente 1 respondeu por $61,27 \%$ da variância total (TABELA 3), com maior carga ocasionada pelos parâmetros tempo de fase concêntrica, tempo decorrido entre início da fase concêntrica e o pico de força de propulsão, e o parâmetro pico de força de propulsão (TABELA 4). Tendo em vista a contribuição dos parâmetros, este componente foi considerado como predominantemente temporal.

Por outro lado, o componente 2 respondeu por uma variação de $20,70 \%$ (TABELA 3) sendo composto pelos parâmetros taxa de desenvolvimento de força e impulso (TABELA 4), podendo ser considerado um componente predominantemente cinético. 
TABELA 4 - Matriz de componentes do teste de salto vertical (SV)

\begin{tabular}{lcc}
\hline & \multicolumn{2}{c}{ Componente } \\
& $\mathbf{1}$ & $\mathbf{2}$ \\
\hline Tempo de fase concêntrica (s) & 0,94 & $-0,13$ \\
Tempo decorrido entre início da fase concêntrica e o pico de força de propulsão (s) & 0,92 & $-0,20$ \\
Taxa de desenvolvimento de força (N/ms) & $-0,37$ & 0,72 \\
Impulso (N•s) & $-0,02$ & 0,93 \\
Pico de força de propulsão (PC) & $-0,64$ & 0,60 \\
\hline
\end{tabular}

segundo (s); Newton (N); milésimo de segundo (ms); vezes do peso corporal (PC)

Para o salto vertical precedido de corrida ( $S V_{\text {corrida }}$ ), a média e o desvio-padrão (DP) dos parâmetros são reportados na TABELA 5.

TABELA 5 - Média e desvio-padrão (DP) dos parâmetros biomecânicos obtidos a partir do salto vertical precedido de corrida $\left(\mathrm{SV}_{\text {corrida }}\right)$

\begin{tabular}{lcc}
\hline Parâmetros & Média & DP \\
\hline Velocidade média de aproximação $\left(\mathrm{m}^{-1} \mathrm{~s}^{-1}\right)$ & 3,45 & 0,40 \\
\hline Tempo total do movimento (s) & 0,34 & 0,05 \\
Tempo decorrido entre início da fase de apoio e o pico de força passiva (s) & 0,08 & 0,05 \\
Tempo decorrido entre início da fase de apoio e o pico de força de propulsão (s) & 0,15 & 0,05 \\
Load Rate (N/ms) & 47,46 & 26,39 \\
Taxa de desenvolvimento de força (N/ms) & 21,46 & 14,42 \\
Pico de força passiva (PC) & 3,41 & 0,95 \\
Pico de força de propulsão (PC) & 3,17 & 0,70 \\
\hline segundo (s); Newton (N); milésimo de segundo (ms); vezes do peso corporal (PC); metro (m)
\end{tabular}

A matriz dos fatores gerada a partir do teste de salto vertical precedido de corrida ( $\left(\mathrm{V}_{\text {corrida }}\right)$ é apresentada na TABELA 6 e a contribuição dos parâmetros para cada um dos componentes pode ser visualizada na TABELA 7 . 
TABELA 6 - Variação explicada para cada componente no teste de salto vertical precedido de corrida ( $\mathrm{SV}_{\text {corrida }}$ )

\begin{tabular}{cccc}
\hline componente & autovalor & \% de variação & \% acumulado \\
\hline 1 & 4,70 & 58,72 & 58,72 \\
2 & 1,23 & 15,37 & 74,09 \\
3 & 1,02 & 12,79 & 86,88 \\
4 & 0,51 & 6,32 & 93,21 \\
5 & 0,33 & 4,17 & 97,37 \\
6 & 0,13 & 1,64 & 99,02 \\
7 & 0,05 & 0,67 & 99,69 \\
8 & 0,02 & 0,31 & 100,00 \\
\hline
\end{tabular}

Ao considerar o teste de salto vertical precedido de corrida $\left(S V_{\text {corrida }}\right)$ foi gerada uma matriz de oito fatores. Todavia, três componentes (fatores) foram retidos ao considerar somente os componentes com autovalor igual ou maior do que 1.

O componente principal 1 , respondeu por $58,72 \%$ da variância total (TABELA 6), com maior carga ocasionada pelos parâmetros tempo total do movimento, tempo decorrido entre início da fase de apoio e o pico de força passiva, tempo decorrido entre início da fase de apoio e o pico de força de propulsão, Load Rate e taxa de desenvolvimento de força sendo considerado como componente predominantemente temporal (TABELA 7).

O componente 2 respondeu por uma variação de 15,37\% (TABELA 6), sendo composto pelos parâmetros pico de força passiva e pico de força de propulsão (TABELA 7), logo, este componente foi considerado como sendo um componente predominantemente cinético; o componente 3 respondeu 12,79\% (TABELA 6) correspondendo ao parâmetro velocidade média de aproximação, portanto considerado como um componente de velocidade (TABELA 7). 
TABELA 7 - Matriz de componentes do teste de salto vertical precedido de corrida $\underline{(\mathrm{SV}} \underline{\text { corrida) }}$

\begin{tabular}{|c|c|c|c|}
\hline & \multicolumn{3}{|c|}{ Componente } \\
\hline & 1 & 2 & 3 \\
\hline Velocidade média de aproximação $\left({\left.\mathrm{m} \cdot \mathrm{s}^{-1}\right)}^{-1}\right.$ & 0,04 & 0,00 & 0,98 \\
\hline Tempo total do movimento (s) & 0,70 & $-0,61$ & $-0,22$ \\
\hline Tempo decorrido entre início da fase de apoio e pico de força passiva (s) & 0,87 & 0,05 & 0,05 \\
\hline $\begin{array}{l}\text { Tempo decorrido entre início da fase de apoio e o pico de força de } \\
\text { propulsão (s) }\end{array}$ & 0,93 & $-0,21$ & 0,03 \\
\hline Load Rate (N/ms) & $-0,87$ & 0,29 & $-0,12$ \\
\hline Taxa de desenvolvimento de força (N/ms) & $-0,85$ & 0,23 & 0,16 \\
\hline Pico de força passiva $(\mathrm{N})$ & $-0,05$ & 0,94 & $-0,11$ \\
\hline Pico de força de propulsão $(\mathrm{N})$ & $-0,57$ & 0,65 & 0,33 \\
\hline
\end{tabular}

segundo (s); Newton (N); milésimo de segundo (ms); vezes do peso corporal (PC); metro (m)

Apesar da busca pela sumarização dos parâmetros que mais contribuíssem para a formação dos componentes, a análise de componentes principais revelou peso significativo de todos os parâmetros considerados, e portanto, o delineamento do modelo para a identificação dos parâmetros que mais contribuíram para os dois diferentes tipos de saltos e conseqüentemente para a posterior análise de associação destes com o teste $\mathrm{T}$ pode ser assumida.

Deste modo, todos os parâmetros foram utilizados na análise subseqüente, objetivando a identificação de um possível construto do desempenho no teste $\mathrm{T}$ a partir dos parâmetros biomecânicos dos dois diferentes tipos de saltos.

$\mathrm{Na}$ TABELA 8 são apresentados os valores referentes aos parâmetros (tempos) obtidos durante a realização do teste $\mathrm{T}$, considerado no presente estudo um indicador das múltiplas acelerações.

TABELA 8 - Média e desvio-padrão (DP) dos parâmetros considerados no teste T

\begin{tabular}{llcc} 
& Média & DP \\
\hline Tempo para percorrer a distância de 0 a 40 metros $-\mathrm{T}_{\text {total }}(\mathrm{s})$ & 9,20 & 0,34 \\
Tempo para percorrer a distância de 0 a 10 metros $-\mathrm{T}_{1}(\mathrm{~s})$ & 2,20 & 0,15 \\
Tempo para percorrer a distância de 15 a 25 metros $-\mathrm{T}_{2}(\mathrm{~s})$ & 2,57 & 0,17 \\
Tempo para percorrer a distância de 30 a 40 metros $-\mathrm{T}_{3}(\mathrm{~s})$ & 1,86 & 0,10 \\
\hline
\end{tabular}

segundo (s) 
Os valores de correlação entre o teste $T$ e os parâmetros biomecânicos obtidos a partir do salto vertical (SV) são reportados na TABELA 9 enquanto que os valores de correlação entre o teste $T$ e os parâmetros biomecânicos obtidos a partir do salto vertical precedido de corrida ( $\left(\mathrm{V}_{\text {corrida }}\right)$ são apresentados na TABELA 10.

Como apresentado na TABELA 9 e TABELA 10, salvo as correlações entre tempo de fase concêntrica e $\mathrm{o}_{3}$, tempo decorrido entre início da fase concêntrica e o pico de força de propulsão e $T_{1}$, e entre velocidade média de aproximação e $T_{3}$, os valores de correlação entre os parâmetros parciais do teste $T\left(T_{1}, T_{2}\right.$ e $\left.T_{3}\right)$ foram baixos e não significantes tanto para o salto vertical (SV) quanto o salto vertical precedido de corrida ( $\left.\mathrm{SV}_{\text {corrida}}\right)$.

Desta forma, optou-se por considerar apenas a correlação entre tempo para percorrer a distância de 0 a 40 metros $\left(T_{\text {total }}\right)$ e os parâmetros biomecânicos obtidos a partir dos testes SV e SV corrida.

No que diz respeito aos parâmetros biomecânicos obtidos a partir do salto vertical (SV), apenas uma correlação estatisticamente significante foi revelada, sendo esta entre o tempo de fase concêntrica e o $T_{\text {total }}(r=0,55)$ (TABELA 9).

TABELA 9 - Correlação entre o teste T e os parâmetros biomecânicos obtidos a partir do salto vertical (SV)

\begin{tabular}{lcccc}
\hline Parâmetros & $\mathbf{T}_{\mathbf{1}}$ & $\mathbf{T}_{\mathbf{2}}$ & $\mathbf{T}_{\mathbf{3}}$ & $\mathbf{T}_{\text {total }}$ \\
\hline Tempo de fase concêntrica (s) & 0,44 & 0,38 & $0,56^{*}$ & $0,55^{*}$ \\
Tempo decorrido entre início da fase concêntrica e o pico de força de & & & & \\
propulsão (s) & $0,50^{*}$ & 0,36 & 0,29 & 0,42 \\
Taxa de desenvolvimento de força (N/ms) & $-0,36$ & $-0,13$ & $-0,04$ & $-0,13$ \\
\hline Impulso (N•s) & $-0,07$ & 0,26 & $-0,17$ & $-0,01$ \\
Pico de força de propulsão $(\mathrm{N})$ & $-0,22$ & $-0,29$ & $-0,39$ & $-0,26$ \\
\hline
\end{tabular}

segundo (s); Newtons (N); milésimos de segundo (ms)

${ }^{*} \mathrm{p}<0,05$

Quando considerado os parâmetros biomecânicos obtidos a partir do salto vertical precedido de corrida ( $S V_{\text {corrida }}$ ) e o desempenho no teste $T$ (TABELA 10), a velocidade média de aproximação apresentou correlação significante de $-0,54$ com 
$T_{\text {total, }}$ enquanto que o pico de força de propulsão apresentou correlação significante de $-0,49$ com $T_{\text {total }}$.

Sendo assim, e refutando as hipóteses iniciais, apenas 3 dos 13 parâmetros apresentaram importante contribuição para o desempenho do teste $T$, e esta contribuição foi teste vertical-dependente, uma vez que os parâmetros biomecânicos decorrentes dos dois tipos de saltos não foram associados de forma semelhante ao desempenho no teste $\mathrm{T}$.

TABELA 10 - Correlação entre o teste $T$ e os parâmetros biomecânicos obtidos a partir do salto vertical precedido de corrida (SV ${ }_{\text {corrida }}$ )

\begin{tabular}{lcccc}
\hline Parâmetros & $\mathbf{T}_{1}$ & $\mathbf{T}_{\mathbf{2}}$ & $\mathbf{T}_{\mathbf{3}}$ & $\mathbf{T}_{\text {total }}$ \\
\hline Velocidade média de aproximação (m/s) & $-0,40$ & $-0,39$ & $-0,50^{*}$ & $-0,54^{*}$ \\
\hline Tempo total do movimento (s) & 0,14 & 0,35 & 0,14 & 0,34 \\
Tempo decorrido entre início da fase de apoio e o pico de força & & & & \\
passiva (s) & $-0,06$ & 0,14 & 0,20 & 0,09 \\
Tempo decorrido entre início da fase de apoio e o pico de força & & & & \\
propulsiva (s) & 0,04 & $-0,05$ & 0,05 & 0,04 \\
Load Rate (N/ms) & 0,12 & 0,03 & 0,13 & 0,08 \\
Taxa de desenvolvimento de força (N/ms) & $-0,12$ & 0,02 & 0,02 & $-0,07$ \\
\hline Pico de força passiva (N) & $-0,01$ & $-0,05$ & 0,00 & $-0,05$ \\
Pico de força de propulsão (N) & $-0,24$ & $-0,46$ & $-0,31$ & $-0,49^{*}$ \\
\hline
\end{tabular}

segundo (s); Newtons (N); milésimos de segundo (ms)

${ }^{*} p<0,05$

\section{DISCUSSÃO}

\subsection{Contribuição dos parâmetros biomecânicos para o desempenho no salto vertical e no salto vertical precedido de corrida.}

Dentre os objetivos específicos do estudo, foi investigado os parâmetros biomecânicos de maior contribuição para o desempenho no salto vertical (SV) e salto vertical precedido de corrida ( $\mathrm{SV}_{\text {corrida }}$ ).

Neste sentido, pela análise de componentes principais pode ser percebido que ambos os saltos apresentaram maior variação explicada pelos parâmetros predominantemente temporais $(61,27 \%$ e $58,72 \%$, respectivamente), corroborando com a idéia de que a força produzida por unidade de tempo parece ser de grande 
importância para o desempenho nestas ações (DE RUITER et al., 2006; HAKKINEN, 1993; JARIC, RISTANOVIC \& CORCOS, 1989; KYROLAINEN et al., 2005; THORLUND, AAGAARD \& MADSEN, 2009; VIITASALO \& AURA, 1984).

No entanto, foi evidenciado também importante papel do componente predominantemente cinético para o desempenho, uma vez que este componente explicou $20,70 \%$ da variação do salto vertical (SV) e $15,37 \%$ da variação do salto vertical precedido de corrida $\left(\mathrm{SV}_{\text {corrida }}\right)$.

Portanto, poder-se-ia dizer que parece ser importante não só produzir força de forma mais rápida possível (DE RUITER et al., 2006; HAKKINEN, 1993; JARIC, RISTANOVIC \& CORCOS, 1989; KYROLAINEN et al., 2005; THORLUND, AAGAARD \& MADSEN, 2009; VIITASALO \& AURA, 1984) mas também produzir elevada magnitude de força (HAKKINEN, 1989; HAM, KNEZ \& YOUNG, 2007; JARIC, RISTANOVIC \& CORCOS, 1989; KAWAMORI et al., 2006; KOLLIAS et al., 2001; LAFFAYE, BARDY \& DUREY, 2007; NUZZO et al., 2008; UGARKOVIC et al., 2002; VANEZIS \& LEES, 2005), justificando a associação reportada por alguns estudos entre a altura de salto vertical e pico de força produzida durante o salto (DOWLING \& VAMOS, 1993) e na execução de exercícios como leg press (YAMAUCHI \& ISHII, 2007), agachamento (KAWAMORI et al., 2006; STONE, SANDS, CARLOCK, CALLAN, DICKIE, DAIGLE, COTTON, SMITH \& HARTMAN, 2004; WISLOFF et al., 2004) e extensão de joelho (HAKKINEN, 1989; MATAVULJ, KUKOLJ, UGARKOVIC, TIHANYI \& JARIC, 2001; UGARKOVIC et al., 2002) e de quadril (MATAVULJ et al., 2001; UGARKOVIC et al., 2002).

Corroborando com tal argumentação, DOWLING \& VAMOS (1993) ao analisar os determinantes do salto vertical com contramovimento, apontaram que as maiores alturas de salto são as que apresentam maior pico de força de propulsão; segundo os autores, considerando exclusivamente o pico de força de propulsão, este explicaria aproximadamente $27 \%$ da variação da altura do salto vertical com contramovimento, o que justificaria o fato do melhor modelo preditivo da altura de salto vertical ser composto por componentes predominantemente temporais (tempo da fase propulsiva, e o tempo entre máxima velocidade de fase excêntrica e início de fase concêntrica) e por componentes predominantemente cinéticos, como o pico de força de propulsão. 
Os achados do presente estudo sinalizam que embora tenha existido semelhante comportamento de SV e SV $\mathrm{Corrida}_{\text {no }}$ que diz respeito a variação explicada pelo componente predominantemente temporal $(61,27 \%$ e $58,72 \%)$ e predominantemente cinético $(20,70 \%$ e $15,37 \%)$, a reposta quanto a proficiência do salto parece ser teste vertical-dependente, fundamentalmente pelo fato da taxa de desenvolvimento de força ser incluída no componente predominantemente cinético

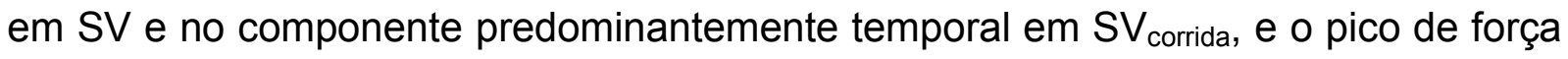
de propulsão, que foi incluído no componente predominantemente temporal em SV, porém, incluído no componente predominantemente cinético em SV $\mathrm{S}_{\text {corrida. }}$.

Poder-se-ia considerar a possibilidade da velocidade média de aproximação (Vel $I_{\text {média }}$ ), que explicou em $12,79 \%$ a variação de $S V_{\text {corrida, }}$ produzir alterações quanto a amplitude de movimento nas articulações joelho, tornozelo e quadril, repercutindo em diferentes contribuições dos parâmetros biomecânicos no desempenho do salto.

Embora não tenha sido encontrado na literatura (pesquisa realizada em novembro de 2009 no banco de dados PubMed com a combinação dos unitermos run AND jump AND range movement), estudos que investigaram o efeito da corrida na amplitude de movimento do salto realizado de forma subseqüente, assim como da modulação quanto a contribuição dos parâmetros biomecânicos para o desempenho de salto após a realização desta corrida, esta hipótese deve ser considerada. Haja vista que modulações quanto a amplitude de movimento já foram evidenciadas em estudos que compararam a execução de um único salto vertical com contramovimento a uma série de saltos verticais sucessivos (KOMI, 1984) e ao comparar o salto vertical com contramovimento com o salto horizontal (ECKERT, 1968), o que levaria a diferentes respostas mecânicas e neurais para produção de força (KOMI, 1984).

Exemplo encontrado no presente estudo que sinaliza para tais modulações, é o fato de não ter sido apresentada grande diferença entre os parâmetros biomecânicos tempo de fase concêntrica em SV e o tempo total de movimento em $S V_{\text {corrida }}(0,30$ e 0,34 , respectivamente). Tendo em vista que o parâmetro tempo de fase concêntrica em SV envolve somente a fase concêntrica, apesar de não ter sido quantificada a variação angular, é razoável aceitar que modificações quanto a 
amplitude de movimento tenham ocorrido em SV corrida, sendo que em praticamente uma mesma grandeza de tempo foram realizadas as fases excêntrica e concêntrica.

Considerando a ocorrência das modificações quanto a amplitude de movimento, tempo das fases excêntrica e concêntrica (em $S V_{\text {corrida }}$ ) e a diferentes predomínios quanto as respostas mecânicas e neurais para produção de força (KOMI, 1984) entre os saltos SV e SV corrida, o estudo de ANDERSEN \& AAGAARD (2006) ratifica com os achados no que diz respeito a taxa de desenvolvimento de força.

No citado estudo, os autores (ANDERSEN \& AAGAARD, 2006) encontraram que quanto maior o tempo de contração, como o ocorrido no SV frente a SV corrida, maior a magnitude de associação da taxa de desenvolvimento de força com as propriedades contráteis predominantemente cinéticas, como a magnitude da força máxima, o que explicaria o fato da taxa de desenvolvimento de força ter sido incluída no componente predominantemente cinético em SV, situação com maior tempo de duração de fase concêntrica.

Ainda, e como demonstrado por ANDERSEN \& AAGAARD (2006), em situações de menor tempo de duração de fase concêntrica, como o que supostamente ocorreu em $\mathrm{SV}_{\text {corrido }}$ frente a SV, a taxa de desenvolvimento de força parece estar menos associada as propriedades contráteis (magnitude da força máxima), podendo ser melhor explicada por componentes temporais, como o encontrado no presente estudo.

Logo, não pode ser descartada a hipótese dos parâmetros biomecânicos contribuírem de diferentes formas quando considerado outros tipos de salto, como saltos horizontais, únicos ou sucessivos, assim como saltos unipodais, bipodais, em profundidade, etc., uma vez que estudos, adotando diferentes recursos, têm apontado para tais diferenças (BISSAS \& HAVENETIDIS, 2008; MAULDER \& CRONIN, 2005; MEYLAN et al., 2009; MOREIRA et al., 2005; MOREIRA, OLIVEIRA, OKANO, SOUZA \& ARRUDA, 2004; SMIRNIOTOU et al., 2008; ZIV \& LIDOR, 2009b).

Sendo assim, a análise de componentes principais parece ser uma estratégia importante a ser considerada em futuros estudos no tocante a investigação quanto a 
contribuição de parâmetros predominantemente cinéticos e predominantemente temporais em diferentes tipos de saltos.

\subsection{Construto do teste T}

Uma vez determinado os parâmetros que estariam associados ao desempenho dos saltos, buscou-se um maior entendimento do construto do teste $\mathrm{T}$.

Neste sentido, inicialmente alguns apontamentos conceituais devem ser feitos.

$\mathrm{O}$ teste $\mathrm{T}$ tem sido referenciado como sendo um teste de agilidade (BRUGHELLI et al., 2008; CHAOUACHI et al., 2009; DELEXTRAT \& COHEN, 2008; DELEXTRAT \& COHEN, 2009; PAUOLE et al., 2000; SASSI et al., 2009; SEMENICK, 1990).

No entanto, a agilidade é definida como sendo um movimento do corpo com mudança de velocidade e/ou direção, em reposta a um dado estímulo (SHEPPARD \& YOUNG, 2006; YOUNG, JAMES \& MONTGOMERY, 2002), portanto, abrangendo componentes de percepção visual, de tomada de decisão, assim como de demanda física, como a aceleração, desaceleração e mudança de direção (SHEPPARD \& YOUNG, 2006). Sendo assim, para que sejam contemplados os pré-requisitos da agilidade, tem sido proposto que uma dada tarefa ou teste apresente além da demanda física, produzida pelas ações de aceleração, desaceleração e mudança de direção, a necessidade de reagir a um estímulo não previamente informado (SHEPPARD \& YOUNG, 2006).

Vista que o teste T consiste em uma tarefa pré-programada e esclarecida, onde não existe a interferência de qualquer fator externo, o que faz com que não exista a necessidade de percepção visual e tomada de decisão frente a qualquer estímulo, este não pode ser classificado com um teste de agilidade.

Outro ponto importante é o fato de ter sido assumido no decorrer do texto, o teste T como sendo um teste de múltiplas acelerações, única e exclusivamente pelo fato da constante mudança de direção, o que produziria maior alternância de velocidade, que por sua vez é a tônica da aceleração.

Apesar deste raciocínio ter validade lógica atribuída pelas leis da física, tal denominação carece de maior respaldo científico para aceitação desta conceituação, ainda mais pelo fato dos deslocamentos em alta velocidade serem tarefas compostas 
por distintas fases (DELECLUSE, VAN COPPENOLLE, WILLEMS, VAN LEEMPUTTE, DIELS \& GORIS, 1995)

Neste sentido, o estudo de DELECLUSE et al. (1995) pode fundamentar a atribuição feita ao teste $\mathrm{T}$, tendo em vista que o objetivo dos autores foi estabelecer as distâncias compreendidas em cada uma das fases da corrida.

Para tanto, DELECLUSE et al. (1995) mensuraram a velocidade a intervalos de dois metros durante um deslocamento em máxima velocidade de 100 metros, e por meio da análise de componentes principais, identificaram que a fase de aceleração (componente 3) compreende a distância entre 0 e 10 metros, conforme apresentado na FIGURA 25.

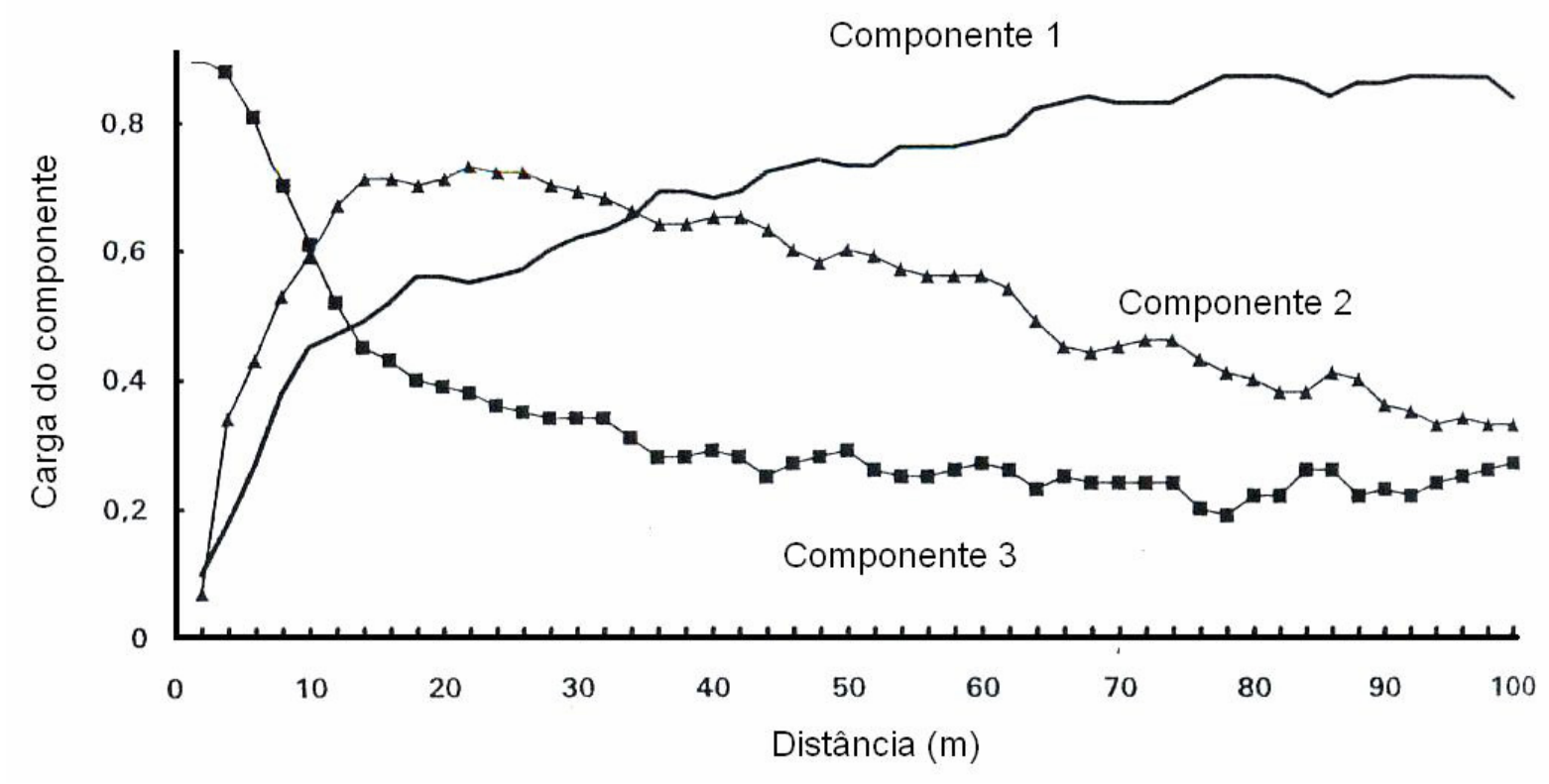

FIGURA 25 - Fases da corrida (adaptado de DELECLUSE et al., 1995)

Onde:

Componente 1 = Manutenção de máxima velocidade (entre 36 e 100 metros); Componente 2 = Fase de máxima velocidade (aceleração continuada - entre 10 e 36 metros); Componente 3 = Fase de aceleração (entre 0 e 10 metros)

Sendo assim, embora o teste T compreenda uma distância de 40 metros, que tornaria predominante o componente de manutenção de máxima velocidade (componente 1), a máxima distância encontrada entre parciais para aceleração e desaceleração, dada a necessidade da mudança de direção, é de 10 metros, distância classificada como de predomínio da aceleração (DELECLUSE et al., 1995). 
Como durante a execução do teste $\mathrm{T}$ são realizadas três parciais de 10 metros, intercaladas por duas parciais de cinco metros, todas as distâncias com predomínio da fase de aceleração, o teste $\mathrm{T}$ deve ser denominado em sua essência como um teste de múltiplas acelerações.

Posto isto, buscou-se a associação dos parâmetros biomecânicos com o teste de múltiplas acelerações.

Para tanto, cabe lembrar que alguns parâmetros foram significantemente correlacionados com o desempenho no teste T, sendo eles, PFP em SV corrida $(r=-$ $0,49), T_{\text {con }}$ em SV $(r=0,55)$ e Vel média $(r=-0,54)$ em SV corrida.

Estes resultados indicam que aproximadamente 24\%, 30\% e 29\% da variação do desempenho no teste T poderia ser explicada pela variação dos parâmetros PFP em SV $\mathrm{Corrida}_{\text {con }}$ em SV e Vel $\mathrm{T}_{\text {média }}$ em $\mathrm{SV}_{\text {corrida, }}$ respectivamente.

Considerando que aproximadamente $30 \%$ da variação do desempenho no teste $\mathrm{T}$ poderia ser explicada pela variação de um único componente predominantemente temporal ( $\left.T_{\text {con }}\right)$, e $29 \%$ pela variação isolada de um componente predominantemente cinético (PFP), seria esperado que outros parâmetros predominantemente temporais, como tempo decorrido entre início de fase concêntrica e pico de força de propulsão (TPFP) em SV e tempo decorrido entre início da fase de apoio e o pico de força propulsiva (TPFPp) em $\mathrm{SV}_{\text {corrida, }}$ também apresentassem associação significante, o mesmo ocorrendo com o outro parâmetro predominantemente cinético, pico de força de propulsão (PFP) em SV.

Seria ainda esperado que parâmetros resultantes da combinação de parâmetros predominantemente cinéticos e predominantemente temporais, como impulso (I) em SV e as taxas de desenvolvimento de força (TDF), tanto de SV quanto de $\mathrm{SV}_{\text {corrida }}$ apresentassem importante contribuição para o desempenho no teste $\mathrm{T}$.

Todavia, tais resultados não foram encontrados.

Considerando o impulso, uma possível explicação para os baixos valores de correlação com o teste $\mathrm{T}$ pode residir na forma utilizada para a estimativa deste parâmetro.

Embora tenha sido identificado os instantes de início e de fim de fase concêntrica a partir dos valores de força de reação do solo normalizada pelo peso corporal, foi considerado para efeito de cálculo do impulso, a força de reação do solo 
em sua forma absoluta (não normalizada pelo peso corporal individual). No entanto, visto que a grandeza de força gerada é proporcional a resistência oferecida (BOSCO, 2007; BRET et al., 2002; CARVALHO \& CARVALHO, 2006; ZATSIORSKY, 2006), não pode ser descartada a possibilidade dos indivíduos mais pesados terem gerado maior impulso absoluto, porém com pior desempenho no teste $T$, fazendo com a relação esperada entre impulso e o desempenho no teste $\mathrm{T}$ não tenha sido alcançada.

Logo, em estudos futuros, seria desejado calcular o impulso a partir dos valores de força de reação do solo normalizados pelo peso corporal para um melhor entendimento quanto a relação em questão (entre impulso e múltiplas acelerações), assim como o uso de algum recurso que viabilizasse a identificação do inicio da fase concêntrica em $\mathrm{SV}_{\text {corrida, }}$ para cálculo do impulso neste tipo de salto.

Quanto as associações dos parâmetros TPFP em SV e TPFPp em SV corrida, $_{\text {, }}$

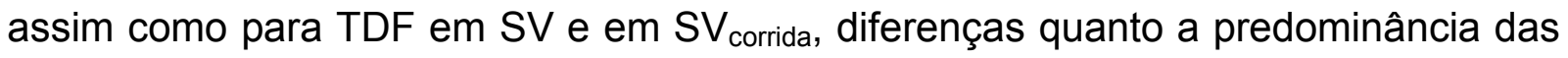
respostas mecânica e neural nos gestos analisados talvez possam explicar tais resultados.

Para tanto, se faz inicialmente importante esclarecer que tais repostas (mecânicas e neurais) são apontadas como os mecanismos responsáveis pela melhora no output motor obtido pelo uso do ciclo do alongamento-encurtamento (BOBBERT, GERRITSEN, LITJENS \& VAN SOEST, 1996; BOSCO, TARKKA \& KOMI, 1982; BOSCO, VIITASALO, KOMI \& LUHTANEN, 1982; KOMI, 1984; KOMI \& GOLLHOFER, 1997).

Embora seja difícil à quantificação da magnitude de contribuição de cada uma destas respostas, assim como a dissociação destas na execução do movimento humano, usualmente tem sido atribuído ao ciclo do alongamento-encurtamento classificações em função de suas características, e predomínio das respostas mecânica e neural.

No ciclo do alongamento-encurtamento lento (duração maior do que 250 milésimos de segundos), presente em ações com 0 salto vertical com contramovimento, uma maior amplitude de movimento das articulações e maior tempo de contato torna predominante a resposta mecânica (SMIRNIOTOU et al., 2008), enquanto que no ciclo alongamento-encurtamento rápido (duração menor do 
que 250 milésimos de segundos), presente, por exemplo, nos saltos em profundidade, uma menor variação angular e menor tempo de contato torna a reposta neural o mecanismo predominante (SMIRNIOTOU et al., 2008; UGRINOWITSCH \& BARBANTI, 1998). Por vezes, esta reposta tem sido apontada como índice de força reativa, ou como força reativa (SMIRNIOTOU et al., 2008).

Tendo em vista que ao se comparar a realização de ações únicas com a realização de ações sucessivas de reduzido tempo de contato, a realização de ações sucessivas de reduzido tempo de contato, como as produzidas na tarefa de múltiplas acelerações, promovem redução da amplitude de movimento entre $26 \%$ e $30 \%$ (KOMI, 1984), e que o salto em profundidade e a tarefa de múltiplas acelerações tem características peculiares, dentre elas a reduzida amplitude de movimento e tempo de contato, é possível aceitar que nas tarefas de acelerações múltiplas haja predomínio do ciclo alongamento-encurtamento rápido, logo com predomínio da resposta neural (SMIRNIOTOU et al., 2008).

Corroborando com tal hipótese, YOUNG, JAMES \& MONTGOMERY (2002) relataram correlação significante entre a resposta neural, indicada pela força reativa (razão entre altura de salto em profundidade e tempo de contato para salto vertical em profundidade) e múltiplas acelerações.

Estas possíveis diferenças quanto a predomínio das repostas do ciclo do alongamento-encurtamento nas tarefas adotadas ( $S V, S_{\text {corrida }}$ e teste T) podem contribuir para o entendimento dos resultados encontrados, uma vez a manifestação e a contribuição dos parâmetros de força são movimento-dependente como postulado em alguns artigos (KOMI \& GOLLHOFER, 1997; NICOL, AVELA \& KOMI, 2006; ZIV \& LIDOR, 2009b).

$\mathrm{Na}$ tentativa de melhor evidenciar a possibilidade destes diferentes predomínios quanto a reposta do ciclo do alongamento-encurtamento, SMIRNIOTOU et al. (2008) consideraram a altura de salto vertical com contramovimento e diferentes índices relacionados a reposta neural (força reativa) obtidos a partir da realização do salto vertical, sendo estes: tempo de contato para salto vertical em profundidade, diferença da altura de salto vertical com e sem contramovimento, e razão entre altura de salto em profundidade e tempo de contato para salto vertical em profundidade. 
Como resultado, os autores (SMIRNIOTOU et al., 2008) reportaram correlações não significantes entre altura de salto vertical com contramovimento e estes índices ( $r=-0,13 ; r=0,17$ e $r=0,36$, respectivamente), demonstrando que o predomínio das repostas mecânicas e neurais parecem ser de fato movimentodependente, que não estariam obrigatoriamente associadas, e que poderiam em uma segunda instância, contribuir de forma diferenciada na aceleração, como reportado por MAULDER \& CRONIN (2005), que ao considerarem a aceleração na distância de 20 metros, encontraram diferentes coeficientes de correlação desta com a altura de salto vertical com contramovimento $(r=-0,73)$, sem contramovimento $(r=-0,56)$ e em profundidade $(r=-0,52)$.

Sendo assim, a diferença quanto ao predomínio das repostas mecânicas no salto vertical (SV), e as respostas neurais, assumidas como predominante no teste $\mathrm{T}$, pode ter contribuído para que os parâmetros TPFP e TDF não tenham sido estatisticamente correlacionados com o desempenho no teste $\mathrm{T}$.

Considerando aos parâmetros relacionados ao $S V_{\text {corrida }}$ (TPFPp e TDF), a impossibilidade de determinação de início de fase concêntrica pelos métodos utilizados no presente estudo, pode ter influenciado a magnitude das correlações e significância destes com o desempenho no teste T. Neste sentido, métodos que permitiam a identificação do início desta fase talvez possam ajudar na elucidação do fenômeno.

Por outro lado, cabe lembrar que o desempenho no teste $T\left(T_{\text {total }}\right)$ apresentou correlação significante com o pico de força de propulsão (PFP) em SV corrida $(r$ = $0,49)$, com o tempo de fase concêntrica $\left(T_{\text {con }}\right)$ em SV $(r=0,55)$, e com a velocidade média de aproximação (Vel $\left.l_{\text {média }}\right)$ em SV $\mathrm{Sorrida}(r=-0,54)$.

No que diz respeito aos achados do PFP, estes vão ao encontro do estudo de YOUNG, MCLEAN \& ARDAGNA (1995), que demonstraram em atletas juniores de atletismo, correlação significante entre a aceleração na distância de 2,5 metros e o pico de força obtido no salto vertical sem contramovimento com adição de sobrecarga. Ainda, corrobora com os estudos de CHELLY, CHERIF, AMAR, HERMASSI, FATHLOUN, BOUHLEL, TABKA \& SHEPHARD (2010) e de WISLOFF et al. (2004), ambos realizados em atletas de futebol de nível nacional. 
Nestes, CHELLY et al. (2010) encontraram correlações significantes entre a aceleração na distância de cinco metros e o pico de força obtido no salto vertical sem contramovimento $(r=0,60)$ e com a força máxima produzida no agachamento $(r=$ 0,66), enquanto que WISLOFF et al. (2004) ao analisar um sprint, encontraram correlações significantes do pico de força no salto vertical sem contramovimento com a velocidade produzida nos primeiros três passos $(r=0,46)$, com a velocidade produzida na distância de cinco metros $(r=0,56)$, com a aceleração produzida nos primeiros três passos $(r=0,44)$ e com a aceleração produzida na distância de cinco metros $(r=0,60)$.

Os autores (WISLOFF et al., 2004) reportam também, correlações significantes entre a força máxima produzida no agachamento e a velocidade produzida nos primeiros três passos $(r=0,58)$ e a velocidade produzida na distância de cinco metros $(r=0,66)$, e entre a força máxima produzida no agachamento e o tempo para percorrer a distância de 10 metros $(r=-0,94)$, semelhante reposta encontrada por MCBRIDE et al. (2009) em atletas de futebol americano e por CHAOUACHI et al. (2009) em atletas de basquetebol.

Cabe ressaltar que no presente estudo, o PFP em SV apresentou correlação significante de 0,50 para a primeira parcial do teste $T\left(T_{1}\right)$.

Sendo assim, estes ratificam o postulado por outros autores quanto a necessidade da produção de considerável magnitude de força concêntrica nas acelerações em reduzida distância (HARRIS, CRONIN, HOPKINS \& HANSEN, 2008; PETERSON, ALVAR \& RHEA, 2006).

Quanto aos achados de $\mathrm{T}_{\text {con, }}$ estes podem ser justificados pelo estudo de MURPHY, LOCKIE \& COUTTS (2003), que ao comparar a aceleração em um grupo formado por atletas de rugby, futebol e futebol australiano, encontraram que os atletas de maior aceleração em distância reduzida apresentaram menor tempo de contato, portanto com menor tempo para contração, tanto excêntrica quanto concêntrica.

Mecanicamente tais resultados têm fundamentação, uma vez que o teste $T$ (múltiplas acelerações) apresenta como uma de suas características, a freqüente necessidade de deixar o estado de repouso, pois se faz imperativo a mudança de direção. 
Logo, quanto maior for a força disponível para ser aplicada para o movimento, menor será o tempo necessário para vencer a inércia, portanto, menor o tempo de fase concêntrica, favorecendo o aumento da velocidade alcançada na fase precedente a mudança de direção e o desempenho no teste $\mathrm{T}$.

Por conseguinte, ainda que não seja o foco do presente estudo, considerações quanto a organização do conteúdo de treinamento faz-se necessária a fim de sinalizar a importância não somente de um método especifico de treinamento para o incremento destes atributos, mas sim de uma programação que contemple o nível de treinabilidade do atleta, etapa em que este se encontra dentro de uma programação e tipo de periodização adotado. Como exemplo, MOREIRA et al. (2005) e MOREIRA et al. (2004) apontam para um seqüência lógica e racional de conteúdo de treinamento de força, e ainda, revelam o impacto de diferentes estruturas de organização das cargas nas distintas medidas de desempenho.

Recorrendo aos resultados apontados na presente investigação, as informações que emergem, sinalizam para maior entendimento do construto do teste $\mathrm{T}$, como sendo um teste de múltiplas acelerações, em que se faz necessário produzir além elevado nível de força, o reduzido tempo de fase concêntrica e a máxima velocidade antes do alcance do ponto de mudança de direção, o que em parte corrobora com MORENO, IWAMOTO \& ARRUDA (2008) e com YOUNG, JAMES \& MONTGOMERY (2002) que postulam que seria desejável para uma rápida mudança de direção, produzir breve tempo de contato, gerando força da forma mais breve possível, e que facilitaria o uso destes tanto no monitoramento mais apropriado na prática do treinamento, quanto nas inferências decorrentes de investigação, especialmente aqueles que buscam conhecer as relações entre salto e tarefas de múltiplas acelerações.

Não obstante, alguns achados devem igualmente ser ressaltados no que concerne a dependência do tipo de teste quanto aos parâmetros e suas relações com as múltiplas acelerações.

Os resultados encontrados refutaram a hipótese do presente estudo, de que estas relações não seriam teste vertical-dependente.

Sendo assim, o tipo de teste de salto adotado parece ter fundamental importância na construção de um modelo que tente explicar as tarefas de múltiplas 
acelerações, uma vez que os parâmetros de força parecem ser movimentodependente, logo, diferentes grandezas dos parâmetros podem ser obtidas a partir de diferentes estratégias.

Tais atributos reforçam a coerência no modelo proposto, no qual o uso de dois tipos de saltos revelariam distintos parâmetros, que conseqüentemente, poderiam melhor explicar o desempenho em um teste de múltiplas acelerações.

Todavia, e contraponto o modelo proposto na presente investigação, poderia ser a consideração do salto vertical analisado parecer ser mais representativo das repostas mecânicas do ciclo do alongamento-encurtamento e portanto, apesar de contribuir com importantes considerações a respeito do construto do teste $T$, talvez tenha suas limitações.

Sendo assim, em posteriores investigações, poderia ser considerado o uso de testes em que a contribuição da reposta mecânica fosse menos presente, como o salto horizontal (BISSAS \& HAVENETIDIS, 2008; ECKERT, 1968), uma vez que por apresentar menor amplitude de movimento nas articulações do joelho e tornozelo (ECKERT, 1968) seria menos influenciável por tais mecanismos, portanto mais representativo das repostas neurais e da produção de força concêntrica dos músculos extensores de quadril, joelhos e tornozelos (MAULDER \& CRONIN, 2005; MOREIRA et al., 2005; SMIRNIOTOU et al., 2008).

Neste sentido, a adição de parâmetros biomecânicos obtidos a partir do salto horizontal poderia contribuir para melhor entendimento do fenômeno. No entanto, e de acordo com a pesquisa realizada em novembro de 2009 no banco de dados PubMed com a combinação dos unitermos: biomechanics, parameter, horizontal jump, standing broad jump, standing board jump e standing long jump, não é de nosso conhecimento estudos que se propuseram a tal investigação. O que pode ser encontrado na literatura pode em parte sustentar os argumento aqui apresentados.

MOREIRA, SOUZA \& OLIVEIRA (2003) encontraram correlações significantes entre o teste $\mathrm{T}$ e $\mathrm{O}$ salto horizontal $(r=-0,85)$ e com o salto horizontal triplo consecutivo $(r=-0,95)$ em atletas de basquetebol, enquanto que PETERSON, ALVAR \& RHEA (2006) encontraram correlação significante entre o teste T e o salto horizontal em um grupo de mulheres, atletas universitárias, de basquetebol, voleibol e softbol $(r=-0,79)$ e em um grupo de homens, atletas universitários, de 
basquetebol e basebol ( $r=-0,62)$. Os autores (PETERSON, ALVAR \& RHEA, 2006) ainda encontraram que o desempenho no salto horizontal esta melhor associado ao teste $T$ do que o salto vertical, tanto em mulheres ( $r=-0,79$ vs $r=-0,71$ ) quanto nos homens $(r=-0,61$ vs $r=-0,26)$.

Embora não tenham sido realizados com atletas, os estudo de MEYLAN et al. (2009) e de MAULDER \& CRONIN (2005) corroboram com o contexto apontado.

MEYLAN et al. (2009) encontraram que o salto horizontal se mostrou melhor indicador na tarefa de múltiplas acelerações em homens ( $r$ entre - 0,40 e - 0,46) e mulheres ( $r$ entre - 0,47 a - 0,59) do que o salto vertical ( $r$ entre - 0,25 e - 0,41; r entre - 0,49 e - 0,52 respectivamente), enquanto que MAULDER \& CRONIN (2005) encontraram resultados semelhantes para aceleração na distância de 20 metros, logo, com o salto horizontal estando melhor associado do que o salto vertical quando considerado os métodos de salto sem contramovimento $(r=-0,73$ vs $r=-0,53)$ e salto em profundidade $(r=-0,86$ vs $r=-0,52)$, respectivamente.

Ainda, em futuras investigações, sugere-se que sejam considerados além de gestos mais representativos das repostas neurais, parâmetros biomecânicos obtidos a partir de ações sucessivas realizadas de forma unipodal e considerado o componente horizontal da força, justificados pelo fato dos movimentos realizados na aceleração serem produzidos de forma unipodal e resultantes das forças atuantes predominantemente nos eixos ântero-posterior e vertical (BRUGHELLI et al., 2008; MEYLAN et al., 2009), e que o avanço no conhecimento a partir de outros tipos de salto poderia auxiliar no entendimento das relações aqui exploradas, na sustentação dos achados do presente estudo e, ainda, contribuir com mais informações que de algum modo poderiam ser úteis não somente para os pesquisadores da área, mas também para treinadores e preparadores físicos, notadamente, daquelas modalidades com natureza semelhante ao basquetebol, caracterizadas por múltiplas acelerações.

Sugere-se ainda, que estudos com semelhantes abordagens sejam realizados com atletas de diferentes níveis de treinamento, uma vez que pelo fato da amostra analisada ter sido composta por atletas de alto desempenho. 


\section{LIMITAÇÕES DO ESTUDO}

Como evidenciado no decorrer do texto, a opção por alguns procedimentos experimentais, podem ter produzido de alguma forma influência sobre os resultados encontrados. Tendo em vista que estas limitações devam ser ressaltadas com o objetivo de expressar os cuidados a serem tomados na generalização dos achados, segue abaixo alguns pontos importantes.

\subsection{Determinação das fases de salto}

Embora o procedimento adotado no presente estudo para a identificação do instante de início de fase concêntrica em SV tenha respaldo físico, a ausência de uma análise cinemática pode ter influenciado na precisão quanto a determinação deste, logo, na quantificação dos parâmetros biomecânicos da fase concêntrica.

Ainda, tendo em vista a impossibilidade de determinação do início de fase concêntrica em $\mathrm{SV}_{\text {corrida }}$ apenas pela força de reação do solo, a ausência de uma análise cinemática impossibilitou também a identificação de início de fase concêntrica no salto vertical precedido de corrida, assim como a quantificação dos parâmetros relacionados a esta fase, o que poderia ter contribuído ainda mais na elucidação do fenômeno estudado.

\subsection{Característica da amostra}

Embora existam evidências na literatura de que apontem para uma diferença não significativa de diferentes variáveis em relação às diferentes posições de jogo em atletas de basquetebol, não pode ser desprezada a possibilidade destas terem existido na amostra analisada.

Outro ponto importante a ser considerado, é que apesar de todas as voluntárias fazerem parte da seleção brasileira de basquetebol feminino, e estarem sendo submetidas a um mesmo programa de treinamento, não pode ser descartada a possibilidade destas apresentarem diferentes níveis de treinamento em decorrência do processo de treino que eram submetidas em seus clubes. 


\section{CONCLUSÃO}

A partir dos resultados obtidos no presente estudo, pode-se concluir que 0 teste $\mathrm{T}$ deve ser considerado um teste de múltiplas acelerações e que este tipo de tarefa esta associado à grandeza do pico de força gerada na fase de propulsão, da redução no tempo da fase concêntrica, e da velocidade de aproximação precedente a mudança de direção.

No que diz respeito à contribuição dos parâmetros biomecânicos para o desempenho do salto, pode-se concluir que embora ambos os saltos tenham apresentado maior variação explicada pelos parâmetros predominantemente temporais, a contribuição dos parâmetros para o desempenho do salto é teste vertical-dependente, uma vez que, por exemplo, a taxa de desenvolvimento de força e pico de força de propulsão apresentaram comportamentos distintos entre os saltos. 


\section{REFERÊNCIAS BIBLIOGRÁFICAS}

AAGAARD, P.; SIMONSEN, E.B.; ANDERSEN, J.L.; MAGNUSSON, P.; DYHREPOULSEN, P. Increased rate of force development and neural drive of human skeletal muscle following resistance training. Journal of applied physiology, v.93, n.4, p.1318-26, 2002.

ACQUESTA, F.M.; PENEIREIRO, G.M.; BIANCO, R.; AMADIO, A.C.; SERRÃO, J.C. Características dinâmicas de movimentos seleccionados do basquetebol. Revista portuguesa de ciências do desporto, v.7, n.2, p.174-182, 2007.

ANDERSEN, L.L.; AAGAARD, P. Influence of maximal muscle strength and intrinsic muscle contractile properties on contractile rate of force development. European journal of applied physiology, v.96, n.1, p.46-52, 2006.

ARAGÓN-VARGAS, L.F.; GROSS, M.M. Kinesiological factors in vertical jump performance: differences among individuals. Journal of applied biomechanics, v.13, n.1, p.24-44, 1997.

ARRUDA, M.D.; HESPANHOL, J.E. Saltos verticais: procedimentos de avaliação em desportos coletivos, São Paulo, Phorte, 2008.

BEN ABDELKRIM, N.; EL FAZAA, S.; EL ATI, J. Time-motion analysis and physiological data of elite under-19-year-old basketball players during competition. British journal of sports medicine, v.41, n.2, p.69-75, 2007.

BISSAS, A.I.; HAVENETIDIS, K. The use of various strength-power tests as predictors of sprint running performance. Journal of sports medicine and physical fitness, v.48, n.1, p.49-54, 2008. 
BOBBERT, M.F.; GERRITSEN, K.G.; LITJENS, M.C.; VAN SOEST, A.J. Why is countermovement jump height greater than squat jump height? Medicine and science in sports and exercise, v.28, n.11, p.1402-12, 1996.

BOSCO, C. A força muscular: aspectos fisiológicos e aplicações práticas, trad.D. Balancin, São Paulo, Phorte, 2007.

BOSCO, C.; TARKKA, I.; KOMI, P.V. Effect of elastic energy and myoelectrical potentiation of triceps surae during stretch-shortening cycle exercise. International journal of sports medicine, v.3, n.3, p.137-40, 1982.

BOSCO, C.; VIITASALO, J.T.; KOMI, P.V.; LUHTANEN, P. Combined effect of elastic energy and myoelectrical potentiation during stretch-shortening cycle exercise. Acta physiologica Scandinavica, v.114, n.4, p.557-65, 1982.

BRET, C.; RAHMANI, A.; DUFOUR, A.B.; MESSONNIER, L.; LACOUR, J.R. Leg strength and stiffness as ability factors in $100 \mathrm{~m}$ sprint running. Journal of sports medicine and physical fitness, v.42, n.3, p.274-81, 2002.

BRUGHELLI, M.; CRONIN, J.; LEVIN, G.; CHAOUACHI, A. Understanding change of direction ability in sport: a review of resistance training studies. Sports medicine, v.38, n.12, p.1045-63, 2008.

CARVALHO, C.; CARVALHO, A. Não se deve identificar força explosiva com potência muscular, ainda que existam algumas relações entre ambas. Revista portuguesa de ciências do desporto, v.6, n.2, p.241-248, 2006.

CHAOUACHI, A.; BRUGHELLI, M.; CHAMARI, K.; LEVIN, G.T.; BEN ABDELKRIM, N.; LAURENCELLE, L.; CASTAGNA, C. Lower limb maximal dynamic strength and agility determinants in elite basketball players. Journal of strength and conditioning research, v.23, n.5, p.1570-7, 2009. 
CHAVES, A.; SAMPAIO, J.F. Movimento no plano e no espaço. A. Chaves e J. F. Sampaio, In: Física Básica - Mecânica, Rio de janeiro, LTC, 2007. cap., 5, p.89 105.

CHELLY, M.S.; CHERIF, N.; AMAR, M.B.; HERMASSI, S.; FATHLOUN, M.; BOUHLEL, E.; TABKA, Z.; SHEPHARD, R.J. Relationships of peak leg power, 1 maximal repetition half back squat, and leg muscle volume to 5-m sprint performance of junior soccer players. Journal of strength and conditioning research, v.24, n.1, p.266-71, 2010.

CORMIE, P.; MCBRIDE, J.M.; MCCAULLEY, G.O. Power-time, force-time, and velocity-time curve analysis of the countermovement jump: impact of training. Journal of strength and conditioning research, v.23, n.1, p.177-86, 2009.

CRONIN, J.; MCNAIR, P.; MARSHALL, R. Relationship between strength qualities and motor skills associated with court performance. Journal of human movement studies, v.40, p.207-24, 2001.

CRONIN, J.B.; HANSEN, K.T. Strength and power predictors of sports speed. Journal of strength and conditioning research, v.19, n.2, p.349-57, 2005.

DE RUITER, C.J.; VAN LEEUWEN, D.; HEIJBLOM, A.; BOBBERT, M.F.; DE HAAN, A. Fast unilateral isometric knee extension torque development and bilateral jump height. Medicine and science in sports and exercise, v.38, n.10, p.1843-52, 2006.

DELECLUSE, C.; VAN COPPENOLLE, H.; WILLEMS, E.; VAN LEEMPUTTE, M.; DIELS, R.; GORIS, M. Influence of high-resistance and high-velocity training on sprint performance. Medicine and science in sports and exercise, v.27, n.8, p.1203-9, 1995. 
DELEXTRAT, A.; COHEN, D. Physiological testing of basketball players: toward a standard evaluation of anaerobic fitness. Journal of strength and conditioning research, v.22, n.4, p.1066-72, 2008.

Strength, power, speed, and agility of women basketball players according to playing position. Journal of strength and conditioning research, v.23, n.7, p.197481, 2009.

DOWLING, J.J.; VAMOS, L. Identification of kinetic and temporal factors related to vertical jump performance. Journal of applied biomechanics, v.9, n.95-110, 1993.

DRINKWATER, E.J.; PYNE, D.B.; MCKENNA, M.J. Design and interpretation of anthropometric and fitness testing of basketball players. Sports medicine, v.38, n.7, p.565-78, 2008.

ECKERT, H.M. Angular velocity and range of motion in the vertical and standing broad jumps. Research quarterly, v.39, n.4, p.937-42, 1968.

FIBA, F.I.D.B.-- Ranking Women after FIBA U19 World Championship for Women (2009). Disponível em: <http://www.fiba.com/pages/eng/fc/even/rank/p/rankWome.html>. acesso em: 25 de setembro de 2009

FOX, E.L.; BOWERS, R.W.; FOSS, M.L. Recuperação Após o Exercício. E. L. Fox, R. W. Bowers, et al, In: Bases fisiológicas da educação física e dos desportos, 4 ed., Rio de Janeiro, GUANABARA KOOGAN, 1989. cap., 3, p.28-43.

GREIKA. Tripés fotográficos amadores. Disponível em: <http://www.greika.com.br/?OPS=MAIS INFO\&ID=339>. acesso em: 17 de novembro de 2009 
HAKKINEN, K. Maximal force, explosive strength and speed in female volleyball and basketball players. Journal of human movement studies, v.16, n.291-303, 1989.

Changes in physical fitness profile in female volleyball players during the competitive season. Journal of sports medicine and physical fitness, v.33, n.3, p.223-32, 1993.

HAM, D.J.; KNEZ, W.L.; YOUNG, W.B. A deterministic model of the vertical jump: implications for training. Journal of strength and conditioning research, v.21, n.3, p.967-72, 2007.

HARRIS, N.K.; CRONIN, J.B.; HOPKINS, W.G.; HANSEN, K.T. Relationship between sprint times and the strength/power outputs of a machine squat jump. Journal of strength and conditioning research, v.22, n.3, p.691-8, 2008.

HATZE, H. Validity and Reliability of Methods for Testing Vertical Jumping Performance. Journal of applied biomechanics, v.14, n.127-140, 1998.

HENNESSY, L.; KILTY, J. Relationship of the stretch-shortening cycle to sprint performance in trained female athletes. Journal of strength and conditioning research, v.15, n.3, p.326-31, 2001.

HIDROFIT. MultiSprint. Disponivel em: <http://www.hidrofit.com.br/Produtos/MultSprint/Default.aspx>. acesso em: 17 de novembro de 2009

HOLM, D.J.; STALBOM, M.; KEOGH, J.W.; CRONIN, J. Relationship between the kinetics and kinematics of a unilateral horizontal drop jump to sprint performance. Journal of strength and conditioning research, v.22, n.5, p.1589-96, 2008. 
IFM ELETRONIC. Sensores ópticos. Disponível em: <http://www.ifm.com/ifmpt/web/dsfs!O5H200.html>. acesso em: 17 de novembro de 2009

JACKSON, A.S.; POLLOCK, M.L.; WARD, A. Generalized equations for predicting body density of women. Medicine and science in sports and exercise, v.12, n.3, p.175-81, 1980.

JARIC, S.; RISTANOVIC, D.; CORCOS, D.M. The relationship between muscle kinetic parameters and kinematic variables in a complex movement. European journal of applied physiology and occupational physiology, v.59, n.5, p.370-6, 1989.

JOHNSON, B.L.; NELSON, J.K. The Measurement of Power. B. L. Johnson e J. K. Nelson, In: Practical measurements for evaluation in physical education, 2 ed., Minnesota, Burgess Publishing Company, 1974. cap., 7, p.166-183.

KAWAMORI, N.; ROSSI, S.J.; JUSTICE, B.D.; HAFF, E.E.; PISTILLI, E.E.; O'BRYANT, H.S.; STONE, M.H.; HAFF, G.G. Peak force and rate of force development during isometric and dynamic mid-thigh clean pulls performed at various intensities. Journal of strength and conditioning research, v.20, n.3, p.483-91, 2006.

KISTLER INSTRUMENTE AG. Operating instructions: multicomponent force plate for biomechanics - Type 9287A, Winterthur, Switzerland, 1993.

KOLLIAS, I.; HATZITAKI, V.; PAPAIAKOVOU, G.; GIATSIS, G. Using principal components analysis to identify individual differences in vertical jump performance. Research quarterly for exercise and sport, v.72, n.1, p.63-7, 2001. 
KOMI, P.V. Physiological and Biomechanical Correlates of Muscle Function: Effects of Muscle Structure and Stretch-Shortening Cycle on Force and Speed. Exercise and sport sciences reviews, v.12, n.1, p.81-121, 1984.

KOMI, P.V.; GOLLHOFER, A. Stretch reflexes can have an important role in force enhancement during SSC exercise. Journal of applied biomechanics, v.13, n.4, p.451-460, 1997.

KYROLAINEN, H.; AVELA, J.; MCBRIDE, J.M.; KOSKINEN, S.; ANDERSEN, J.L.; SIPILA, S.; TAKALA, T.E.; KOMI, P.V. Effects of power training on muscle structure and neuromuscular performance. Scandinavian journal of medicine $\&$ science in sports, v.15, n.1, p.58-64, 2005.

LAFFAYE, G.; BARDY, B.G.; DUREY, A. Principal component structure and sportspecific differences in the running one-leg vertical jump. International journal of sports medicine, v.28, n.5, p.420-5, 2007.

LITTLE, T.; WILLIAMS, A.G. Specificity of acceleration, maximum speed, and agility in professional soccer players. Journal of strength and conditioning research, v.19, n.1, p.76-8, 2005.

MATAVULJ, D.; KUKOLJ, M.; UGARKOVIC, D.; TIHANYI, J.; JARIC, S. Effects of plyometric training on jumping performance in junior basketball players. Journal of sports medicine and physical fitness, v.41, n.2, p.159-64, 2001.

MAULDER, P.; CRONIN, J. Horizontal and vertical jump assessment: reliability, symmetry,discriminative and predictive ability. Physical therapy in sport, v.6, n.7482, 2005.

MCBRIDE, J.M.; BLOW, D.; KIRBY, T.J.; HAINES, T.L.; DAYNE, A.M.; TRIPLETT, N.T. Relationship between maximal squat strength and five, ten, and forty yard sprint times. Journal of strength and conditioning research, v.23, n.6, p.1633-6, 2009. 
MCINNES, S.E.; CARLSON, J.S.; JONES, C.J.; MCKENNA, M.J. The physiological load imposed on basketball players during competition. Journal of sports sciences, v.13, n.5, p.387-97, 1995.

MEYLAN, C.; MCMASTER, T.; CRONIN, J.; MOHAMMAD, N.I.; ROGERS, C.; DEKLERK, M. Single-leg lateral, horizontal, and vertical jump assessment: reliability, interrelationships, and ability to predict sprint and change-of-direction performance. Journal of strength and conditioning research, v.23, n.4, p.1140-7, 2009.

MOIR, G.; SANDERS, R.; BUTTON, C.; GLAISTER, M. The effect of periodized resistance training on accelerative sprint performance. Sports biomechanics, v.6, n.3, p.285-300, 2007.

MOREIRA, A. Testes de campo para monitorar desempenho, fadiga e recuperação em basquetebolistas de alto rendimento. Revista da educação física, v.19, n.2, p.241-150, 2008.

MOREIRA, A.; MORTATTI, A.L.; GOMES, J.H.; PAES, F.D.O.; JELEILATE, D.M. Monitoramento no basquetebol: a utilização da análise dos componentes. Revista da educação física, v.20, n.1, p.51-59, 2009.

MOREIRA, A.; OKANO, A.H.; RONQUE, E.R.V.; OLIVEIRA, P.R.D.; ARRUDA, M.D.; MORTATTI, A.L.; PAES, F.D.O. A dinâmica da variáveis morfológicas e de performance motora de jovens jogadores de basquetebol. Revista da educação física, v.19, n.4, p.539-548, 2008a.

MOREIRA, A.; OKANO, A.H.; RONQUE, E.R.V.; SOUZA, M.D.; OLIVEIRA, P.R.D. The effect of different models of training and competition-load structuration in the acceleration of adult male high level basketball players. Lecturas educación física y deportes, v.12, n.1-11, 2008b. 
MOREIRA, A.; OKANO, A.H.; SOUZA, M.D.; OLIVEIRA, P.R.D.; GOMES, A.C. Sistema de cargas seletivas no basquetebol durante um mesociclo de preparação: implicações sobre a velocidade e as diferentes manifestações de força. Revista brasileira de ciência e movimento, v.13, n.2, p.7-15, 2005.

MOREIRA, A.; OLIVEIRA, P.R.D.; OKANO, A.H.; SOUZA, M.D.; ARRUDA, M.D. A dinâmica de alteração das medidas de força e o efeito posterior duradouro de treinamento em basquetebolistas submetidos ao sistema de treinamento em bloco. Revista brasileira de medicina do esporte, v.10, n.4, p.243-250, 2004.

MOREIRA, A.; OLIVEIRA, P.R.D.; RONQUE, E.R.V.; OKANO, A.H.; SOUZA, M.D. Análise de diferentes modelos de estruturação da carga de treinamento e competição no desempenho de basquetebolistas no Yo-Yo intermittent endurance test. Revista brasileira de ciência e movimento, v.29, n.2, p.165-183, 2008c.

MOREIRA, A.; SOUZA, M.D.; OLIVEIRA, P.R.D. A velocidade de deslocamento no basquetebol. Revista brasileira de ciências do esporte, v.24, n.2, p.210-215, 2003.

MORENO, E.; IWAMOTO, E.; ARRUDA, M.D. Força Explosiva: deslocamentos curtos no futebol Movimento \& percepção, v.9, n.13, p.379-396, 2008.

MURPHY, A.J.; LOCKIE, R.G.; COUTTS, A.J. Kinematic determinants of early acceleration in field sport. Journal of sports science and medicine, v.2, n.4, p.144150, 2003.

NARAZAKI, K.; BERG, K.; STERGIOU, N.; CHEN, B. Physiological demands of competitive basketball. Scandinavian journal of medicine \& science in sports, v.19, n.3, p.425-32, 2009.

NICOL, C.; AVELA, J.; KOMI, P.V. The stretch-shortening cycle : a model to study naturally occurring neuromuscular fatigue. Sports medicine, v.36, n.11, p.977-99, 2006. 
NORTON, K.; WHITTINGHAM, N.; CARTER, L.; KERR, D.; GORE, C.; MARFELLJONES, M. Técnicas de medição em antropometria. K. Norton e T. Olds, In: Antropométrica, Porto Alegre, Artmed, 2005. cap., 2, p.41-87.

NUZZO, J.L.; MCBRIDE, J.M.; CORMIE, P.; MCCAULLEY, G.O. Relationship between countermovement jump performance and multijoint isometric and dynamic tests of strength. Journal of strength and conditioning research, v.22, n.3, p.699707, 2008.

PAUOLE, K.; MADOLE, K.; GARHAMMER, J.; LACOURSE, M.; ROZENEK, R. Reliability and Validity of the T-Test as a Measure of Agility, Leg Power, and Leg Speed in College-Aged Men and Women. Journal of strength and conditioning research, v.14, n.4, p.443-450, 2000.

PETERSON, M.D.; ALVAR, B.A.; RHEA, M.R. The contribution of maximal force production to explosive movement among young collegiate athletes. Journal of strength and conditioning research, v.20, n.4, p.867-73, 2006.

ROUSANOGLOU, E.N.; GEORGIADIS, G.V.; BOUDOLOS, K.D. Muscular strength and jumping performance relationships in young women athletes. Journal of strength and conditioning research, v.22, n.4, p.1375-8, 2008.

SANTOS, F.V.D. Relacionamento entre alguns tipos de força e a velocidade de deslocamento em jogadores de basquetebol juvenil. 2006. 61 f. Dissertação (Mestrado em Educação Física) - Universidade Federal do Paraná, Curitiba.

SASSI, R.H.; DARDOURI, W.; YAHMED, M.H.; GMADA, N.; MAHFOUDHI, M.E.; GHARBI, Z. Relative and absolute reliability of a modified agility T-test and its relationship with vertical jump and straight sprint. Journal of strength and conditioning research, v.23, n.6, p.1644-51, 2009. 
SEMENICK, D. Tests and Measurements: The T-test Strength and conditioning journal, v.12, n.1, p.36-37, 1990.

SHEPPARD, J.M.; YOUNG, W.B. Agility literature review: classifications, training and testing. Journal of sports sciences, v.24, n.9, p.919-32, 2006.

SLEIVERT, G.; TAINGAHUE, M. The relationship between maximal jump-squat power and sprint acceleration in athletes. European journal of applied physiology and occupational physiology, v.91, n.46-52, 2004.

SMIRNIOTOU, A.; KATSIKAS, C.; PARADISIS, G.; ARGEITAKI, P.; ZACHAROGIANNIS, E.; TZIORTZIS, S. Strength-power parameters as predictors of sprinting performance. Journal of sports medicine and physical fitness, v.48, n.4, p.447-54, 2008.

STONE, M.H.; SANDS, W.A.; CARLOCK, J.; CALLAN, S.; DICKIE, D.; DAIGLE, K.; COTTON, J.; SMITH, S.L.; HARTMAN, M. The importance of isometric maximum strength and peak rate-of-force development in sprint cycling. Journal of strength and conditioning research, v.18, n.4, p.878-84, 2004.

THORLUND, J.B.; AAGAARD, P.; MADSEN, K. Rapid muscle force capacity changes after soccer match play. International journal of sports medicine, v.30, n.4, p.2738, 2009.

UGARKOVIC, D.; MATAVULJ, D.; KUKOLJ, M.; JARIC, S. Standard anthropometric, body composition, and strength variables as predictors of jumping performance in elite junior athletes. Journal of strength and conditioning research, v.16, n.2, p.227-30, 2002.

UGRINOWITSCH, C.; BARBANTI, V.J. O ciclo alongamento e encurtamento e a "perfomance" no salto vertical. Revista paulista de educação física, v.12, n.1, p.8594, 1998. 
UGRINOWITSCH, C.; BARBANTI, V.J.; GONÇALVES, A.; PERES, B.A. Capacidade dos testes isocinéticos em predizer a "performance" no salto vertical em jogadores de voleibol. Revista paulista de educação física, v.14, n.2, p.172-83, 2000.

VANEZIS, A.; LEES, A. A biomechanical analysis of good and poor performers of the vertical jump. Ergonomics, v.48, n.11-14, p.1594-603, 2005.

VIITASALO, J.T.; AURA, O. Seasonal fluctuations of force production in high jumpers. Canadian journal of applied sport sciences, v.9, n.4, p.209-13, 1984.

VIITASALO, J.T.; KOMI, P.V. Force-time characteristics and fiber composition in human leg extensor muscles. European journal of applied physiology and occupational physiology, v.40, n.1, p.7-15, 1978.

WILMORE, J.H.; COSTILL, D.L. Metabolismo e sistemas energéticos básicos. In: Fisiologia do esporte e do exercício, 2 ed., São Paulo, Manole, 2001. cap., 4, p.115-154.

WINTER, D.A. Kinematics. In: Biomechanics and motor control of human movement, 3 ed., New Jersey, John Wiley \& Sons, 2004. cap., 2, p.13-58.

WISLOFF, U.; CASTAGNA, C.; HELGERUD, J.; JONES, R.; HOFF, J. Strong correlation of maximal squat strength with sprint performance and vertical jump height in elite soccer players. British journal of sports medicine, v.38, n.3, p.285-8, 2004.

YAMAUCHI, J.; ISHII, N. Relations between force-velocity characteristics of the kneehip extension movement and vertical jump performance. Journal of strength and conditioning research, v.21, n.3, p.703-9, 2007.

YOUNG, W.; MCLEAN, B.; ARDAGNA, J. Relationship between strength qualities and sprinting performance. Journal of sports medicine and physical fitness, v.35, n.1, p.13-9, 1995. 
YOUNG, W.; WILSON, G.; BYRNE, C. Relationship between strength qualities and performance in standing and run-up vertical jumps. Journal of sports medicine and physical fitness, v.39, n.4, p.285-93, 1999.

YOUNG, W.B.; JAMES, R.; MONTGOMERY, I. Is muscle power related to running speed with changes of direction? Journal of sports medicine and physical fitness, v.42, n.3, p.282-8, 2002.

YOUNG, W.B.; MCDOWELL, M.H.; SCARLETT, B.J. Specificity of sprint and agility training methods. Journal of strength and conditioning research, v.15, n.3, p.3159, 2001.

ZATSIORSKY, V.M. Ciência e prática do treinamento de força, trad.S. R. F. Batista, São Paulo, Phorte, 1999.

Biomecânica da força e do treinamento de força. P. V. Komi, In: Força e Potência no Esporte, 2 ed., Porto Alegre, ArtMed, 2006. cap., 23, p.455 a 502.

ZINK, A.J.; PERRY, A.C.; ROBERTSON, B.L.; ROACH, K.E.; SIGNORILE, J.F. Peak power, ground reaction forces, and velocity during the squat exercise performed at different loads. Journal of strength and conditioning research, v.20, n.3, p.658-64, 2006.

ZIV, G.; LIDOR, R. Physical attributes, physiological characteristics, on-court performances and nutritional strategies of female and male basketball players. Sports medicine, v.39, n.7, p.547-68, 2009a.

- Vertical jump in female and male basketball players-A review of observational and experimental studies. Journal of science and medicine in sport, 2009b, DOI: 10.1016/j.jsams.2009.02.009. 


\title{
APÊNDICE 1 - Termo de Consentimento Livre e Esclarecido
}

\author{
ESCOLA DE EDUCAÇÃO FÍSICA E ESPORTE
}

DA

UNIVERSIDADE DE SÃO PAULO

TERMO DE CONSENTIMENTO LIVRE E ESCLARECIDO

I - DADOS DE IDENTIFICAÇÃO DO SUJEITO DA PESQUISA OU RESPONSÁVEL LEGAL

1. NOME DO INDIVÍDUO:

DOCUMENTO DE IDENTIDADE No :

SEXO :M F

DATA NASCIMENTO: .......................

ENDEREÇO.

CIDADE

BAIRRO

CEP:.

TELEFONE: (

APTO.

2.RESPONSÁVEL LEGAL:

NATUREZA (grau de parentesco, tutor, curador, etc.)

DOCUMENTO DE IDENTIDADE

SEXO: $M \quad F$

DATA NASCIMENTO.: ....................

ENDEREÇO.

BAIRRO:

CIDADE

$\mathrm{N}^{\circ}$

APTO

CEP. TELEFONE:

$\mathrm{N}^{\circ}$

..)

II - DADOS SOBRE A PESQUISA CIENTÍFICA

TÍTULO DO PROJETO DE PESQUISA:

ASSOCIAÇÃO DE PARÂMETROS CINÉTICOS E TEMPORAIS COM O DESEMPENHO NO SALTO E DESLOCAMENTO EM VELOCIDADE

PESQUISADOR RESPONSÁVEL: Prof. Dr. Alexandre Moreira CARGO/FUNÇÃO: Professora Titular 
AVALIAÇÃO DO RISCO DA PESQUISA:

$\begin{array}{ll}\text { RISCO MÍNIMO } & X \quad \text { RISCO MÉDIO } \\ \text { RISCO BAIXO } & \text { RISCO MAIOR }\end{array}$

(probabilidade de que o indivíduo sofra algum dano como conseqüência imediata ou tardia do estudo)

III - EXPLICAÇÕES DO PESQUISADOR AO INDIVÍDUO OU SEU

REPRESENTANTE LEGAL SOBRE A PESQUISA, DE FORMA CLARA E SIMPLES, CONSIGNANDO:

\section{Justificativa e os Objetivos da Pesquisa.}

\section{Justificativa da Pesquisa}

Durante o jogo de basquetebol são realizados saltos e deslocamentos envolvendo paradas bruscas e mudanças rápidas de direção, fazendo com que estes tenham sido utilizados na investigação de diferentes modelos de treinamento. Contudo, estudos que investigaram a associação do salto e velocidade de deslocamento com os valores de força, potência e velocidade levam a resultados não conclusivos.

Por outro lado, alguns estudos têm evidenciado que um maior nível de força e potência parece não ser os únicos fatores relacionados ao desempenho em tais ações, entretanto tais estudos ainda são escassos, ainda mais considerado atletas de basquetebol.

Desta forma, a identificação dos parâmetros relacionados ao desempenho nestas ações em atletas de basquetebol brasileiro de alto nível se faz necessário para que estes possam ser utilizados como parâmetros para o processo de treinamento e melhora do desempenho.

\section{Objetivo da Pesquisa}

Associar os parâmetros cinéticos e temporais obtidos no salto vertical e salto vertical precedido de corrida de dois metros ao desempenho no salto vertical e de velocidade em atletas de basquetebol. 


\section{Procedimentos que serão utilizados para a realização da pesquisa.}

Você está participando de uma reunião prévia ao período de aplicação dos testes e coleta de dados, e que tem por objetivo fornecer esclarecimentos e explicações no que diz respeito a todo e qualquer procedimento e teste os quais você estará sendo submetido, sendo estes iniciados somente após leitura integral e assinatura do termo de consentimento livre e esclarecido (TCLE), concordando assim, e por livre e espontânea vontade, a participar do presente estudo.

\section{Medidas}

Você será submetido inicialmente à coleta de dados relacionados a cineantropometria, o qual tem por finalidade caracterizar o grupo que esta sendo estudado. Para tanto serão coletados os seguintes dados: estatura corporal total, comprimento tronco-cefálico, massa corporal total, dobra cutânea triciptal, subescapular e abdominal.

\section{Testes}

Salto vertical (SV): Você deverá assumir a posição em pé, mantendo os calcanhares em afastamento bitrocanteriano e mantendo os braços na posição que julgar mais confortável e sobre a plataforma de força. Nesta posição, após receber por parte do avaliador a voz de comando "ATENÇÃO, JÁ !", realizará um salto de esforço máximo tentando alcançar a máxima amplitude possível. Não será permitido ações de saltitar, qualquer tipo de deslocamento antes da realização do salto porém, será permitida a livre movimentação dos braços durante o salto.

\section{Salto vertical precedido de corrida de dois metros (SV2 metros): Antes da} coleta do salto, você deverá realizar uma corrida de dois metros buscando a máxima velocidade. Ao tocar a plataforma, você deverá realizar um salto buscando a máxima projeção vertical.

Serão realizados 03 (três) saltos para cada metodologia, sendo considerado para análise o salto de maior amplitude em cada metodologia. O intervalo entre os saltos de uma mesma série será de aproximadamente de 60 segundos. 
Teste de velocidade de deslocamento (Teste $\mathrm{T}$ ): Você deverá estar posicionado em pé atrás da linha de saída/chegada e com afastamento ânteroposterior das pernas. Ao ouvir a voz de comando "ATENÇÃO, JÁ !" você deverá correr em máxima velocidade possível em linha reta, até uma linha demarcada com um cone. Ao pisar nesta linha deverá mudar a direção para a esquerda sem cruzar as pernas percorrendo até a linha também demarcada com um cone. Ao pisar nessa linha, mudará de direção sem cruzar as pernas e irá correr na direção oposta, portanto, até a outra extremidade da linha, ou outro extremo do T. Ao pisar na linha, também demarcada com um cone, deverá novamente mudar de direção sem cruzar as pernas e correr em direção ao cone central e retornar a linha de saída/chegada. Será realizada 03 (três) tentativas, com pausas de três minutos entre cada tentativa, e considerado para análise o menor tempo obtido nas tentativas

\section{Desconfortos e possíveis riscos para o atleta}

Em nosso estudo, não identificamos qualquer risco para o atleta quanto a sua integridade física e mental, visto que os dados que serão coletados em nada influenciarão seu ritmo normal de treinamentos e jogos, não prejudicando seus resultados e/ou performance.

\section{Benefícios da participação do atleta na pesquisa}

A colaboração do atleta em nosso estudo se deve a possibilidade do conhecimento quanto a contribuição de diferentes componentes na execução do salto, proporcionando adequação quanto a estímulo a ser dado durante o treinamento para ganho de desempenho.

IV - ESCLARECIMENTOS DADOS PELO PESQUISADOR SOBRE GARANTIAS DO SUJEITO DA PESQUISA:

1. Acesso, a qualquer tempo, às informações sobre procedimentos, riscos e benefícios relacionados à pesquisa, inclusive para dirimir eventuais dúvidas. 
Os resultados obtidos neste estudo serão mantidos em sigilo absoluto, e apenas serão divulgados em publicações científicas, congressos e com fins acadêmicos, não sendo mencionados em hipótese alguma dados pessoais do atleta. Caso desejar, o atleta poderá pessoalmente tomar conhecimento dos resultados ao final das etapas do estudo, e/ou eventuais esclarecimentos sobre todos os procedimentos em qualquer fase do estudo.

2. Liberdade de retirar seu consentimento a qualquer momento e de deixar de participar do estudo, sem que isto traga prejuízo à continuidade da assistência;

O atleta terá total liberdade de desistir ou interromper sua participação no estudo no momento em que este desejar, sem necessidade de qualquer explicação ou aviso prévio. Sua desistência não Ihe causará qualquer ônus e penalidade, ou ainda prejuízo à saúde e bem estar físico. O pesquisador responsável ficará à disposição para eventuais dúvidas, mesmo após o término do estudo ou a exclusão do atleta do mesmo.

3. Salvaguarda da confidencialidade, sigilo e privacidade;

Os resultados obtidos durante este estudo serão mantidos em sigilo, e apenas serão divulgados em publicações científicas, através de média e desvio padrão (ou outras medidas de tendência central), sem que os dados pessoais sejam mencionados.

4. Disponibilidade de assistência no HU ou HCFMUSP, por eventuais danos à saúde, decorrentes da pesquisa.

Qualquer possível desconforto provocado pelos procedimentos desta pesquisa será prontamente atendido no próprio local (por pessoal capacitado), e/ou em casos mais cuidadosos, terá assistência médica no HU ou na HCFMUSP, sem qualquer ônus. 
$V$ - INFORMAÇÕES DE NOMES, ENDEREÇOS E TELEFONES DOS RESPONSÁVEIS PELO ACOMPANHAMENTO DA PESQUISA, PARA CONTATO EM CASO DE INTERCORRÊNCIAS CLÍNICAS E REAÇÕES ADVERSAS.

Prof. Rodrigo Maciel Andrade

Av. Prof Mello Moraes, 65 - Cidade Universitária - Butantã- São Paulo - SP

Tel res.: (0xx11) 3091 - 2308

Email: rodmaciel@usp.br

Prof. Dr. Alexandre Moreira

Av. Prof Mello Moraes, 65 - Cidade Universitária - Butantã- São Paulo - SP

Tel res.: (0xx11) $3091-2308$

Email: alemoreira@usp.br

VII - CONSENTIMENTO PÓS-ESCLARECIDO

Declaro que, após convenientemente esclarecido pelo pesquisador e ter entendido o que me foi explicado, consinto em participar do presente Projeto de Pesquisa

São Paulo, de de 2009.

Assinatura do sujeito da pesquisa

(ou responsável legal)
Assinatura do pesquisador

(carimbo ou nome legível) 


\section{APÊNDICE 2 - Coeficiente de correlação intraclasse $(\mathrm{CCI})$ dos parâmetros biomecânicos}

\begin{tabular}{lcc}
\hline Teste T & CCI & p \\
\hline Tempo para percorrer a distância de 0 a 40 metros $-T_{\text {total }}(\mathbf{s})$ & 0,76 & 0,001 \\
Tempo para percorrer a distância de 0 a 10 metros $-\mathrm{T}_{1}(\mathrm{~s})$ & 0,64 & 0,01 \\
Tempo para percorrer a distância de 15 a 25 metros $-\mathrm{T}_{2}(\mathrm{~s})$ & 0,64 & 0,01 \\
Tempo para percorrer a distância de 30 a 40 metros $-\mathrm{T}_{3}(\mathrm{~s})$ & 0,88 & 0,001 \\
SV & & \\
\hline Tempo de fase concêntrica & 0,81 & 0,001 \\
Impulso & 0,95 & 0,001 \\
Pico de força de propulsão & 0,95 & 0,001 \\
Tempo decorrido entre início da fase concêntrica e o pico de força de propulsão & 0,62 & 0,01 \\
Taxa de desenvolvimento de força & 0,89 & 0,001 \\
SV corrida & & \\
\hline Velocidade média de aproximação & 0,86 & 0,001 \\
Tempo total de movimento & 0,93 & 0,001 \\
Pico de força passiva & 0,84 & 0,001 \\
Tempo decorrido entre início da fase de apoio e o pico de força passiva & 0,84 & 0,001 \\
Pico de força de propulsão & 0,88 & 0,001 \\
Tempo decorrido entre início da fase de apoio e o pico de força de propulsão & 0,91 & 0,001 \\
Load Rate & 0,83 & 0,001 \\
Taxa de desenvolvimento de força & 0,90 & 0,001 \\
\hline
\end{tabular}

